\title{
Comparative Study of Conocarpus erectus and Phoenix dactylifera as Plant Biomonitors of Particulate Matter Pollution in Kuwait over Three Land Use Classes
}

\author{
Athari Abdulaziz Almutawa ${ }^{1}$, Samson Roeland ${ }^{2}$ \\ ${ }^{1}$ Laboratory of Environmental and Urban Ecology, Department of Bioscience Engineering, University of Antwerp, \\ Antwerpen, Belgium \\ ${ }^{2}$ Department of Desert Rehabilitation and Restoration, Public Authority of Agriculture and Fisheries, Rabia, Safat, Kuwait \\ Email: *atharialmutawa@gmail.com
}

How to cite this paper: Almutawa, A.A. and Roeland, S. (2022) Comparative Study of Conocarpus erectus and Phoenix dactylifera as Plant Biomonitors of Particulate Matter Pollution in Kuwait over Three Land Use Classes. Atmospheric and Climate Sciences, 12, 189-234.

https://doi.org/10.4236/acs.2022.122013

Received: November 8, 2021

Accepted: February 7, 2022

Published: February 10, 2022

Copyright $\odot 2022$ by author(s) and Scientific Research Publishing Inc. This work is licensed under the Creative Commons Attribution International License (CC BY 4.0).

http://creativecommons.org/licenses/by/4.0/

(c) (i) Open Access

\begin{abstract}
Magnetic plant biomonitoring has been proven to be an effective tool in the assessment of air quality. Kuwait presents a unique environment due to its dry desert climatic conditions and prevailing dry deposition patterns that may affect accumulation rates of magnetic mineral particles. This study evaluated two widely distributed ornamental species, buttonwood (Conocarpus erectus) and palm (Phoenix dactylifera) for their effectiveness as biomagnetic monitors over three different land use classes (urban, suburban and industrial land classes). The differences between land use classes were classified by their proximity to major pollution sources as well as population density. Leaf sampling was conducted over various heights and distances from the nearest road. Total leaf saturated isothermal magnetization (SIRM), hard isothermal magnetization (HIRM), hard isothermal magnetization percentage (HIRM\%) and $s$-ratio have been measured. Scanning electron microscopy (SEM) was used to analyze leaf surface micromorphology. It was determined that NRM values are similar for all land use classes and species, ranging from 0.3 to 0.5 $\mu \mathrm{A}$. Palm leaf overall magnetic concentration was identified to be higher at the industrial land use class than at the urban land use class, indicating high coercivity minerals to magnetically dominate the land use classes. Additionally, total leaf SIRM was determined to be higher at short distances of 0 - 5 meters from the vicinity of the road. The surface rugosity of palm has deep ridges and furrows with ununiform wax projections across the leaf surface, while buttonwood has a smooth wax film with low relief. Differences in leaf micromorphology in addition to plant physiology, justify species magnetic
\end{abstract}


parametric variances. Palm leaf had an average SIRM value that is $120 \%$ higher than buttonwood. It has been highlighted that through the application of the magnetic parameter results to spatial distribution maps that there is an association between particulate matter (PM) and the locality of main roads and local services that may experience higher intensities of traffic.

\section{Keywords}

Biomonitoring, Kuwait, Particulate Matter, Spatial Distribution, Magnetic Concentration, Pollution Source

\section{Introduction}

The most harmful air pollution component that is widely present in the environment is particulate matter (PM). PM is a mixture of liquid droplets and solid particles. Components of PM are made natural and anthropogenic sources, for example: burning of fossil fuels, power plants, diesel, breakdown of soil through agricultural practices, metals, aerosols, fly ash and dust. It is classed based on its aerodynamic diameter, particles with an aerodynamic diameter smaller than 10 and above a $2.5 \mu \mathrm{m}$ area classed as "coarse" (PM 10), particles smaller than 2.5 $\mu \mathrm{m}$ (PM 2.5) are classed as "fine" particles and "ultrafine" particles (UFPs) are particles smaller than $0.1 \mu \mathrm{m}$ (PM 0.1) [1]. Airborne PM trace metals of anthropogenic origin are of particular interest, as they are not degradable and their inhalation is associated with several adverse health problems; premature deaths, asthma [2] [3] [4].

The intensity of magnetic properties on plant leaves has been regarded as a direct proxy for atmospheric PM concentration [5]-[11]. The assessment of heavy metal spatial distribution through the use of magnetic measurements as a proxy has been proven effective, easily applicable over a large area, low cost and nondestructive in comparison to geochemical monitoring [9] [12]. The amount, concentration, type and grain, size of iron oxides, iron hydroxides and sulphides that are linked to heavy metals can be identified through magnetic parameters [13].

Trees and shrubs have the capability to act as significant sinks for gaseous, aerosol, air pollutants and particulates through deposition and filtration mechanisms [14] [15]. The prevalence of trichomes as well as surface rugosity and leaf size have been recognized as enhancing PM deposition [9] [16]. In recent years several studies have adopted biomonitoring methods as a way to estimation of trace elements concentration originated from traffic or industrial emissions [9] [16] [17] [18] [19]. Biomonitoring is defined by Bondaruk et al. (2015) and Chakrabortty \& Paratkar (2006) as the observation and assessment of the state and ongoing changes in ecosystems, components of biodiversity and landscape, including the types of natural habitats, populations and species through the use of bio-organisms to obtain information on certain characteristics of the biosphere [19] [20]. The application of a passive biomonitoring strategy enables 
this to study to survey selected plant species in their natural growing environment even in remote areas where laboratories are unavailable [19].

Previous studies that have conducted magnetic measurements on plant leaf material, have utilized it towards mapping the spatial distribution of PM, the identification of sources and hotspots, effects of urban landscaping on PM levels; canyon effect, distance from road, species selection; how morphological leaf characteristics of plant species also have an effect on leaf PM deposition and accumulation [2] [12] [21] [22] [23]. It must be noted that the majority of these studies have been conducted in Europe and the United Kingdom where climatic conditions and selected species such as moss, lichen and conifers are not applicable to Kuwait's dry desert environment.

Air quality research in Kuwait distinctly focuses on quantification, pattern, mineral and the chemical characterization of air [24] [25] [26]. The major sources of air pollution in Kuwait are; the petroleum industry this includes oil refineries, by-products and plastic production, personal and public motor vehicles for transport that the majority of the population heavily relies on and heavy and consistent dust storm events that transfer aerosols, particulates and pollutants across the peninsula [27]. Dust storms in Kuwait occur 75\% of time during summer, particularly in June and July and can be attributed to low topographic relief, light-textured top soil, scarce vegetation cover and a strong wind [28] [29]. Days with dust storm events were associated with an $8 \%$ increase in all respiratory admissions in Kuwait [30].

The magnetic biomonitoring to assess the spatial distribution of PM over urban areas in Kuwait has never been conducted. The purpose of this research is; 1) the assessment of plant leaves as potential biomonitors in frequent desert dust storm environments, 2) the comparison of magnetic parameters on two of the most widely distributed urban plant species in Kuwait, palm and buttonwood and their performance as bioindicators of atmospheric PM concentrations over three different land use classes, 3) The assessment of spatial distribution of PM concentration through various magnetic parameters and the identification of pollution hotspots.

\section{Materials and Methods}

\subsection{Description of Study Areas}

Kuwait $\left(29.3117^{\circ} \mathrm{N}: 47.4818^{\circ} \mathrm{E}\right)$ is situated in the Arabian Peninsula and has an area of $17,818 \mathrm{~km}^{2}$. It borders with Iraq to the north and Saudi Arabia to the south and the Arabian Peninsula are located to the east. The topography is made up of gravel and sand with low to moderate relief [31]. Aeolian sands dominate over 50 percent of Kuwait's desert that mirror wind direction on loose desert deposits and aridity of the area [31]. Its dry desert climate experiences extreme temperatures that can reach up to $50^{\circ} \mathrm{C}$ in the summer and mild winters [18]. Sandstorms occur an average to 255.4 days of the year [32]. Wind direction in Kuwait is predominantly northwesterly winds and to a lesser extent southeasterly. 


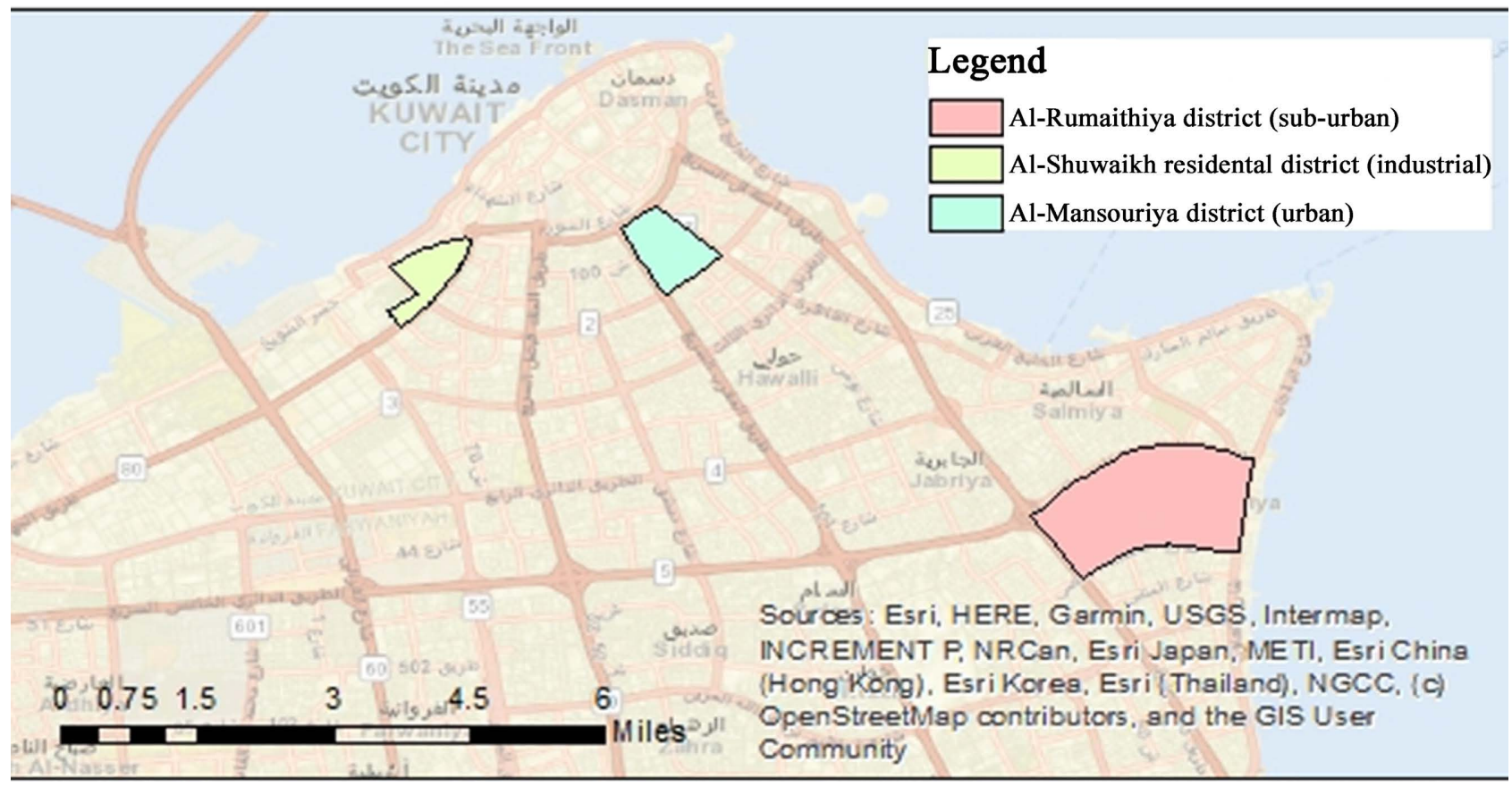

Figure 1. Map indicating the locations of the selected study sites in Kuwait, the blue area signifies the Arabian Peninsula and Kuwait bay.

Three experimental land use classes were selected based on different functionalities and classed depending on population numbers and the vicinity of emission sources (Figure 1). Al-Mansouriya is an "urban" residential area, it is the smallest residential locality in Kuwait, it is made up of 2 blocks and two main roads enclose it; the 40 highway to the west and the $1^{\text {st }}$ ring road to the North, it is situated $4 \mathrm{~km}$ from Kuwait's capital Kuwait City [33].

Al-Shuwaikh Residential area is classed as "industrial", it is located near the ocean side in the vicinity of the port of Shuwaikh and is $3 \mathrm{~km}$ away from Kuwait City. To the west there are three neighboring districts; health, education and commerce, it also in the vicinity of high vehicular activity due to Jahra road highway in the west and Jamal Abdul Nasser street in north. Further information on the sites is shown in Table 1. Al-Rumaithya is classed as a "suburban" land use class; it is made up of 12 blocks with a co-op and mosque at every block. It is located $15 \mathrm{~km}$ from Kuwait's city center. The sources of pollution around Al-Rumaithya are the Mishrif sewage pumping station from south and southwest, the main street from east, Doha station from the west and from the northeast, Al-Subiya station [34].

\subsection{Species}

Two plant species were selected for this study, date palm and buttonwoods they are easily identifiable and widely distributed throughout Kuwait's urban landscape. Date palm ( $P$. dactylifera L.) belongs to the Palmae family. It is an evergreen tree with pinnate leaves that are $4-8 \mathrm{~m}$ long with pointed duplicate leaflets. It has persistent leaf bases and can grow up to $30 \mathrm{~m}$. Buttonwood (C. erectus) 
Table 1. Description of the selected study land use classes (Al-Mansouriya, Al-Rumathiyah and Al-Shuwaikh) indicating area size, population, population density, number of housing and buildings in the area (edited from PACI, 2018) [35] (pop = population, bldg. = building, no $=$ number, $\mathrm{st}=$ street, $\mathrm{LO}=$ longitude, $\mathrm{LA}=$ latitude).

\begin{tabular}{|c|c|c|c|c|c|c|c|c|c|c|}
\hline Locations & $\begin{array}{l}\text { Area } \\
\text { size } \\
\left(\mathrm{km}^{2}\right)\end{array}$ & Pop. & $\begin{array}{l}\text { Pop. } \\
\text { Density } \\
\text { (per } \\
\mathrm{km}^{2} \text { ) }\end{array}$ & Description & $\begin{array}{l}\text { No. of } \\
\text { houses }\end{array}$ & $\begin{array}{l}\text { Bldg. under } \\
\text { construction }\end{array}$ & $\begin{array}{l}\text { Total } \\
\text { no. of } \\
\text { bldg. }\end{array}$ & $\begin{array}{l}\text { Geographic } \\
\text { coordinates }\end{array}$ & $\begin{array}{l}\text { Bldg. under } \\
\text { construction }\end{array}$ & $\begin{array}{l}\text { Total } \\
\text { no. } \\
\text { of } \\
\text { bldg. }\end{array}$ \\
\hline $\begin{array}{l}\text { Urban } \\
\text { Al-Mansouriya }\end{array}$ & 1.26 & 9260 & 7349.206 & $\begin{array}{l}\text { Small residential area, } \\
\text { made up of } 2 \text { blocks, } 4 \\
\text { schools, } 2 \text { parks, } 1 \\
\text { exercise walkway, } 4 \\
\text { mosques, } 1 \text { central } \\
\text { supermarket, } 1 \text { small } \\
\text { supermarket, } 1 \text { sport } \\
\text { club) }\end{array}$ & 371 & 6 & 1175 & $\begin{array}{l}\text { LA: } \\
29^{\circ} 20^{\prime} 11.66^{\prime \prime} \\
\mathrm{N} \\
\text { LO: } \\
47^{\circ} 40^{\prime} 32.02^{\prime \prime} \mathrm{E}\end{array}$ & 6 & 1175 \\
\hline $\begin{array}{l}\text { Sub-urban } \\
\text { Al-Rumaithya }\end{array}$ & 5.31 & 60,211 & 1139.17 & $\begin{array}{l}\text { Residential area ( } 14 \\
\text { mosques, } 13 \text { schools, } 2 \\
\text { parks, } 1 \text { exercise walk } \\
\text { way) }\end{array}$ & 2630 & 19 & 367 & $\begin{array}{l}\text { LA: } \\
29^{\circ} 20^{\prime} 4.68^{\prime \prime} \mathrm{N} \\
\text { LO: } \\
47^{\circ} 55^{\prime} 38.37^{\prime \prime} \mathrm{E}\end{array}$ & 19 & 367 \\
\hline $\begin{array}{l}\text { Industrial } \\
\text { Al-Shuwaikh }\end{array}$ & 2.82 & 5667 & 2009.57 & $\begin{array}{l}\text { Residential area } \\
\text {-surrounded by an } \\
\text { industrial area (port, } \\
\text { hospital, ministries, } \\
\text { educational institute, } \\
\text { petroleum factory, } \\
\text { power station, } \\
\text { desalination plant) As } \\
\text { well as highway (Jamal } \\
\text { Abdul Nasser st). }\end{array}$ & 282 & 9 & 406 & $\begin{array}{l}\text { LA: } \\
29^{\circ} 21^{\prime} 18.62^{\prime \prime} \\
\mathrm{N} \\
\text { LO: } \\
47^{\circ} 59^{\prime} 52.61^{\prime \prime E}\end{array}$ & 9 & 406 \\
\hline
\end{tabular}

belongs to the Combretaceae family. It is an evergreen species that can grow to several forms, either as a shrub or tree with a spreading, irregular branched crown with ridged and scaly dark brown bark. The leaves are yellow green, glabrous, leathery and slightly fleshy. The leaf blades are elliptic to oval or lanceolate and the apex is obtuse or acuminate and can grow up to $20 \mathrm{~m}$. Buttonwood is highly tolerant to extreme conditions withstanding temperatures greater than $47^{\circ} \mathrm{C}[36]$.

\subsection{Sampling Design}

Sampling was conducted in September 2017 and continued for a month. At each selected study land use classes, 100 samples of both species were randomly selected and collected. Plant was sampled at various heights, however height was not specified for this experimental set up, as it was not the main goal of this research. Each sample consists of five leaves per tree from the same randomly selected tree (Figure 2). Leaves were selected on the basis of size similarity and the visual absence of abnormalities or signs of nutritional deficiencies, using a $3 \mathrm{~m}$ telescopic garden tree branch pruning lopper. Leaves were selected from 5 


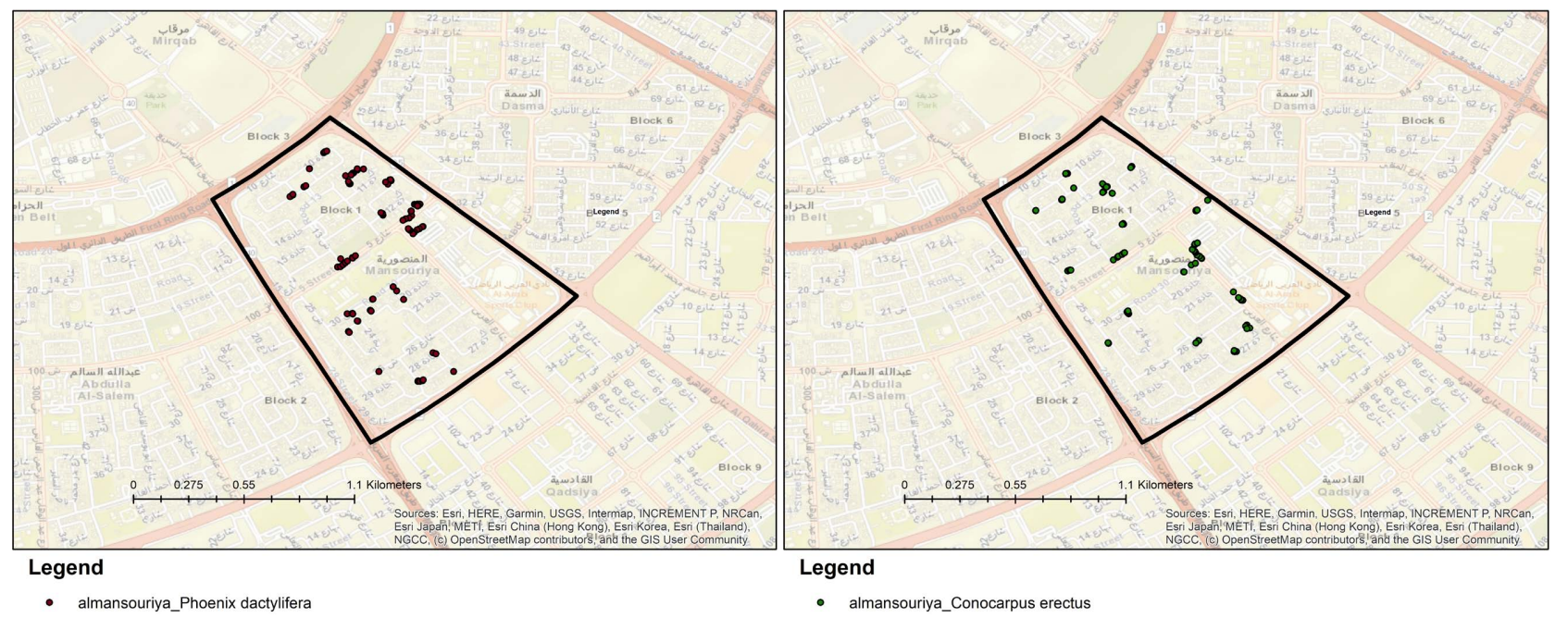

(a)

(b)

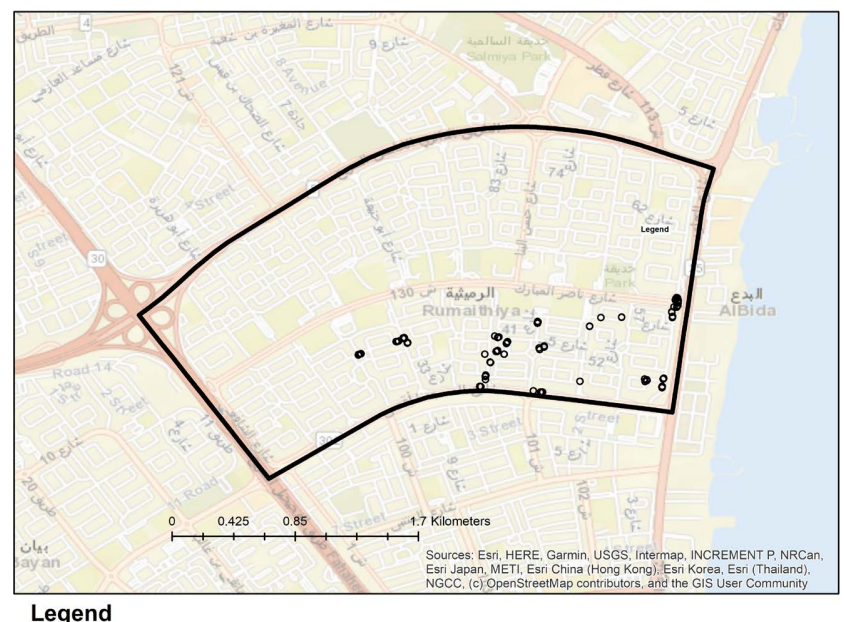

- rumaithiya_Phoenix dactylifera

(c)

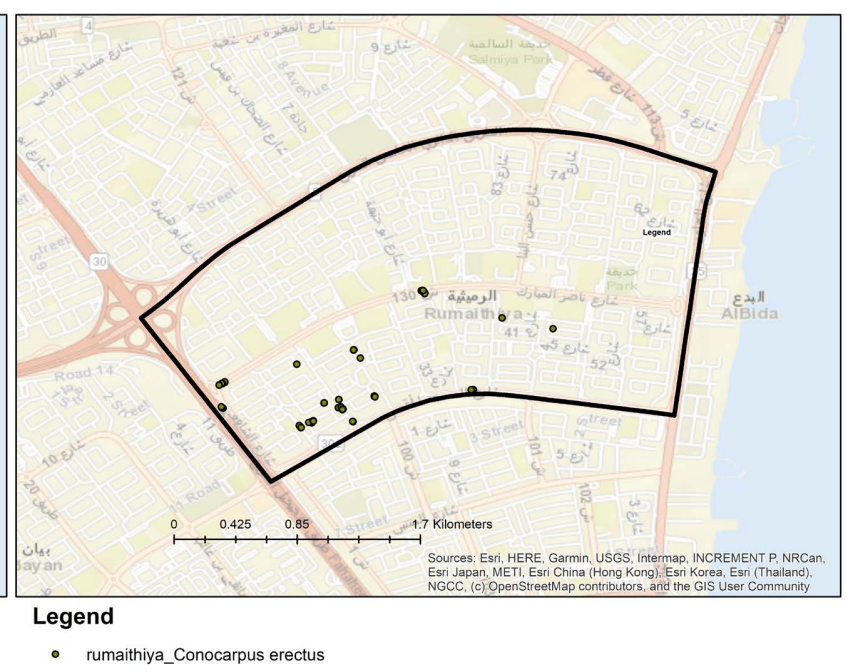

(d)

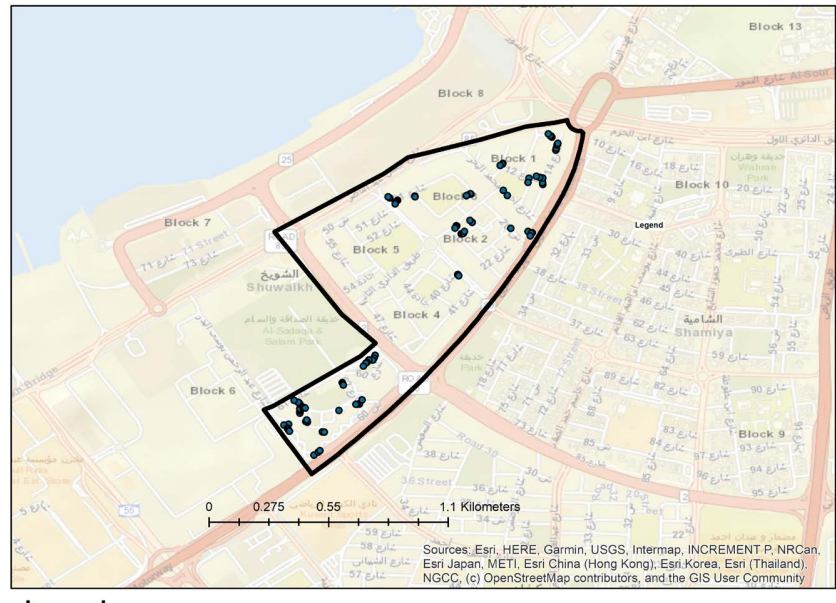

Legend

- alshuwaikh_Phoenix dactylifera

(e)

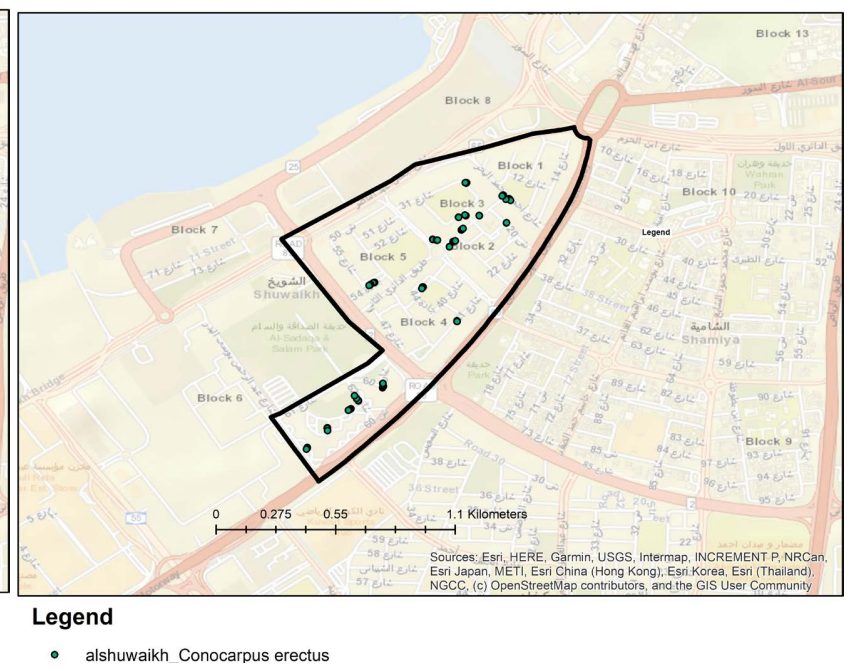

(f)

Figure 2. Sampled areas: Urban: (a) palm, (b) buttonwood; Suburban: (c) palm, (d) buttonwood; Industrial: (e) palm, (f) buttonwood. The dots represent collected samples. 
different axes at an azimuth angle of 70 degrees. The plants, coordinates, height, distance from the nearest road from the stem and distance from the closest plant were noted down. Each sample was stored and transported using a paper envelope to the Public Authority of Agriculture and Fisheries (PAAF), native plant nursey in Aardiyah, Kuwait where they very refrigerated for an average of 2 days until the leaf area measurements were conducted.

\subsection{Magnetic Monitoring}

A variety of magnetic measurements were applied to the leaf samples to enable the quantification of magnetic concentration within selected sites and also identify grain size variations and magnetic mineralogy. All measurements were conducted at the Department of bioscience engineering (University of Antwerp). Prior to magnetic analysis, the 5 leaves from each sample were scanned in (PAAF, Kuwait) using ImageJ software to determine total surface area $\left(\mathrm{cm}^{2}\right)$ to attain NRM, SIRM, HIRM values normalized for leaf area, expressed in $\mathrm{mA} \cdot \mathrm{m}^{-1}$. Subsequently, samples were then air dried for 5 days and each sample consisting of five live from each selected tree were compactly packed in A4 size cling film and placed in a $10 \mathrm{~cm}^{3}$ sampling cube container for magnetic measurement. To avoid measurement errors each sample was magnetically measured thrice, from which the mean value was calculated [37].

Initially the natural remnant magnetization (NRM) was measured. NRM is the permanent magnetization of an object, exclusive of any magnetization being applied to it. NRM was obtained by measuring the permanent magnetization of the samples using an AGICO magnetometer (LDA5/PAM1, Barrington Ltd., U.K.) (UA, Groenenberger). Subsequently, the saturated isothermal remnant magnetization (SIRM) was determined. SIRM is an indicator of the remnant magnetic concentration but also responds to grain size variations and magnetic mineralogy. A magnetic field of 1T was applied to samples using a Molespin magnetizer (Molspin Ltd., UK), then the measurement of remnant magnetization in the samples was conducted using an AGICO magnetometer. "Hard" isothermal remnant magnetization (HIRM) was then acquired. HIRM is an indication of the magnetic mineralogy in a sample and quantifies the absolute concentration of weakly magnetic but high coercivity antiferromagnetic minerals like haematite $\left(\mathrm{aFe}_{2} \mathrm{O}_{3}\right)$ and goethite $(\mathrm{aFeOOH})$ that may also contain magnetite and maghemite [38]. Samples were magnetized at $1 \mathrm{~T}$ followed by demagnetization at $300 \mathrm{mT}$ (Equation (1)). The percentage of HIRM in each sample was calculated using (Equation (2)).

$$
\begin{gathered}
\text { Hard IRM }=0.5 \times\left(\mathrm{SIRM}-\mathrm{IRM}_{-300}\right) \\
\text { Hard IRM\% }=\text { HIRM } / \text { SIRM }
\end{gathered}
$$

To identify variations in the relative abundance of ferrimagnetic and antiferromagnetic minerals, the $s$-ratio was calculated (Equation (3)) [39]. When the $s$-ratio approaches unity, low coercivity minerals such as magnetite and maghemite are interpreted to magnetically dominate samples (Equation (3)). Whereas, 
values approaching zero or are negative are an indication of haematite $\left(\mathrm{aFe}_{2} \mathrm{O}_{3}\right)$ and goethite $(\mathrm{aFeOOH})$ minerals dominating the sample [38].

$$
\text { S-ratio }=- \text { IRM }_{-300} / \text { SIRM }
$$

\subsection{Scanning Electron Microscope}

For the purpose of illustration and interpretation, leaf abaxial and adaxial micro-morphological characteristics were analyzed using scanning electron microscopy (SEM) imaging. Mature leaves from each species were collected in Kuwait. From each species, a $<1 \mathrm{~cm}$ circular diameter leaf sample was extracted from the main vein to the lamina. Each sample was then mounted on an aluminum stub on top of a circular carbon impregnated double sided tape. The samples were then left to air dry for a minimum of three days. Stub samples were then transported to Belgium and analyzed using SEM to study leaf surface characteristics. The stubs were coated in carbon (ca. $20 \mathrm{~nm}$ thick layer: Leica EM ACE600, Germany) and analyzed using a field emission gun, environmental scanning electron microscope (FEG-ESEM) equipped with an energy dispersive X-Ray (EDX) detector (FEI Quanta 250, USA; at AXES and EMAT research groups, University of Antwerp)at a magnification of 100x. Identification of epicuticular waxes was conducted using Wilhelm et al. (1998) "Classification and terminology of plant epicuticular waxes" [40].

\subsection{Statistical Analysis}

The aim of this statical analysis is to compare and assess four different magnetic parameters using two species over three land use classes. The biomagnetic indicators (SIRM, HIRM, s-ratio and NRM) were considered as the primary variables of the research. Descriptive statistics were conducted using Statistical Package for Social Science (SPSS 21.0). The rest of the Statistical analyses were conducted using (R 3.5.1) software. Kolmogorov-Smirnov normality test (K-S) was applied to determine the most suitable statistical test. A General Linear Model (GLM) analysis of variance (ANOVA) was employed to determine the interaction between the two subject factors: tree species and land use classes to assess main effects and interactions. For multiple comparisons, Bonferroni's tests were applied. A Multivariable model was then used to adjust and obtain true effects of distances to neighborhood, to roads and dimensions may play a role in certain aspects therefore an (ANCOVA) model was applied to determine the significant difference between the variable's (species, land use classes and height, distance from plant to plant, distance to road) and assessed the effects of these variables on the parameters. Additionally, the effects of species and land class as well as interactions terms were adjusted and corrected. One-way Anova models were applied to assess the homogeneity of the land use classes and plant species.

To establish the relationship between magnetic parameters in leaf samples correlation coefficients and associated levels of significance $(p)$ were used. For the classification and characterization of samples and to see if there were any 
associations between the magnetic parameters Principal Component Analysis (PCA) was adopted and the components with eigenvalue $>1$ were extracted for this study.

To display the spatial variation in magnetic parameters a map of each site geostatistical interpolation and mapping was performed by Inverse Distance Weighted technique (IDW) using ArcGIS (10.6.1) (Environmental System Research Institute (ESRI), Redlands, Canada). The samples selection was random and clustered in some areas based on species presence in the selected sites.

\section{Results}

\subsection{Plant Leaf Surface Characteristics}

The surface of the palm leaves is characterized by deep ridges and furrows formed by epicuticular wax (Figure 3(b), Figure 3(d)). The wax crust is classed as crystalloids; there are ununiform wax projections across the leaf surface leaving a crust like appearance. The leaf surfaces of Buttonwood are characterized by

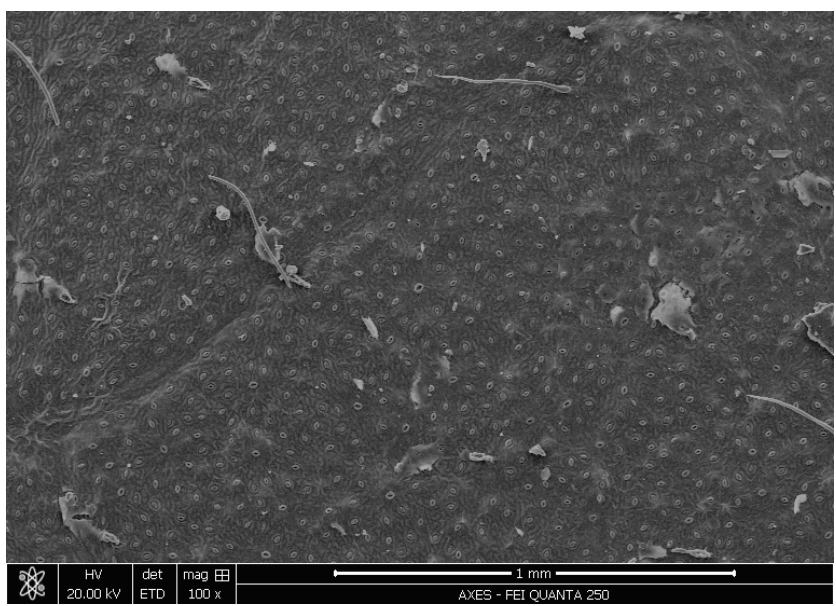

(a)

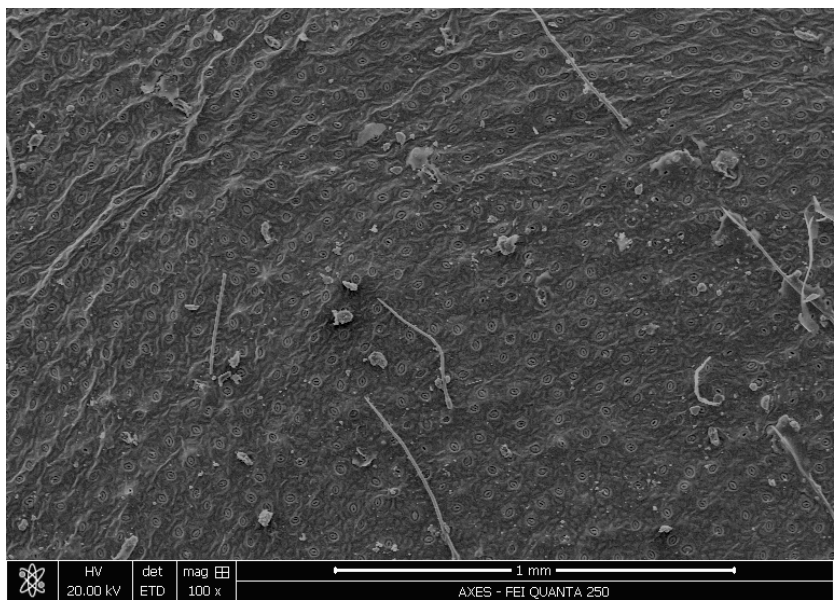

(c)

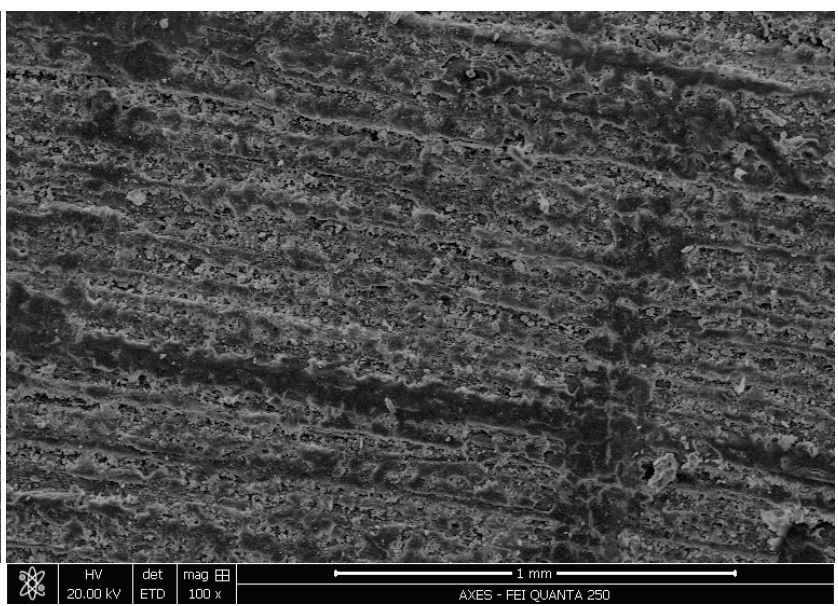

(b)

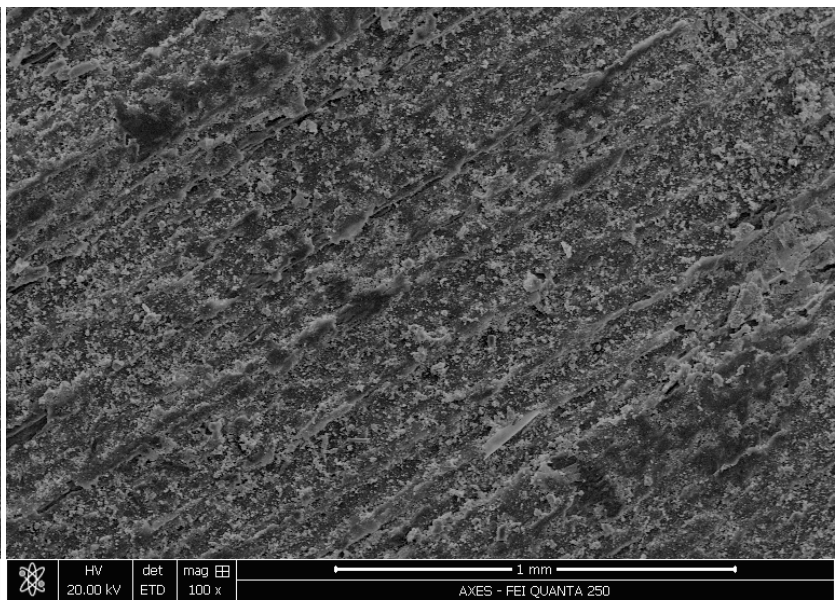

(d)

Figure 3. SEM photomicrographs of leaf micromorphology at $\times 100$ : Abaxial leaf surface of (a) buttonwood and (b) palm, adaxial leaf surface of (c) buttonwood and (d) palm. 
a smooth wax film with low relief. Films are very thin coverings usually less than $1 \mu \mathrm{m}$ thick without a prominent surface sculpturing with the exception of sparse long unicellular trichomes [40]. It is detectable by SEM mainly due to artificial cracking which separates them from the even thinner films [40]. The stomata are visible on both the abaxial and adaxial leaf surface (Figure 3(a), Figure 3(c)).

\subsection{General Information on Sites}

The distance to road is determined to differ over all land use classes. However, plants in the urban site are further away from the road than the other sites. Buttonwood leaf samples were closer to roads than palm ones $(\mathrm{p}=0.008)($ Table 2$)$. The mean distances were $4.7 \mathrm{~m}$ and $5.8 \mathrm{~m}$, respectively. Distances between palms are significantly differed to distances between buttonwood. Palms are separated by $4.9 \mathrm{~m}$ on average, five times more than buttonwood that were distanced $1.0 \mathrm{~m}$ apart. The physical differences between both species are notable; palms had a mean height of $8.0 \mathrm{~m}$ in comparison to $1.4 \mathrm{~m}$ for buttonwood.

\subsection{Magnetic Parameters}

\subsubsection{NRM}

NRM is any magnetization acquired through natural processes without any magnetization being imparted on the sample [13]. Palm leaf NRM values ranged from 0.01 to $2.13 \mu \mathrm{A}$, with mean of $0.36 \mu \mathrm{A}$. While, Buttonwood leaf NRM values ranged from 0.02 to $1.71 \mu \mathrm{A}$, with a mean of $0.31 \mu \mathrm{A}$ (Figure 4). Differences between land use classes are significant and are species dependent $(\mathrm{p}=0.002)$ (Table 3). Reciprocally, differences between species are significant and their magnitude is dependent on land use class. For palms, the industrial land use class showed a significantly higher level of NRM in comparison to the urban and sub-urban land uses classes (Table 4). In the industrial site NRM values for palms were remarkably higher than buttonwood $(\mathrm{p}<0.001)$ (Table 5).

\subsubsection{SIRM}

SIRM is used as a proxy of PM concentration; it indicates the total concentration of magnetic grains. It is quantified by measuring the magnetic remanence of samples once removed from an induced field [6]. SIRM is very sensitive to single-domain magnetic particles with grain sizes between 50 and $150 \mathrm{~nm}$ and multidomain (MD) particles [41]. SIRM values of palm leaves were determined to be

Table 2. Results of independent t-test and F-test ANOVA to test homogeneity of land use classes and species groups according to covariates.

\begin{tabular}{ccc}
\hline & Site & Species \\
\hline Distance to the closest plant & $0.014^{*}$ & $<0.001^{\star * *}$ \\
Distance to road & $<0.001^{* * *}$ & $0.008^{* *}$ \\
Height & 0,145 & $<0.001^{* * *}$ \\
\hline
\end{tabular}

${ }^{\star} \mathrm{p}<0.05 ;{ }^{* *} \mathrm{p}<0.01 ;{ }^{* *} \mathrm{p}<0.001$. 


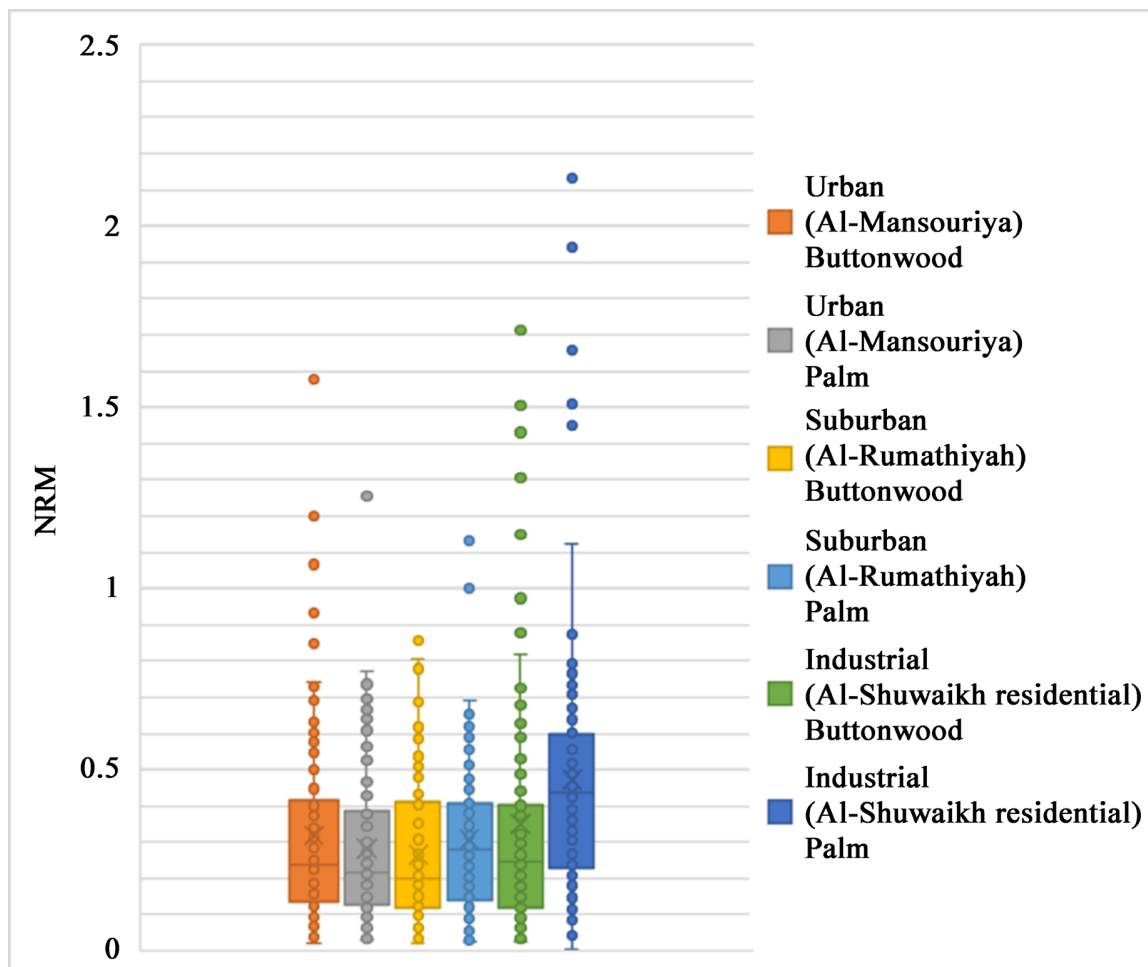

Figure 4. Box-plots of $C$. erectus and $P$. dactylifera NRM $(\mu \mathrm{A})$ values in different land use classes.

Table 3. Two-way ANOVA F-test for main effects and interaction of NRM $(\mu \mathrm{A})$ by land use classes and species.

\begin{tabular}{ccc}
\hline & F & p-value \\
\hline Species & 5.82 & $0.016^{\star}$ \\
Land use class & 12.2 & $<0.001^{\star * *}$ \\
Species $\times$ land uses class & 6.13 & $0.002^{\star *}$ \\
\hline
\end{tabular}

${ }^{*} \mathrm{p}<0.05 ;{ }^{* *} \mathrm{p}<0.01 ;{ }^{* *} \mathrm{p}<0.001$.

Table 4. Bonferroni's post-hoc tests comparison of NRM $(\mu \mathrm{A})$ means of $P$. dactylifera by land use classes.

\begin{tabular}{ccc}
\hline & Urban & Sub-urban \\
\hline Urban & & \\
Sub-urban & 1.000 & \\
Industrial & $<0.001^{* * *}$ & $<0.001^{* * *}$ \\
\hline
\end{tabular}

${ }^{\star} \mathrm{p}<0.05 ;{ }^{* *} \mathrm{p}<0.01 ;{ }^{* *} \mathrm{p}<0.001$.

significantly higher in comparison to buttonwood leaves and differences seem to be more or less dependent on land use classes. Palm leaf SIRM values ranged from 18.5 to $220.3 \mu \mathrm{A}$, with an average value of $67.5 \mu \mathrm{A}$. Buttonwood leaf SIRM 
values ranged from 2.9 to $159.0 \mu \mathrm{A}$ and have an average of $16.8 \mu \mathrm{A}$ (Figure 5). A Two-way ANOVA F-test linear model was used to assess differences between mean SIRM values for main effects and interactions, values were determined to significantly differ between land use classes and are species dependent $(\mathrm{p}<$ 0.001). Reciprocally, differences between species are significant and their SIRM magnitude is dependent on land use classes. Multiple post-hoc comparisons were used to detect particular differences between land use classes. Table 6 shows that palms SIRM values differ depending on land use class. There were significant differences between palms and buttonwood in the urban land class sub-urban and industrial land class $(\mathrm{p}<0.001)$. The SIRM values clearly increase from the urban to the industrial land classes indicated in (Table 6) and (Figure 5). Table 6 indicates a linear correlation $(\mathrm{p}=0.036)$ between SIRM values, (distance from road and land use class) and (species and land use class). The longer the distance from the road the lower the SIRM values, with distances of $0 \sim 5 \mathrm{~m}$ from the road having the highest SIRM values (Figure 6)

\subsubsection{HIRM}

HIRM, "Hard" isothermal remnant magnetization indicates the approximate total concentration ofweakly magnetic but high coercivity mineral phases such as canted antiferromagnetic hematite in a sample [38] [39] [42]. In comparison to $s$-ratio, HIRM is a more sensitive parameter towards indicating the contribution

Table 5. ANCOVA F-test for the comparison of main effects and interactions of NRM $(\mu \mathrm{A})$ means by land use class and plant species adjusting by covariates.

\begin{tabular}{ccc}
\hline Species & F & p-value \\
\hline Land use class & 0.05 & 0.947 \\
Species $\times$ land use class & 0.31 & 0.733 \\
Species $\times$ distance to road & 1.48 & 0.224 \\
Land use class $\times$ distance to road & 0.91 & 0.387 \\
Species $\times$ land use class $\times$ distance to road & 1.39 & 0.249
\end{tabular}

${ }^{*} \mathrm{p}<0.05 ;{ }^{* *} \mathrm{p}<0.01 ;{ }^{* *} \mathrm{p}<0.001$.

Table 6. ANCOVA F-test to compare main effects and interactions to SIRM means by land use classes (urban, sub-urban, industrial) and species. Values in bold indicate relation of significance level to $\mathrm{p}$-values.

\begin{tabular}{ccc}
\hline & F & p-value \\
\hline Species & 36.9 & $<0.001^{* * *}$ \\
Land use class & 4.15 & $0.016^{*}$ \\
Species $\times$ land use class & 11.5 & $<0.001^{* * *}$ \\
Species $\times$ distance to road & 1.05 & 0.306 \\
Land use class $\times$ distance to road & 0.51 & 0.600 \\
Species $\times$ land use class $\times$ distance to road & 3.34 & $0.036^{*}$
\end{tabular}




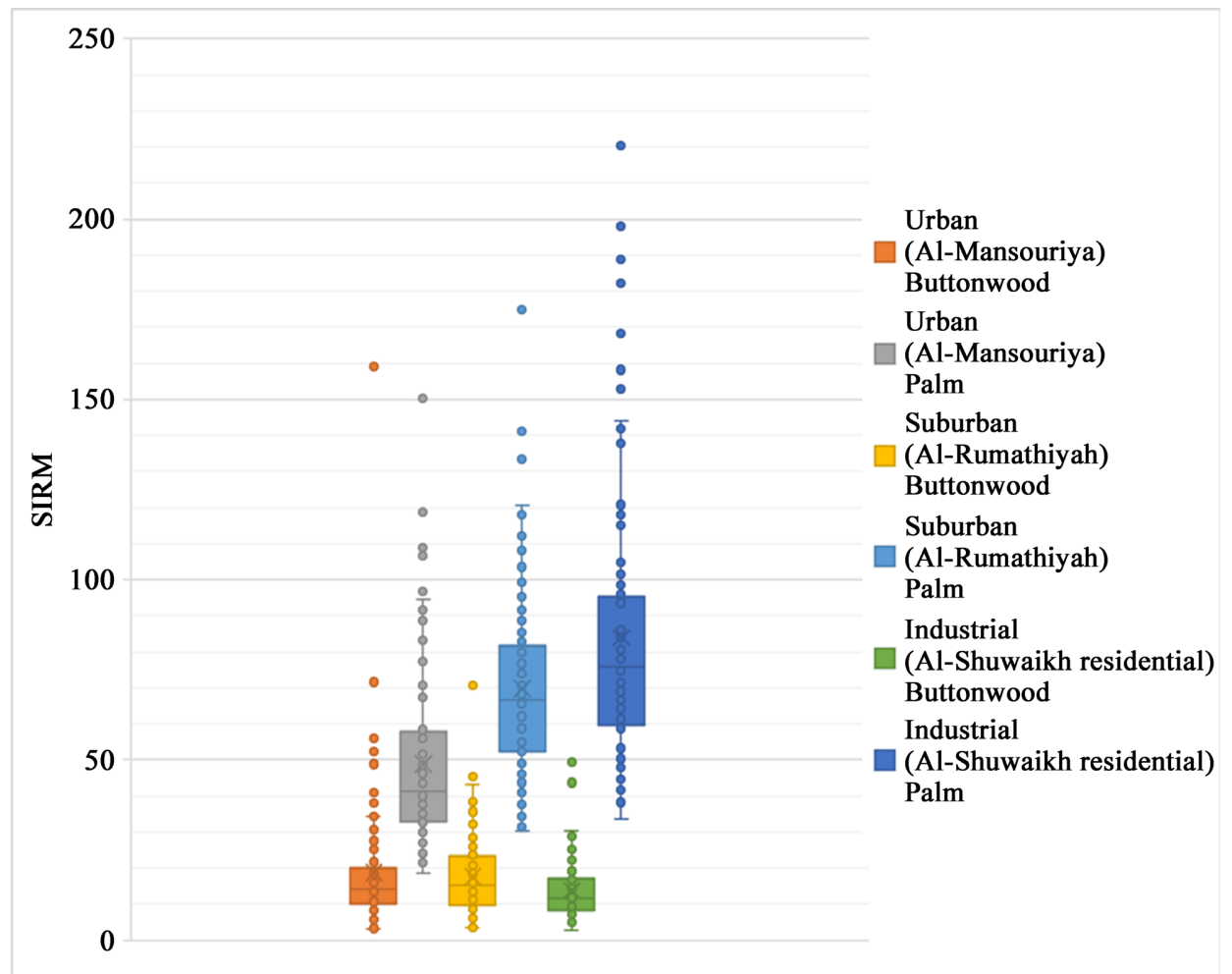

Figure 5. Box-plot indicating mean SIRM values by species (buttonwood, palm) and land use classes (urban, sub-urban, industrial).

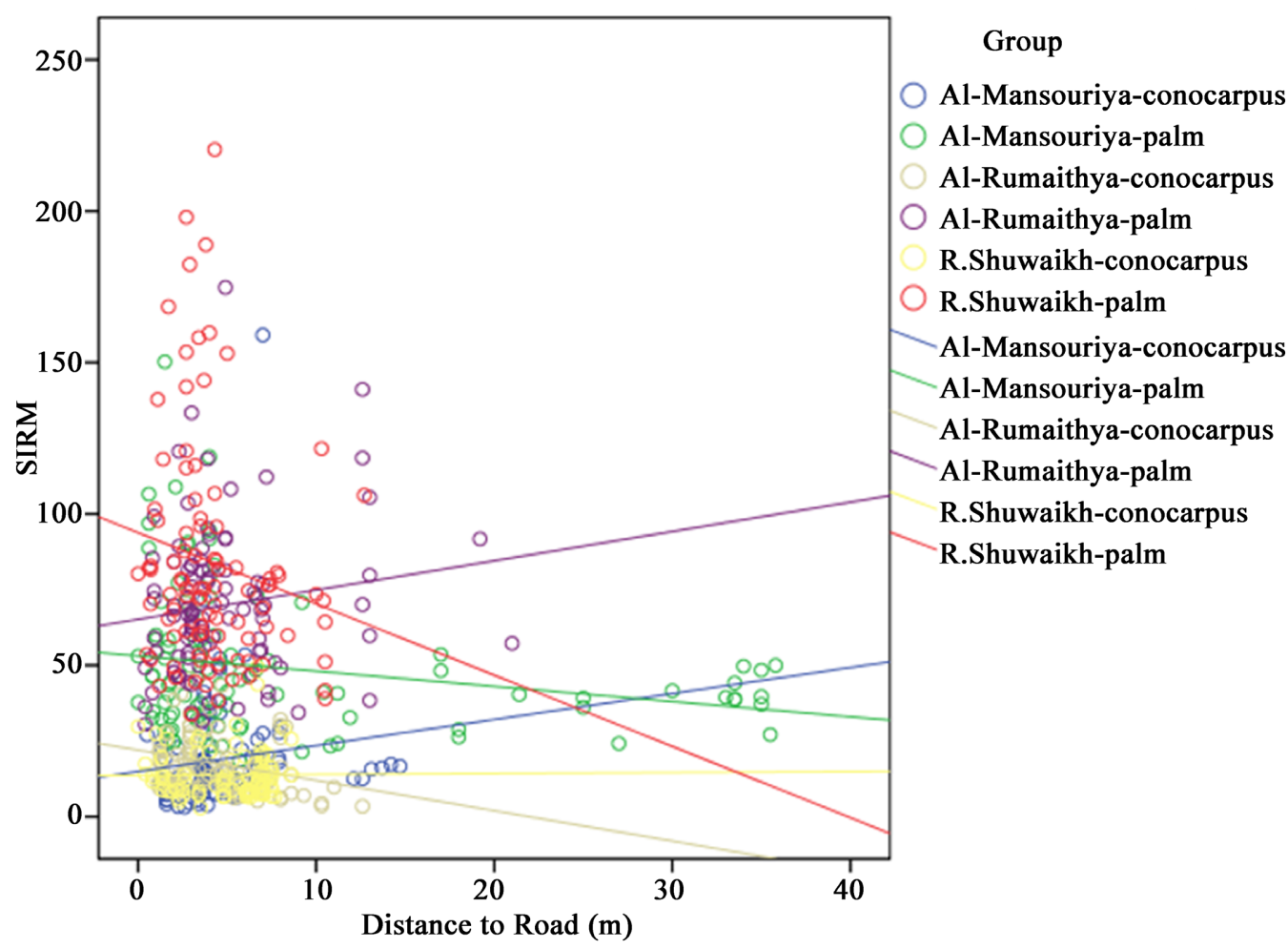

Figure 6. Scatter plot indicating the relationship between distance from road $(\mathrm{m})$ and SIRM $(\mu \mathrm{A})$ and line of best fit. 
of anthropogenically produced high-coercivity magnetic particles (e.g., hematite) in samples [43]. HIRM values from a descriptive point of view are very similar to the SIRM values (Figure 7). Differences between land class use are significant and dependent on species (interaction $\mathrm{p}<0.001$ ). Only palms showed a significant difference between land use classes $(\mathrm{p}<0.001)$. Utilizing the ANCOVA model, the results were very homogeneous. However, the correlation between distance to road and HIRM was weaker than before $(\mathrm{p}=0.070)$ (Table 7). Buttonwood samples located at the suburban land use class, exhibited a HIRM reduction of $0.84 \mu \mathrm{A}(\mathrm{p}=0.041)$ for every additional meter further from the road (Figure 8). Palm samples located at the urban land use class exhibited a reduction of $0.44 \mu \mathrm{A}$ per meter $(\mathrm{p}=0.038)$. Buttonwood at the industrial land use

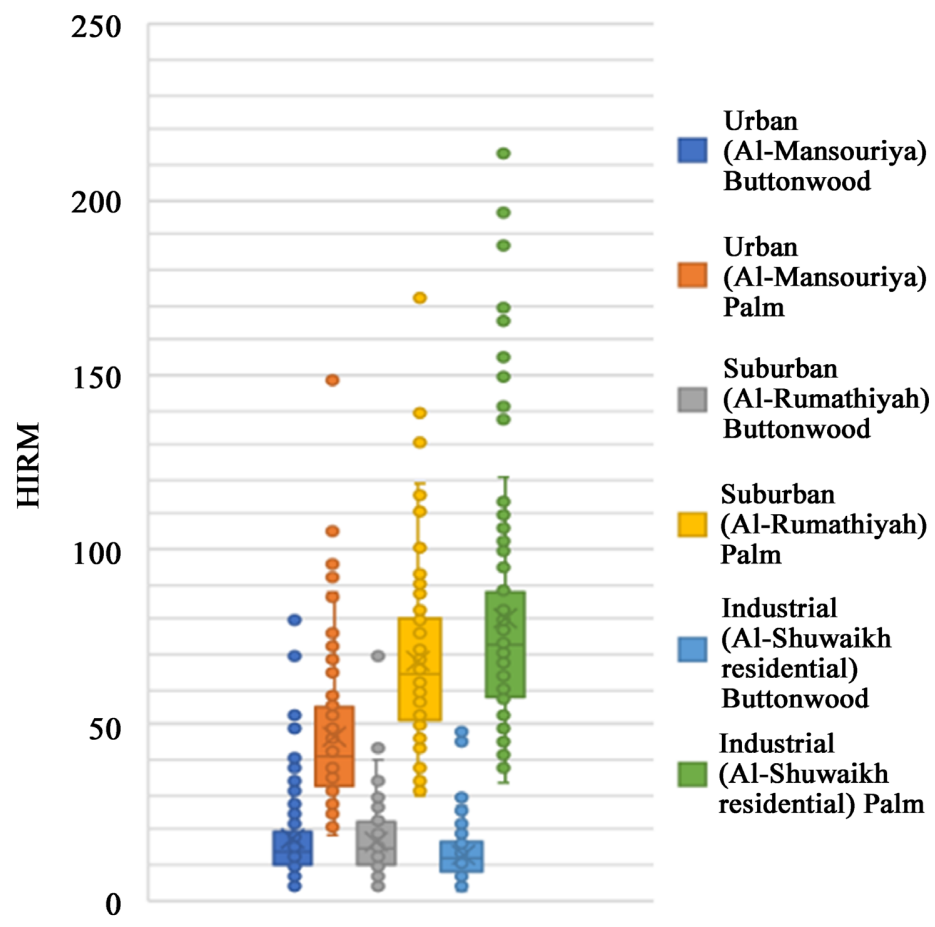

Figure 7. Box-plot indicating mean HIRM $(\mu \mathrm{A})$ values by species (buttonwood, palm) and land use classes (urban, sub-urban, industrial).

Table 7. Comparison of HIRM means by land use classes (urban, sub-urban, industrial) and plant species adjusted by covariates: ANCOVA F-test for main effects and interactions.

\begin{tabular}{ccc}
\hline & F & p-value \\
\hline Species & 38.3 & $<0.001^{\star * *}$ \\
Land use class & 4.24 & $0.015^{*}$ \\
Species $\times$ land use class & 11.0 & $<0.001^{\star * *}$ \\
Species $\times$ distance to road & 0.64 & 0.423 \\
Land class $\times$ distance to road & 0.22 & 0.807 \\
Species $\times$ land class $\times$ distance to road & 2.67 & 0.070 \\
\hline
\end{tabular}


class experienced a HIRM reduction at $1.82 \mu \mathrm{A}$ for every additional meter distance between two plants ( $\mathrm{p}=0.029)$ (Figure 9 ). For height only palms located at the industrial land use class exhibited a HIRM increase of $3.21 \mu \mathrm{A}$ for every additional meter in height $(\mathrm{p}=0.008)$.

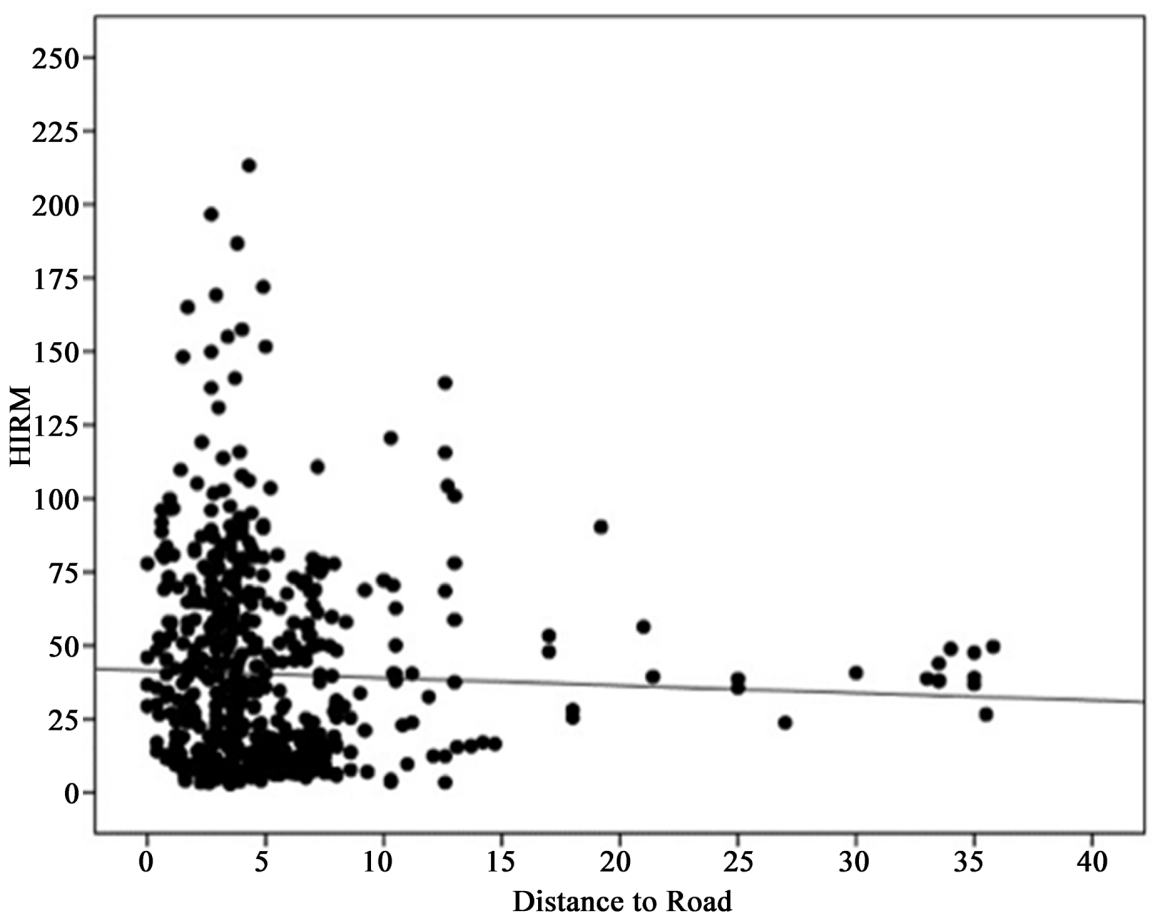

Figure 8. Scatter plot with line of best fit indicating the relationship between distance from road $(\mathrm{m}) \operatorname{HIRM}(\mu \mathrm{A})$ in the suburban land use class.

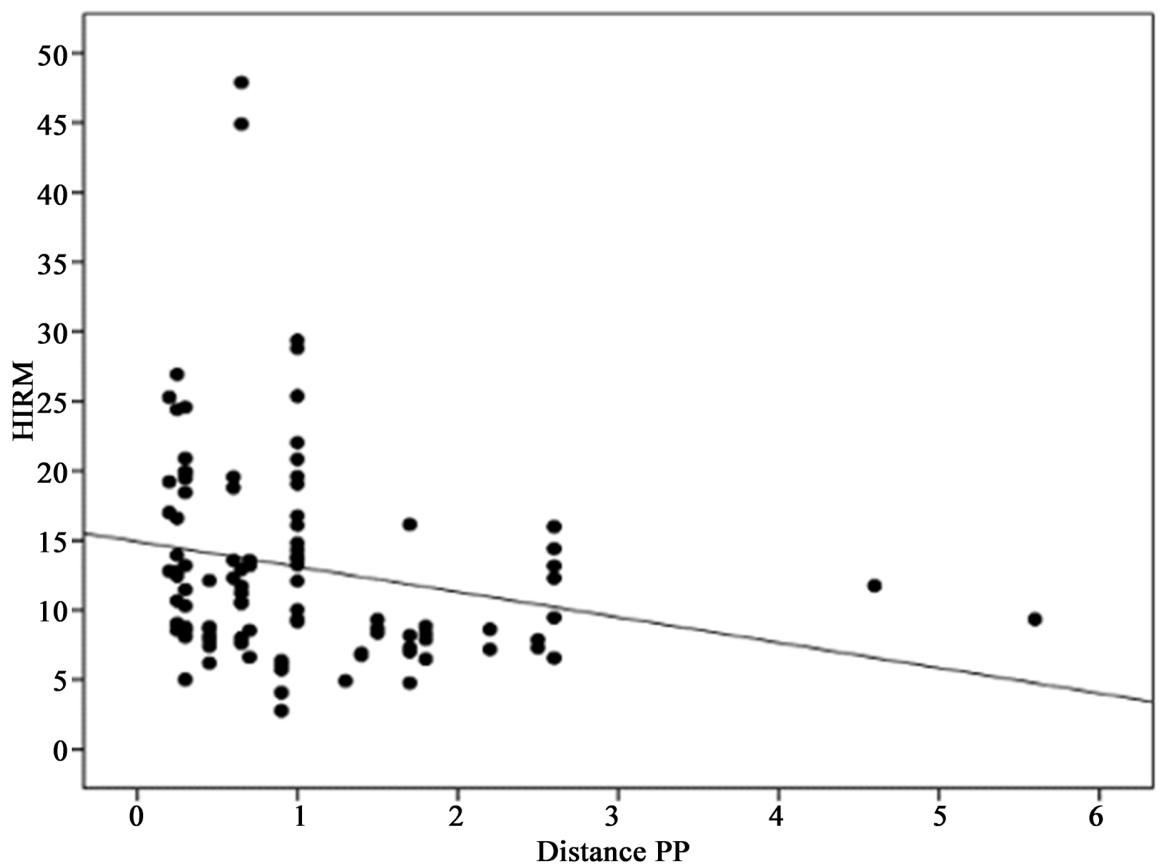

Figure 9. Scatter plot with line of best fit indicating the relationship between distance between two plants $(\mathrm{m})$ and HIRM $(\mu \mathrm{A})$ in the suburban land use class. 


\subsubsection{HIRM\%}

HIRM\% is an indication of the approximate proportion of high coercivity mineral phases, like canted antiferromagnetic hematite, relative to the total remanence carrying mineral assemblage [42]. HIRM \% across all land use classes had a mean range of $2.31 \%-5.38 \%$ (Figure 10 ). HIRM\% vales are affected by land use classes and species interaction were significant $(p=0.029)$. As well as species, land use class and distance from road interactions $(\mathrm{p}=0.025)$. HIRM $\%$ is higher for buttonwood overall. The highest HIRM \% was found at the industrial land use class. Buttonwood in the suburban area displayed a $0.63 \mu \mathrm{A}$ reduction for every additional $1 \mathrm{~m}$ distance to the road, while palms displayed a $0.08 \mu \mathrm{A}$ reduction for every $1 \mathrm{~m}$ in the urban area (Figure 11).

\subsubsection{S-Ratio}

$S$-ratio indicates the relative proportion of soft magnetic components to hard magnetic components (antiferromagnetic and ferrimagnetic minerals) [44]. The $s$-ratio differed significantly $(\mathrm{p}=0.036)$ between land use classes, these differences are identified within species $(\mathrm{p}=0.337)$ (Figure 12) (Table 8). The interaction between species and land use class on $s$-ratio are significant $(\mathrm{p}=0.006)$ (Table 9). Covariates differed across land use classes and species; therefore, effects were estimated using fixed values of covariates (mean height and mean plant to plant distances). Differences were identified between observed and predicted (model) means. Buttonwood $s$-ratio in the sub-urban land use class was estimated to be higher than in the urban land use class $(\mathrm{p}=0.068)$. Also that the interaction and effects between species, land use class and distance to road are significant $(\mathrm{p}=0.025)($ Table 10$)$.

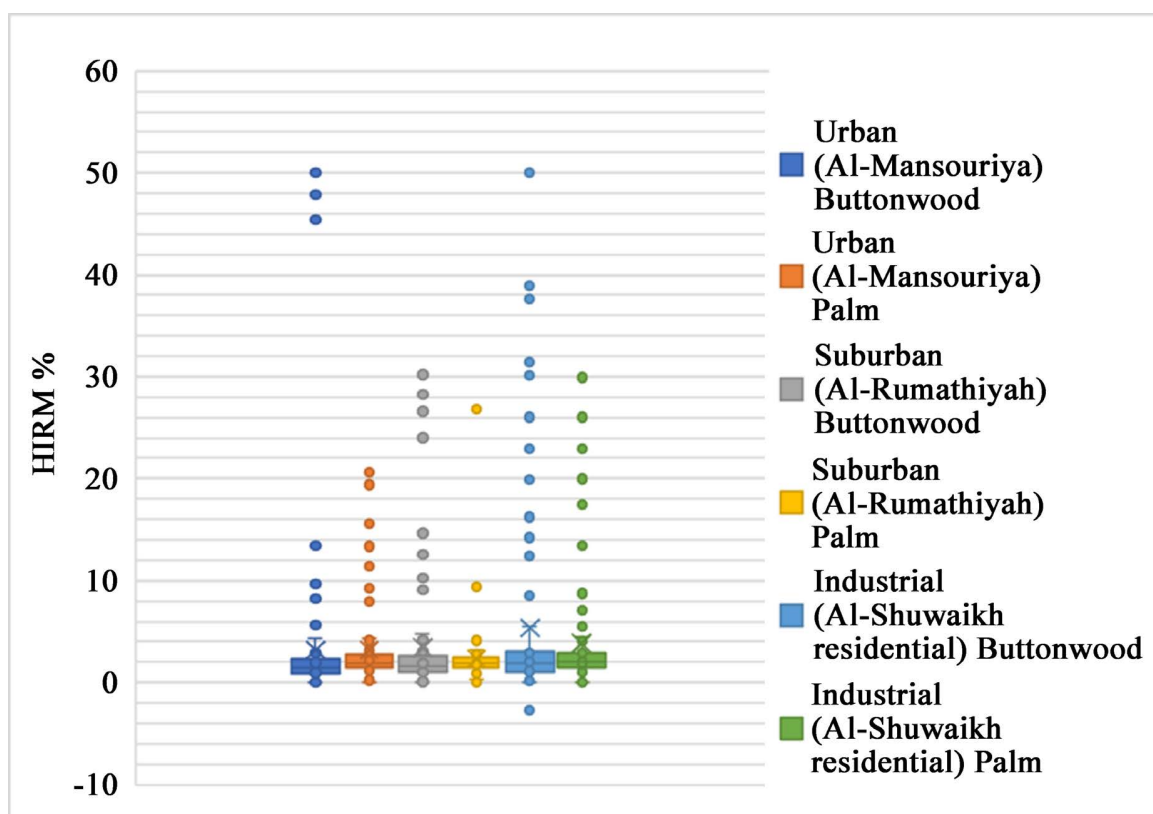

Figure 10. Box-plot indicating mean HIRM\% values by species (buttonwood, palm) and land use classes (urban, sub-urban, industrial). 


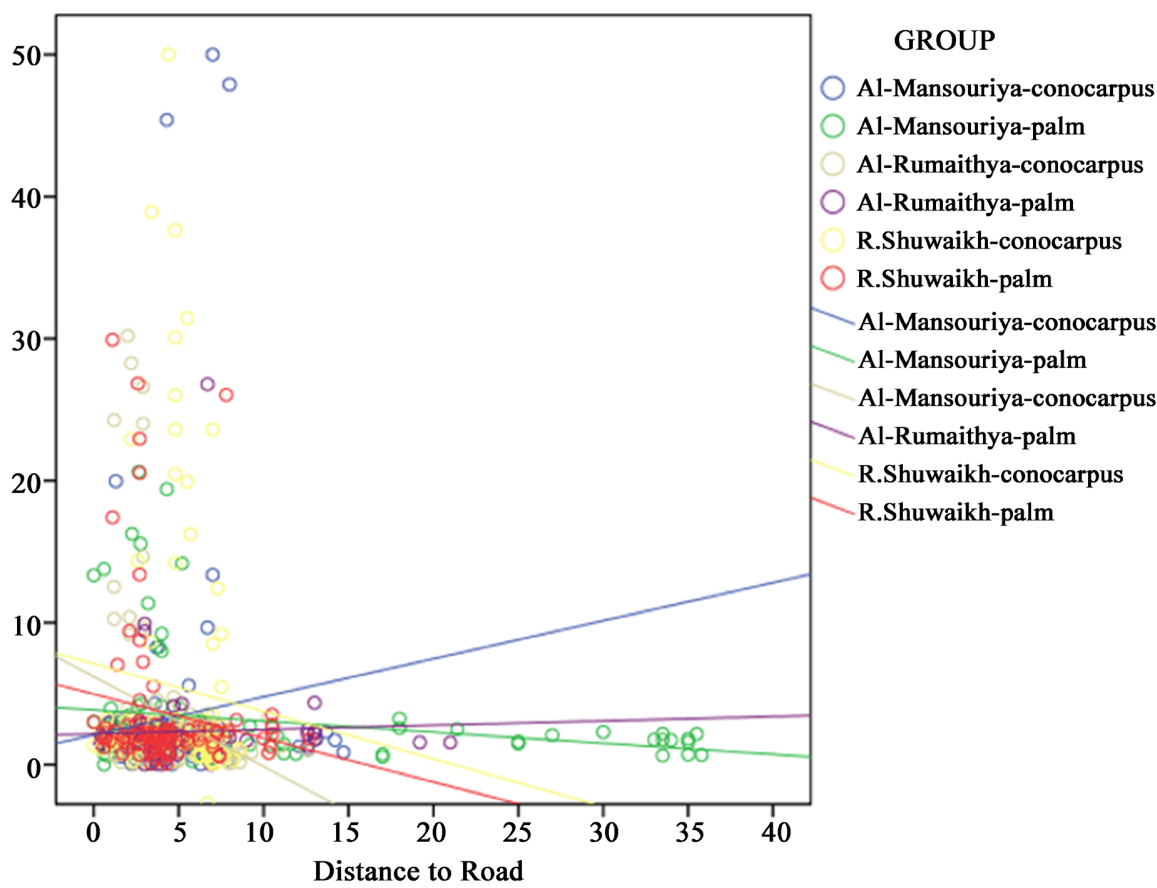

Figure 11. Scatter plot with line of best fit indicating the relationship between distance from road (m) and HIRM\% for both considered plant species and the three considered land use classes (urban, sub-urban, industrial).

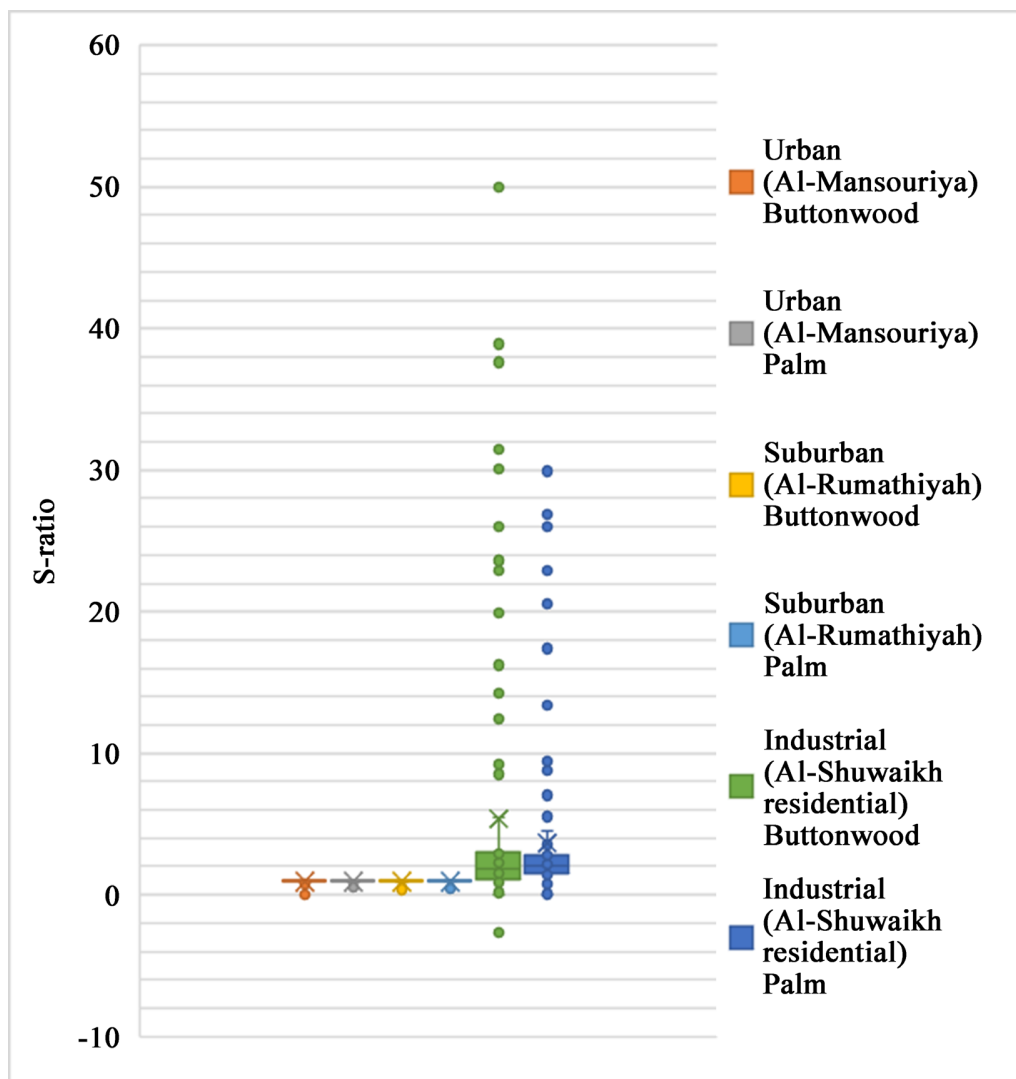

Figure 12. Box-plot indicating mean $s$-ratio values (dimensionless) by species (buttonwood, palm) and land use classes (urban, sub-urban, industrial). 
Table 8. Comparison of HIRM means by land use classes (urban, sub-urban, industrial) and plant species adjusted by covariates: ANCOVA F-test for main effects and interactions.

\begin{tabular}{ccc}
\hline & F & p-value \\
\hline Species & 1.92 & 0.166 \\
Land use class & 3.35 & $0.036^{*}$ \\
Species $\times$ land use class & 1.09 & 0.337 \\
\hline
\end{tabular}

${ }^{*} \mathrm{p}<0.05 ;{ }^{* *} \mathrm{p}<0.01 ;{ }^{* *} \mathrm{p}<0.001$.

Table 9. ANCOVA F-test for main effects and interactions, comparison of $s$-ratio means by land use classes (urban, sub-urban, industrial) and species adjusting by covariates.

\begin{tabular}{ccc}
\hline & F & p-value \\
\hline Species & 0.03 & 0.861 \\
Land use class & 1.28 & 0.278 \\
Species $\times$ land use class & 5.25 & $0.006^{* *}$ \\
species $\times$ distance to road & 0.56 & 0.456 \\
Land class $\times$ distance to road & 2.94 & 0.054 \\
Species $\times$ land class $\times$ distance to road & 3.73 & $0.025^{\star}$ \\
\hline
\end{tabular}

${ }^{*} \mathrm{p}<0.05 ;{ }^{* *} \mathrm{p}<0.01 ;{ }^{* *} \mathrm{p}<0.001$.

Table 10. Bonferroni's post-hoc tests comparison of s-ratio means of $C$. erectus by land use classes (urban, sub-urban, industrial).

\begin{tabular}{ccc}
\hline & Urban & Sub-urban \\
\hline Urban & & \\
Suburban & 0.068 & \\
Industrial & 1.000 & 0.274 \\
\hline
\end{tabular}

${ }^{*} \mathrm{p}<0.05 ;{ }^{* *} \mathrm{p}<0.01 ;{ }^{* *} \mathrm{p}<0.001$.

\subsubsection{Comparison of Magnetic Parameters}

SIRM and HIRM showed an extremely high level of correlation $(r=0.992 ; \mathrm{p}<$ 0.001) (Figure 13). Analogously, $s$-ratio and HIRM\% showed an extremely high level of inverse correlation $(\mathrm{r}=-0.910 ; \mathrm{p}<0.001)$ (Figure 14). If some atypical values are excluded, correlation coefficient are even stronger for both cases (SIRM/HIRM and $s$-ratio/HIRM\%), such high correlations suggest that some variables are a linear transformation from the other ones (Figure 15). NRM shows a weak correlation $(\mathrm{r} \approx 0.2)$ with SIRM/HIRM (Figure 15, Figure 16). This correlation reached statistical significance because of the huge sample size $(\mathrm{n}=600)$.

For the PCA analysis results suggest that there is non-null correlation between parameters $(\mathrm{p}<0.001)$. However, the convenience of a factorial analysis is poor $(\mathrm{KMO}=0.40)$. There are 2 factors that explain $77.2 \%$ of the common variance between the 5 parameters (Table 11 ). The first factor accounted $40.5 \%$ of the va- 
riance relative to the total variance in all the variables. The second factor $36.7 \%$. Finally, the rotated factor matrix provides the partial correlations between original measurements and extracted factors that are necessary to interpret factors

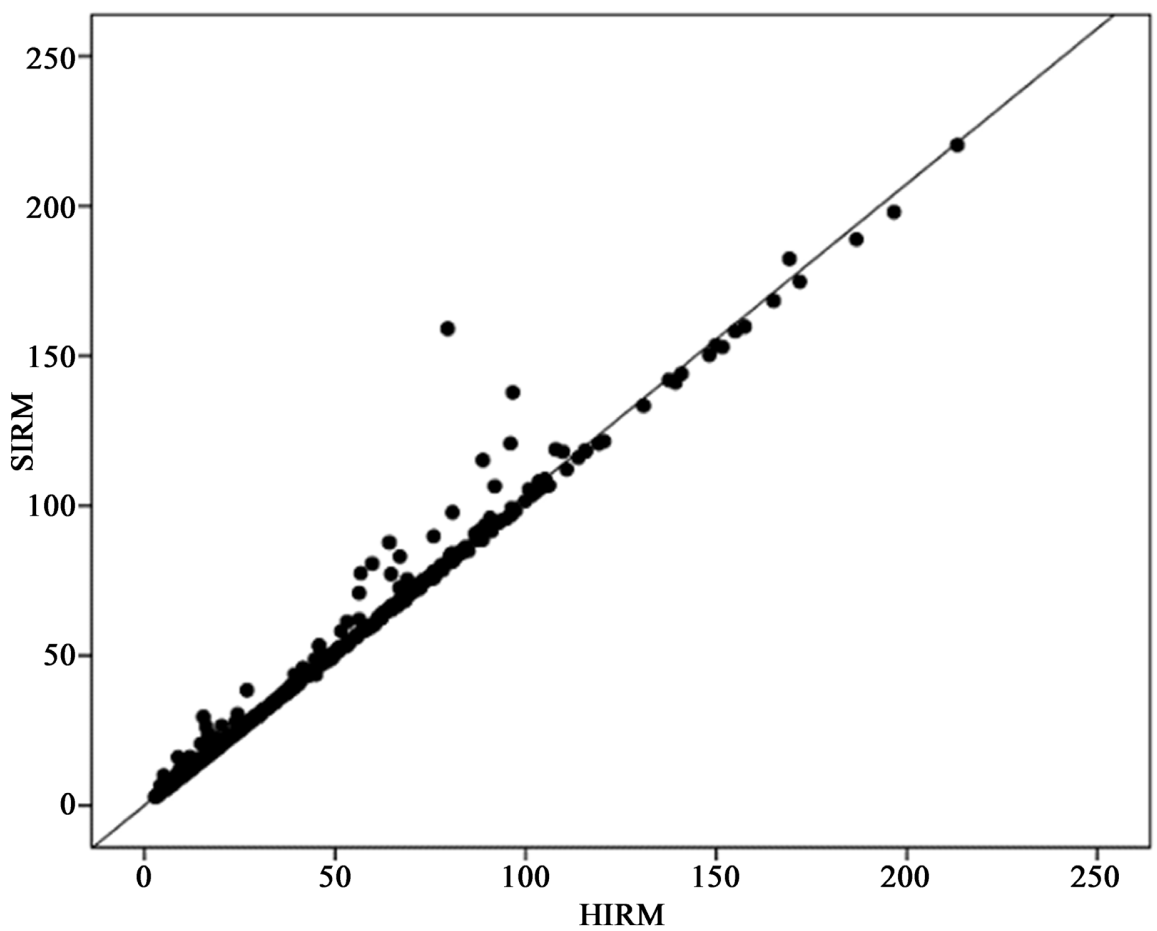

Figure 13. Correlation between SIRM $(\mu \mathrm{A})$ and HIRM $(\mu \mathrm{A})$ values of all tested samples. Line of best fit indicating the relationship between SIRM and HIRM\%.

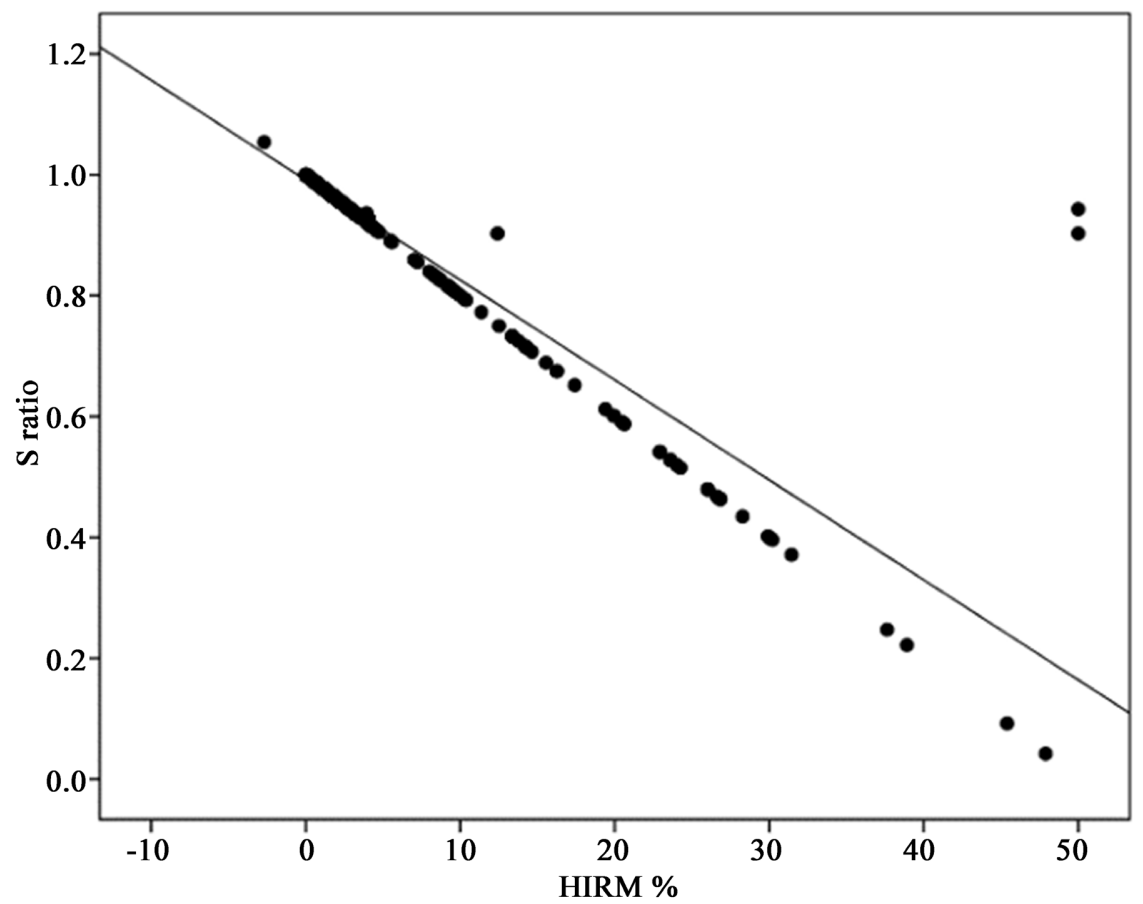

Figure 14. Correlation between $s$-ratio and HIRM\% values of all tested samples. Line of best fit indicating the relationship between $s$-ratio and HIRM\%. 


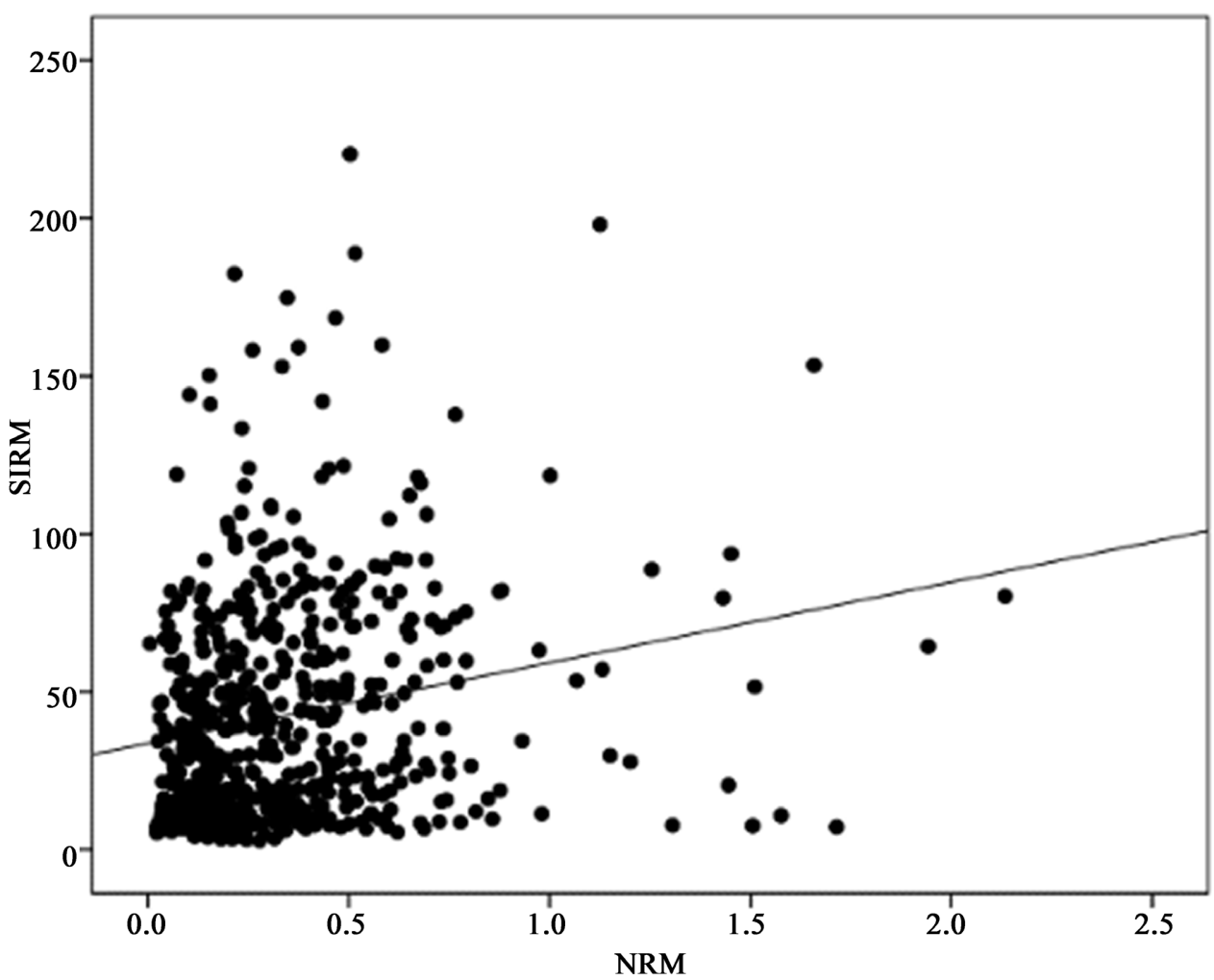

Figure 15. Correlation between SIRM $(\mu \mathrm{A})$ and NRM $(\mu \mathrm{A})$ values of all tested samples. Line of best fit indicating the relationship between NRM and SIRM.

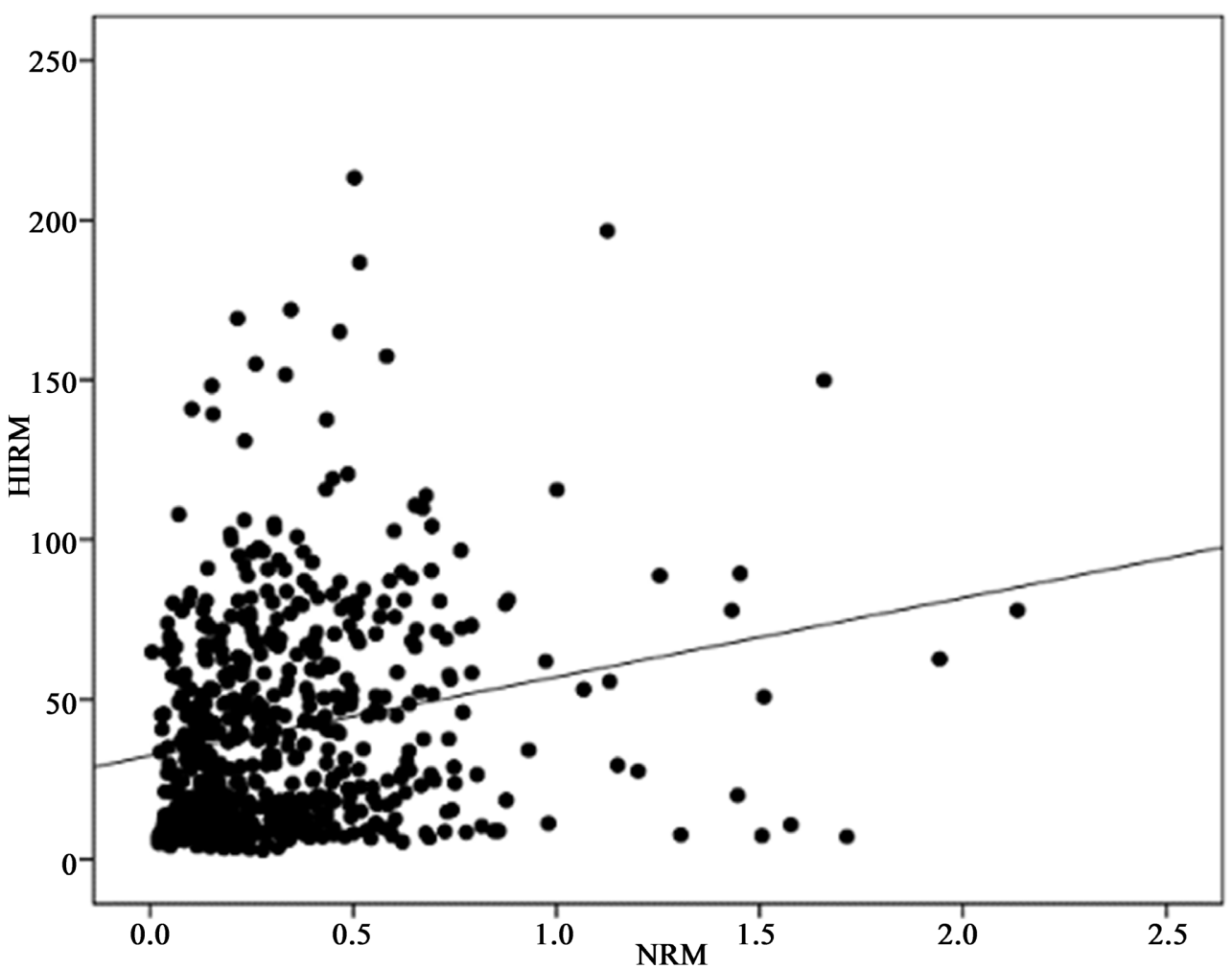

Figure 16. Correlation between HIRM $(\mu \mathrm{A})$ and NRM $(\mu \mathrm{A})$ of all tested samples. Line of best fit indicating the relationship between NRM and HIRM. 
Table 11. Total variance Extraction method (Unweighted least squares).

\begin{tabular}{|c|c|c|c|c|c|c|c|c|c|}
\hline \multirow{2}{*}{ Factor } & \multicolumn{3}{|c|}{ Initial Eigen values } & \multicolumn{3}{|c|}{$\begin{array}{l}\text { Extraction sums of } \\
\text { squared loadings }\end{array}$} & \multicolumn{3}{|c|}{$\begin{array}{l}\text { Rotation sums of } \\
\text { squared loadings }\end{array}$} \\
\hline & Total & $\begin{array}{c}\% \text { of } \\
\text { variance }\end{array}$ & Cumulative \% & & Total & $\begin{array}{c}\% \text { of } \\
\text { variance }\end{array}$ & Cumulative \% & & Total \\
\hline 1 & 2.070 & 41.396 & 41.396 & 1 & 2.070 & 41.396 & 41.396 & 1 & 2.070 \\
\hline 2 & 1.915 & 38.300 & 79.696 & 2 & 1.915 & 38.300 & 79.696 & 2 & 1.915 \\
\hline 3 & 0.921 & 18.420 & 98.117 & 3 & 0.921 & 18.420 & 98.117 & 3 & 0.921 \\
\hline 4 & 0.091 & 1.814 & 99.931 & 4 & 0.091 & 1.814 & 99.931 & 4 & 0.091 \\
\hline 5 & 0.003 & 0.069 & 100.00 & 5 & 0.003 & 0.069 & 100.00 & 5 & 0.003 \\
\hline
\end{tabular}

Table 12. Rotated factor matrix using unweighted least squares. Rotation method: Varimax with Kaiser normalization.

\begin{tabular}{ccc}
\hline & \multicolumn{2}{c}{ Factor } \\
\cline { 2 - 3 } & 1 & 2 \\
\hline SIRM & 0.996 & 0.066 \\
HIRM & 0997 & -0.015 \\
HIRM\% & -0.017 & 0.999 \\
NRM & 0.205 & -0.027 \\
S-ratio & 0.029 & -0.911 \\
\hline
\end{tabular}

${ }^{*} \mathrm{p}<0.05 ;{ }^{* *} \mathrm{p}<0.01 ;{ }^{* *} \mathrm{p}<0.001$.

(Table 12). The $1^{\text {st }}$ dimension positively correlates the levels of SIRM and HIRM. The $2^{\text {nd }}$ dimension negatively correlates levels of $s$-ratio and HIRM (\%).The result is a replicate to those obtained from the bivariate correlation analysis. Therefore, it is highly recommendable to show those correlations but not conduct a PCA analysis as it is not providing an additional value. Moreover, it is not usual to conduct PCA analysis on a set of only 5 parameters as one of the aims of the PCA approach is to reduce the dimensionality and complexity of a large matrix of variables.

\subsubsection{Spatial Variation Mapping}

The magnetic parameters of both species are spatially represented in distribution maps for the three considered land use classes (Figures 17-19). Figure 18(a) and Figure 18(b) interpolate different boundaries of the urban land class because the extrapolated data from buttonwood and palms vary within those areas.

The applied SIRM, HIRM and HIRM\% ranges differed between species were considerably lower for buttonwood and applying the palms range to it would have not have enabled the differentiation of PM magnetic accumulation levels. Furthermore, HIRM\% and $s$-ratio have a limited range, as $s$-ratio is dimensionless (with a ratio of 0 to 1 ) and HIRM\% values did not vary greatly, which confines 


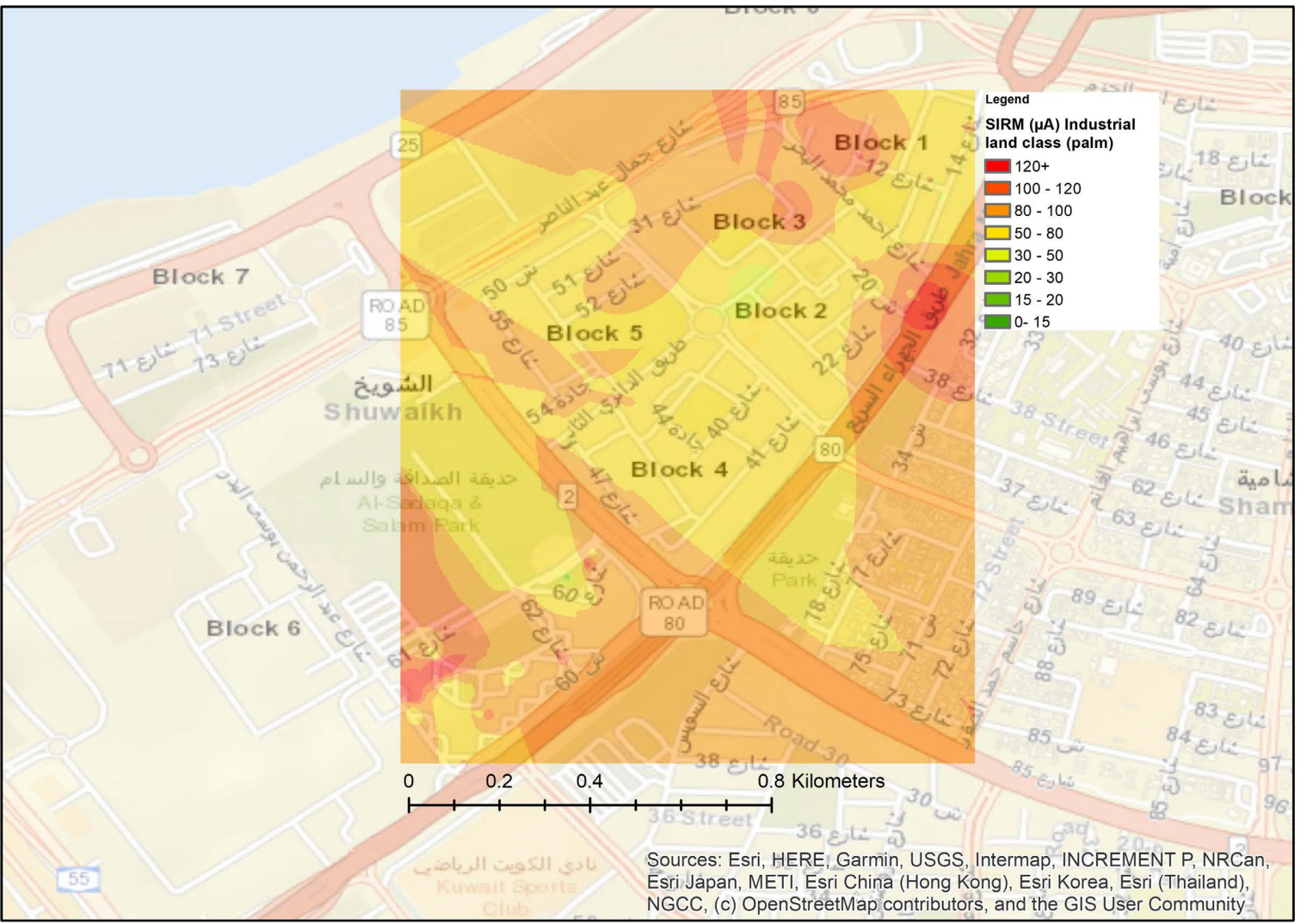

(a)

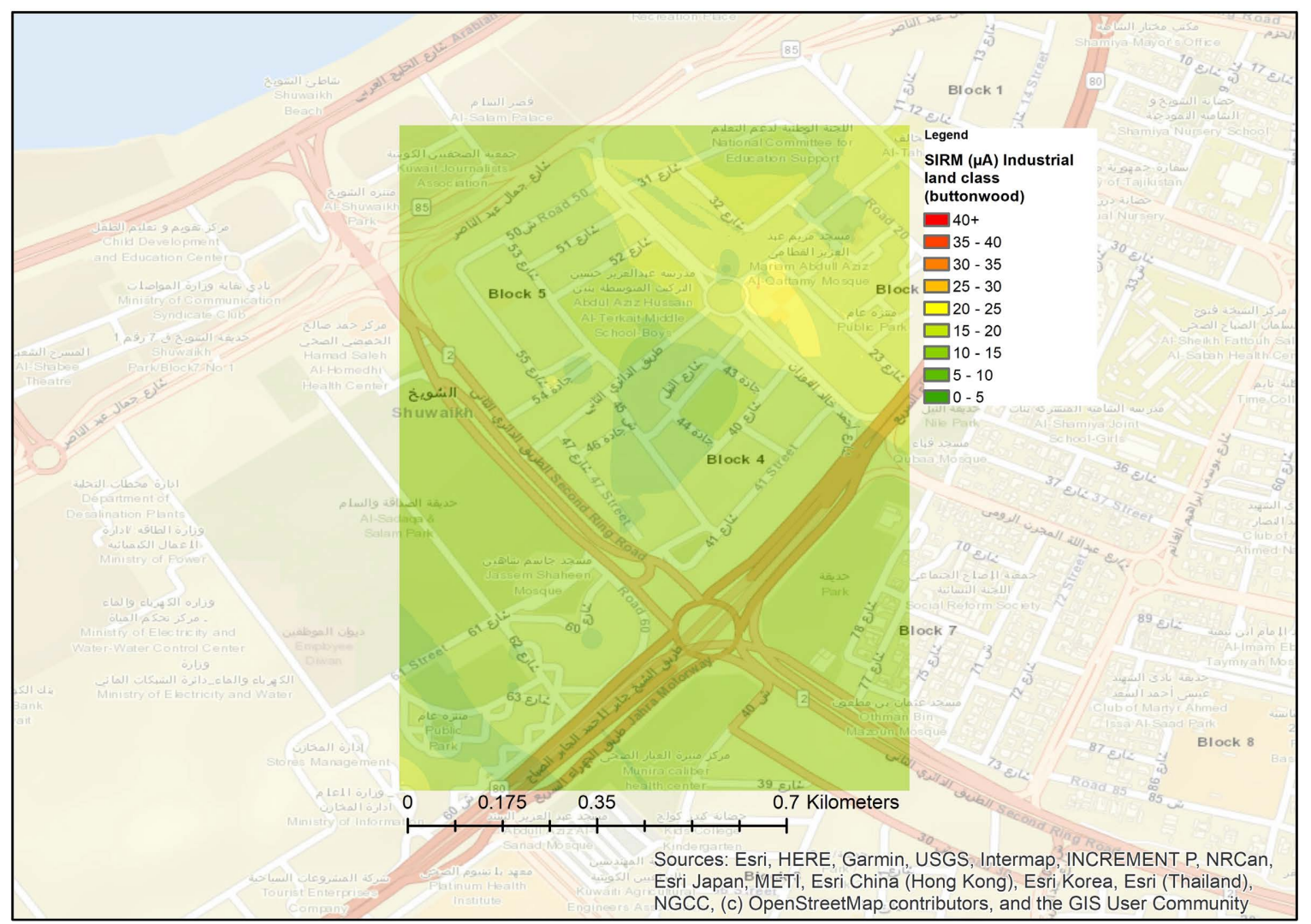

(b) 


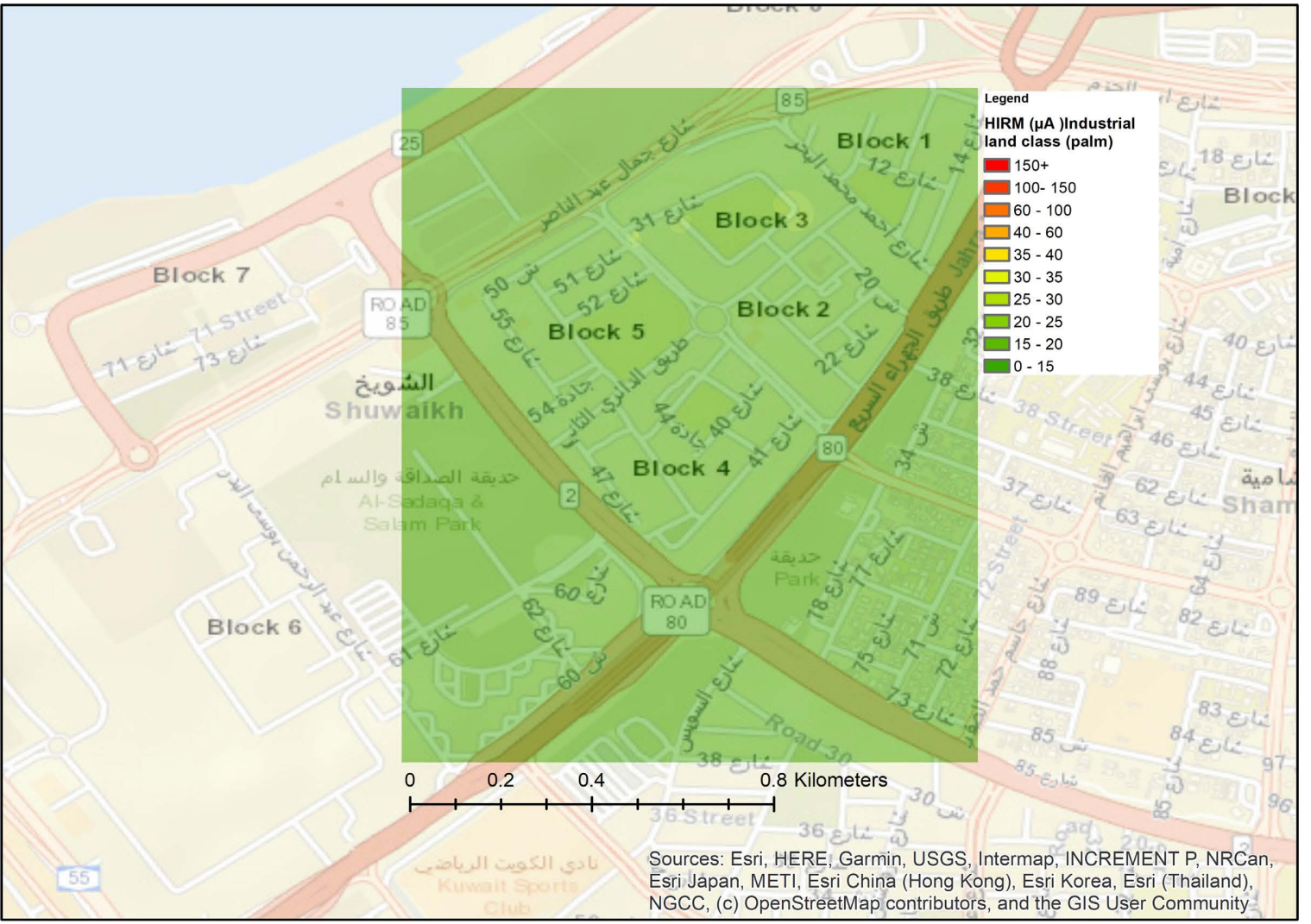

(c)

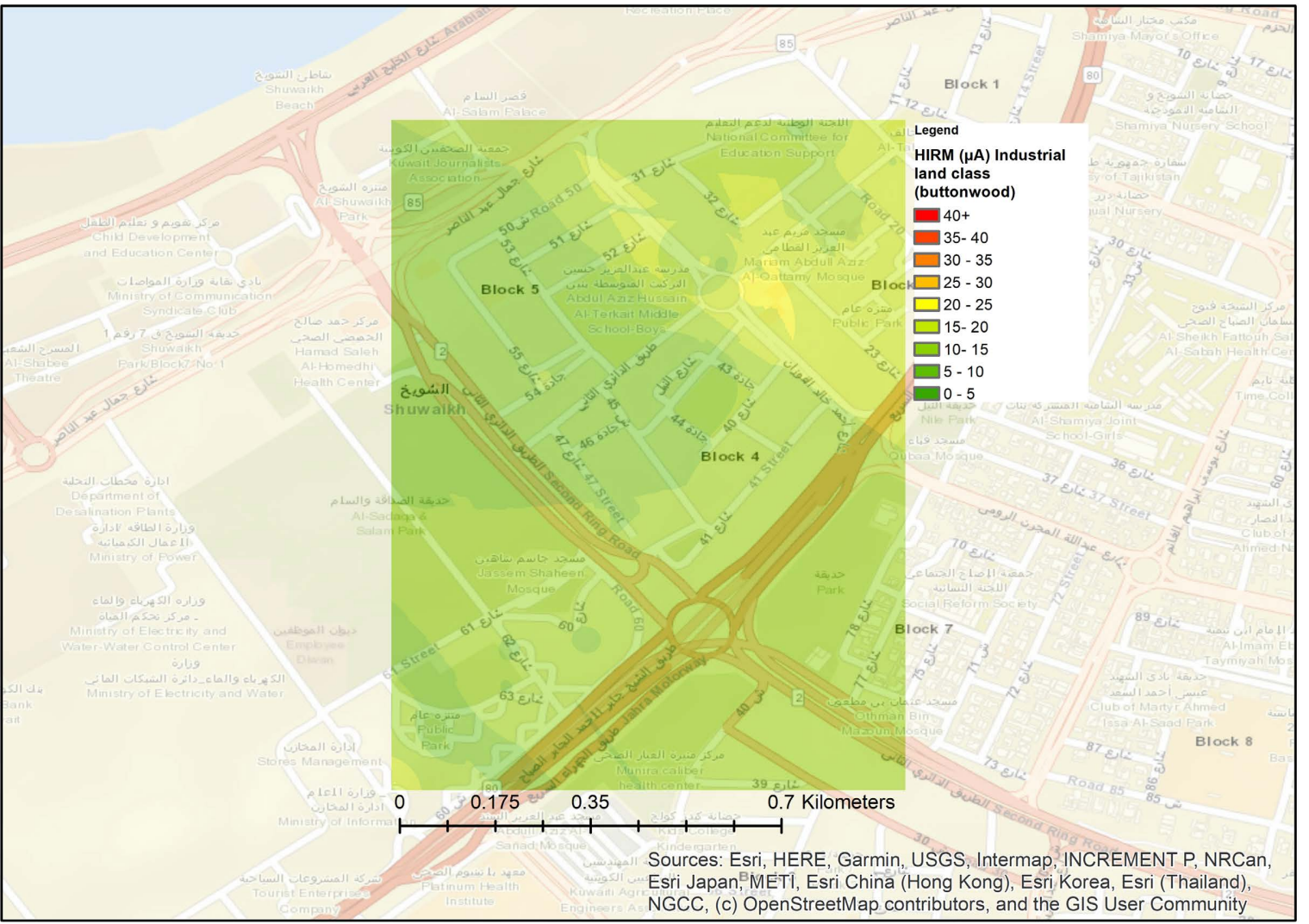

(d) 


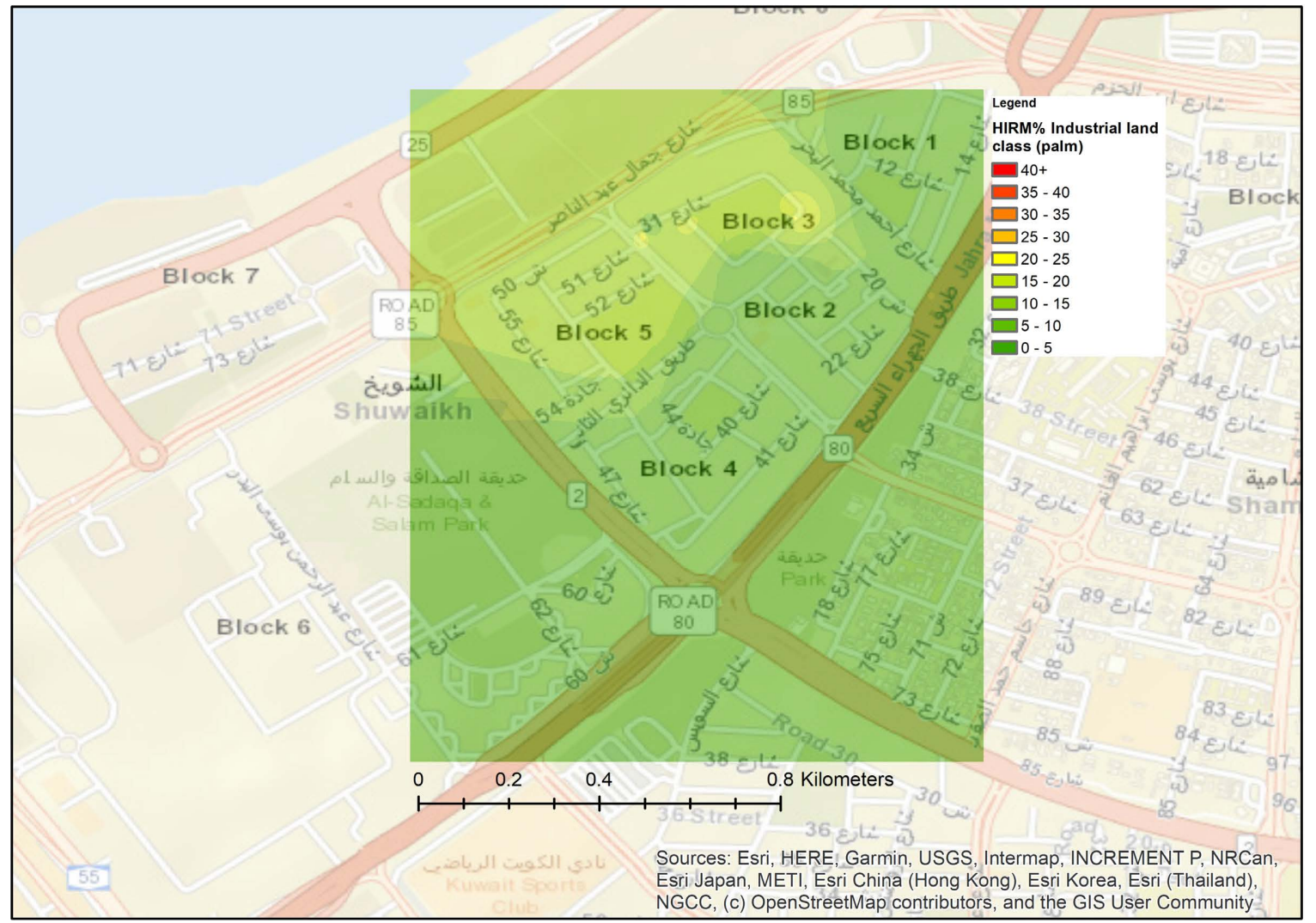

(e)

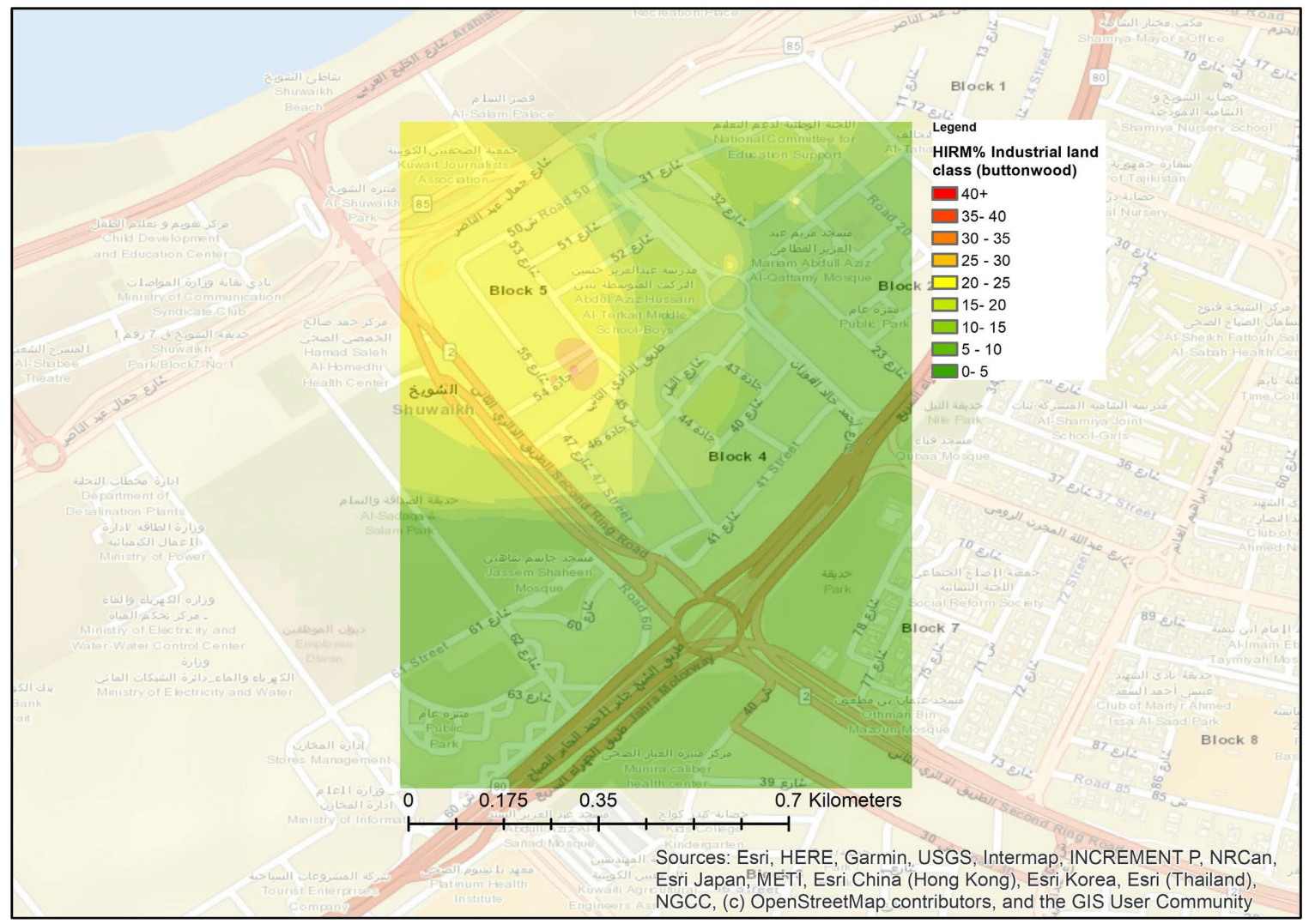

(f) 


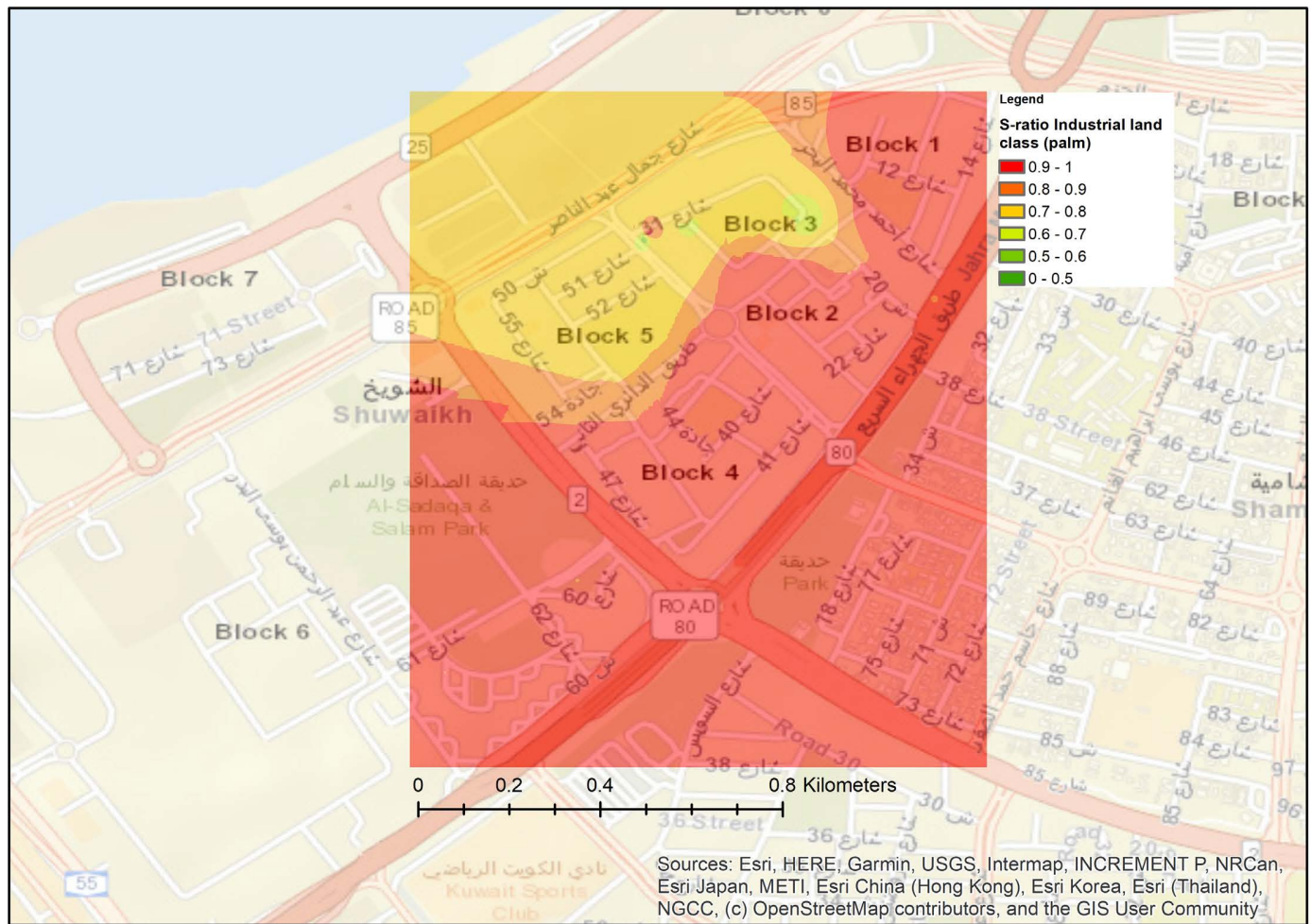

(g)

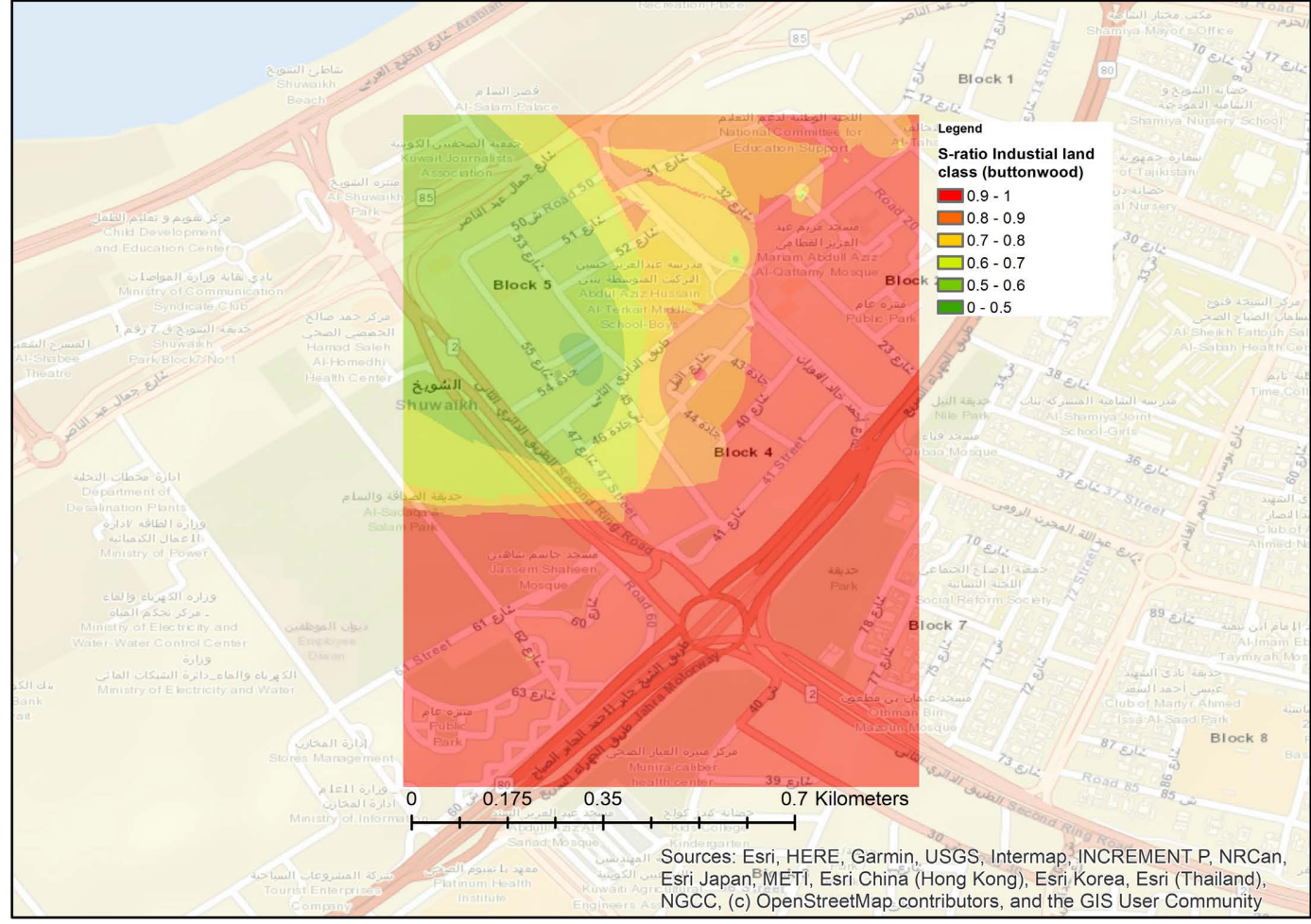

(h)

Figure 17. Industrial land use class spatial distribution of SIRM ( $\mu \mathrm{A})$ : (a) palm, (b) buttonwood. Industrial land use class spatial distribution of HIRM $(\mu \mathrm{A})$ : (c) palm, (d) buttonwood. Spatial distribution of HIRM\% in the industrial land use class: (e) palm, (f) buttonwood. Spatial distribution of $s$-ratio in the industrial land use class: (g) palm, (h) buttonwood. 


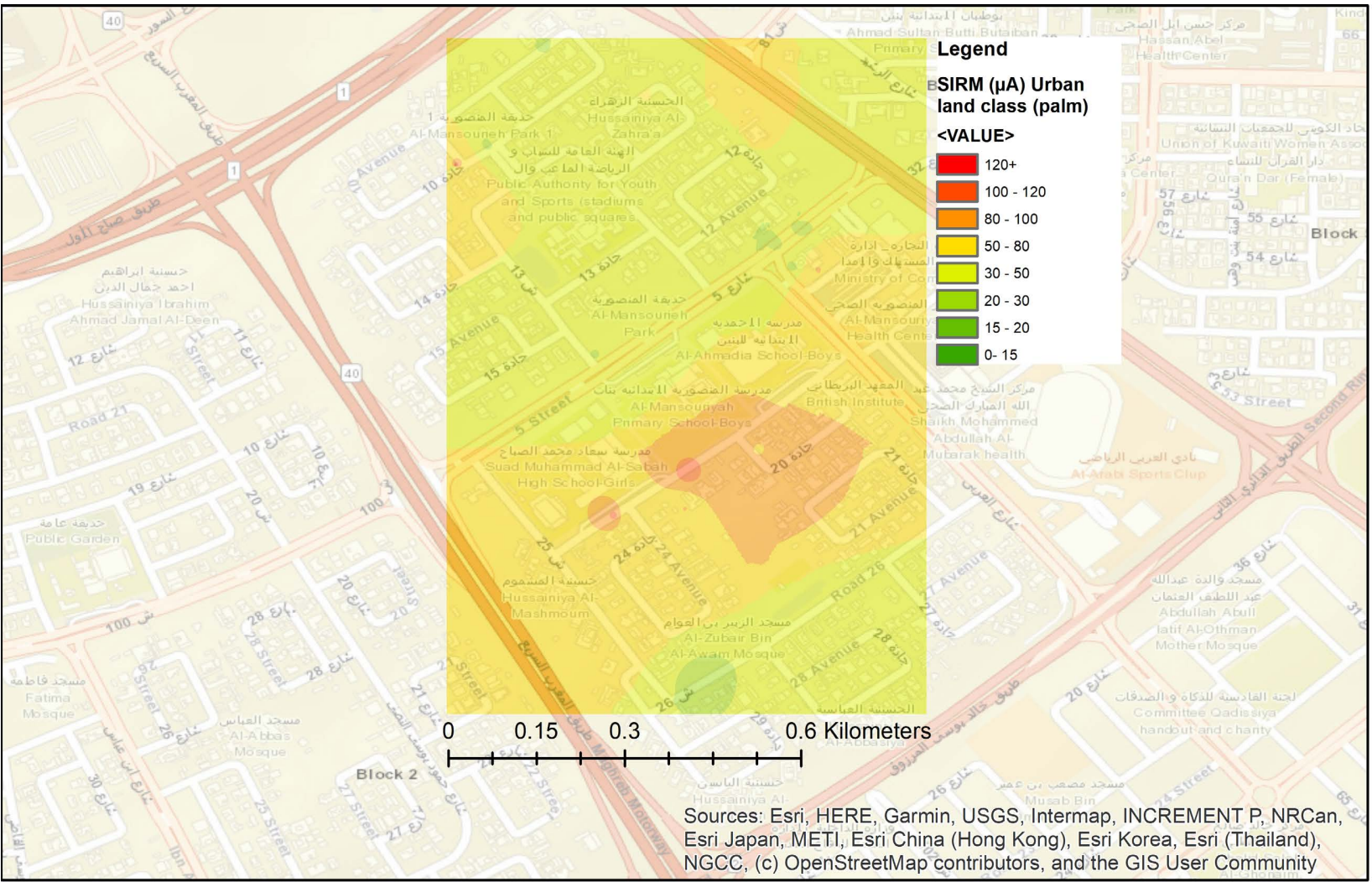

(a)

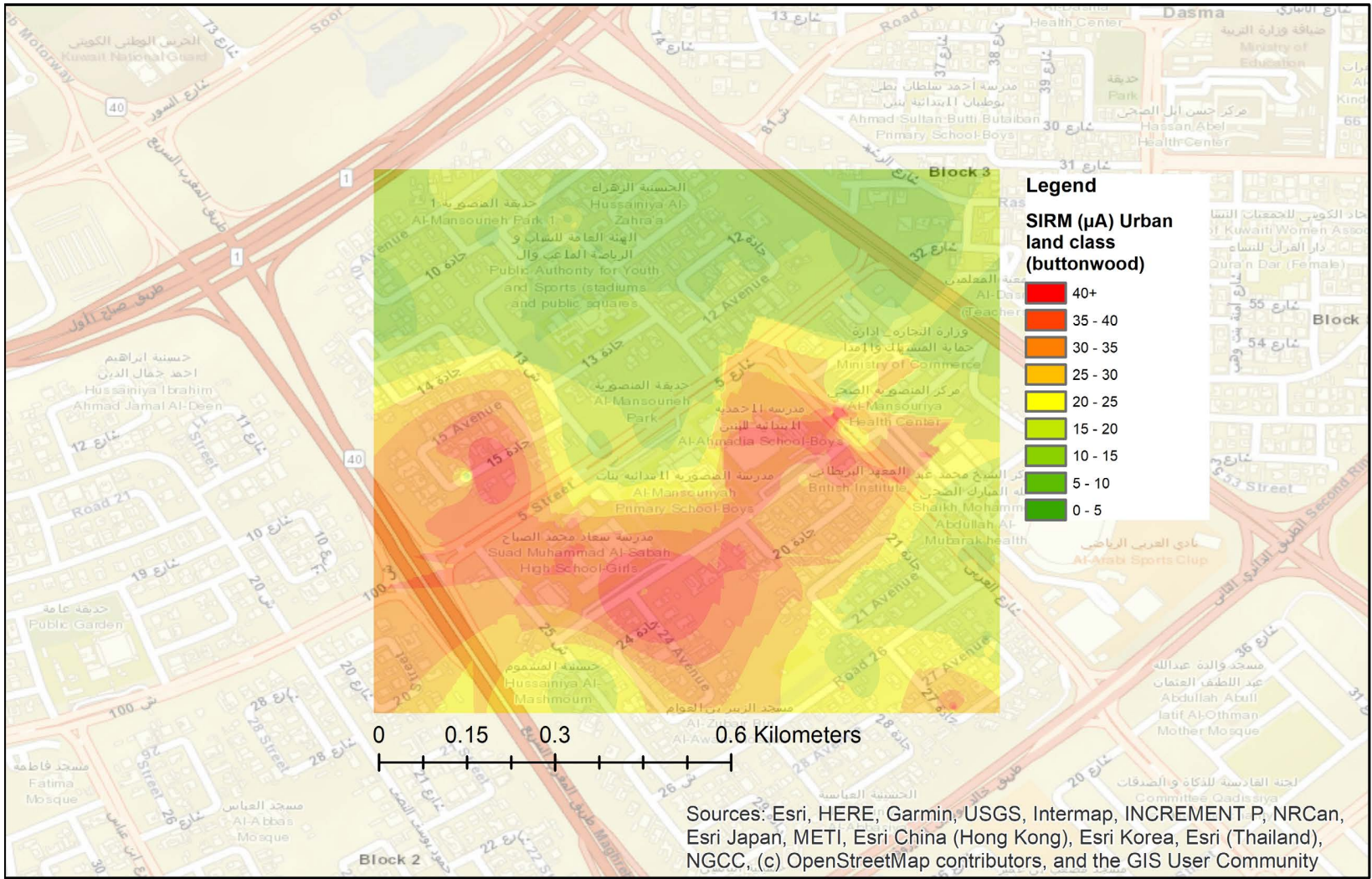

(b) 


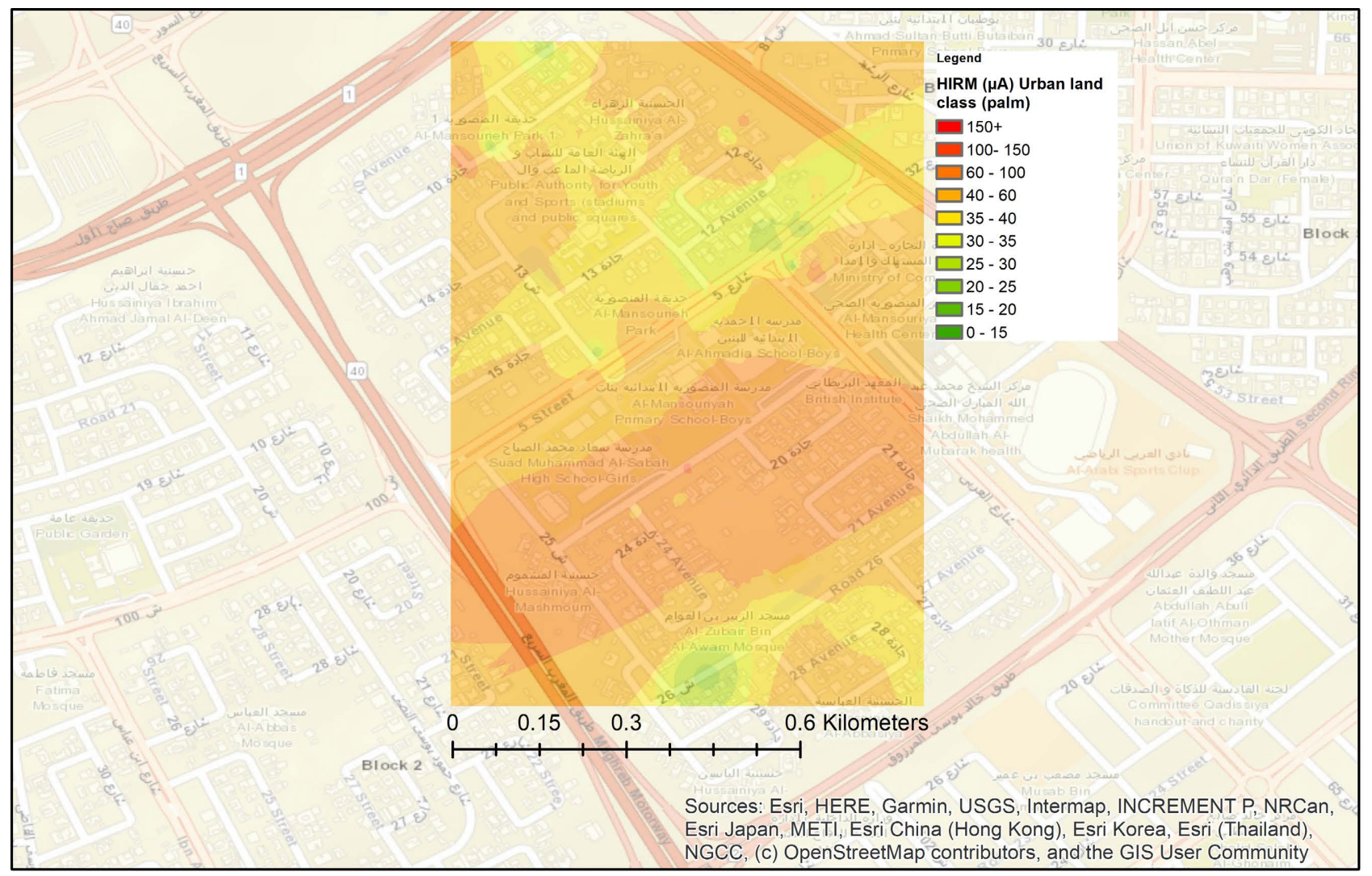

(c)

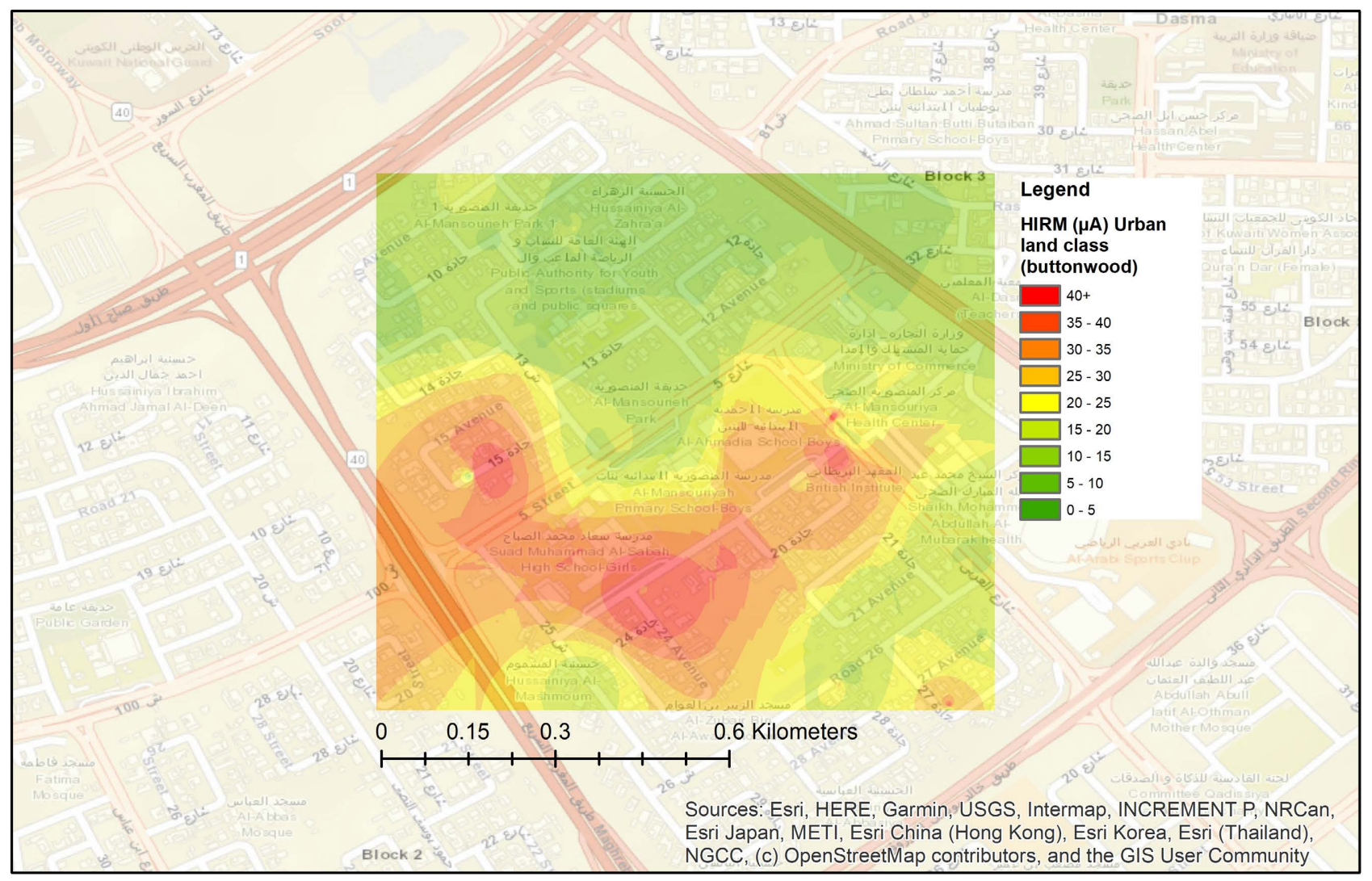

(d) 


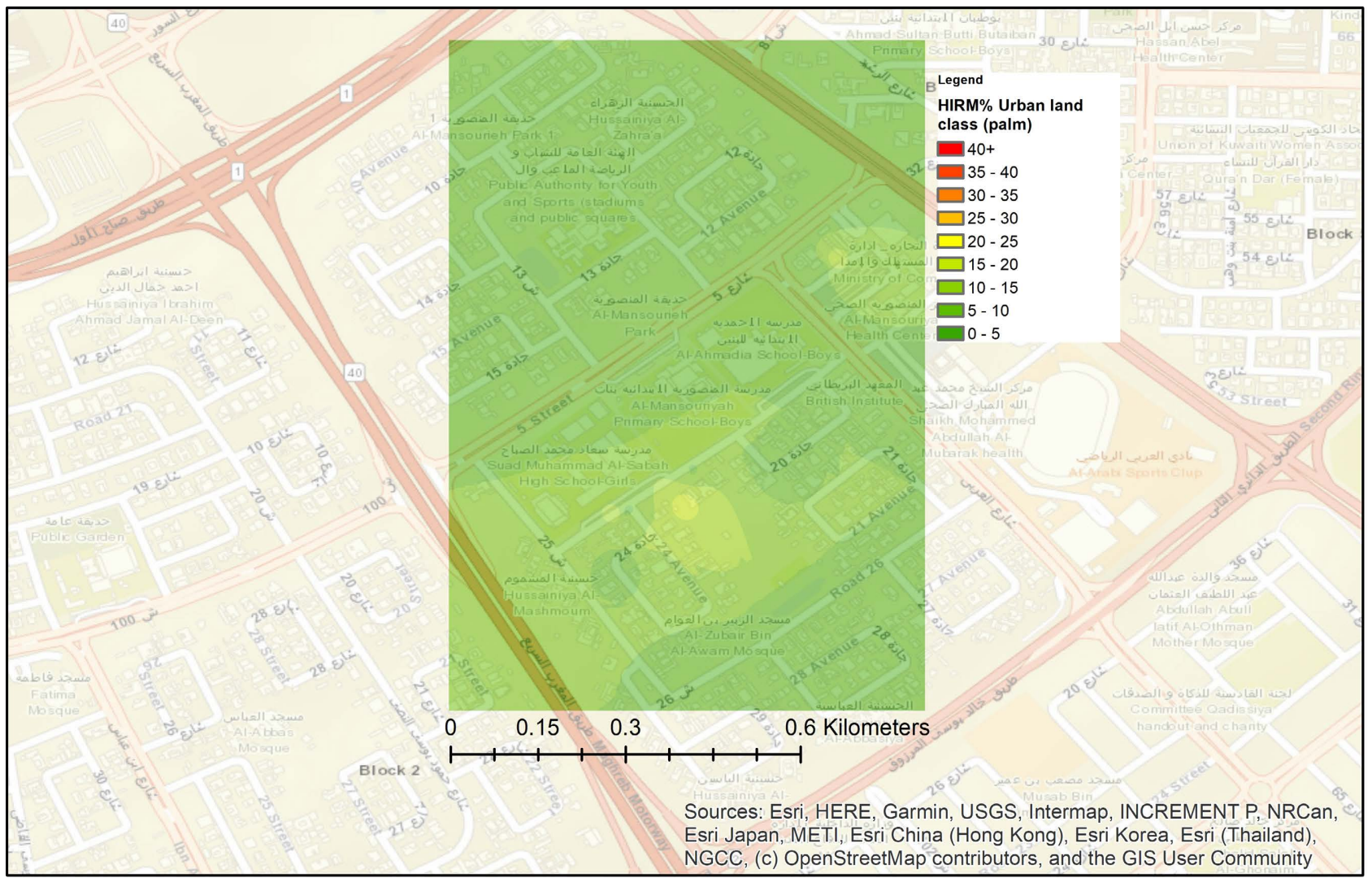

(e)

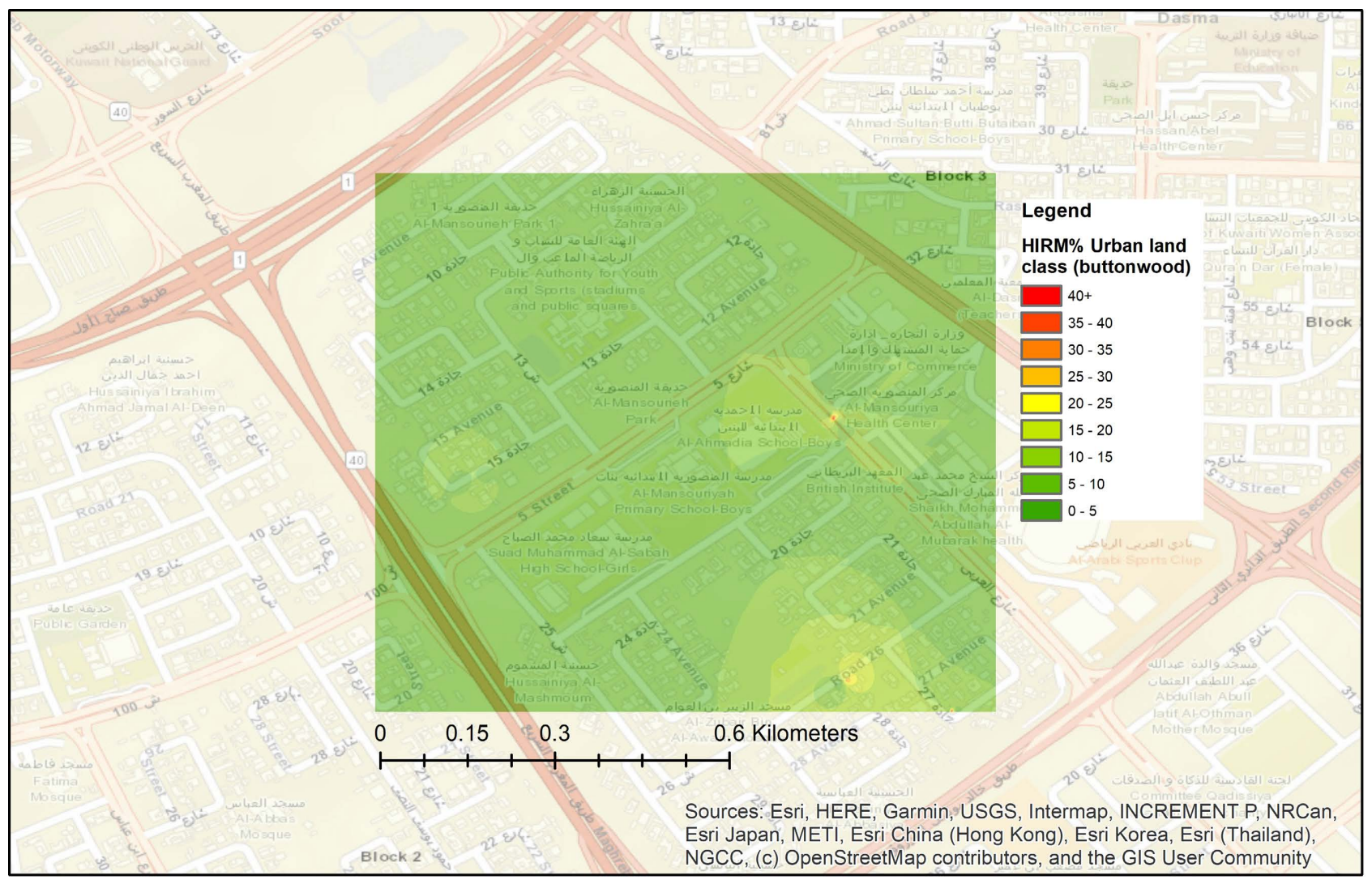

(f) 


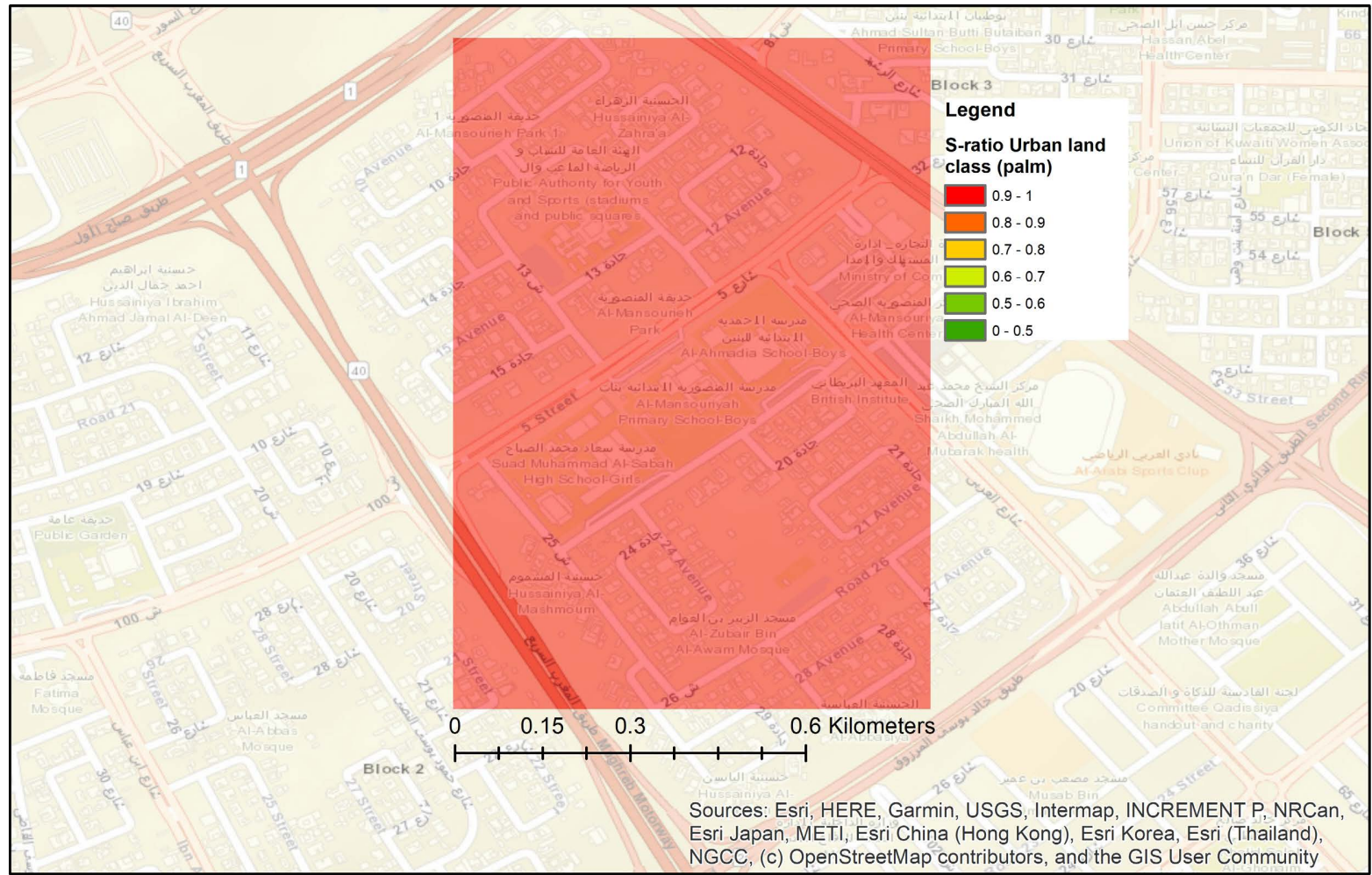

(g)

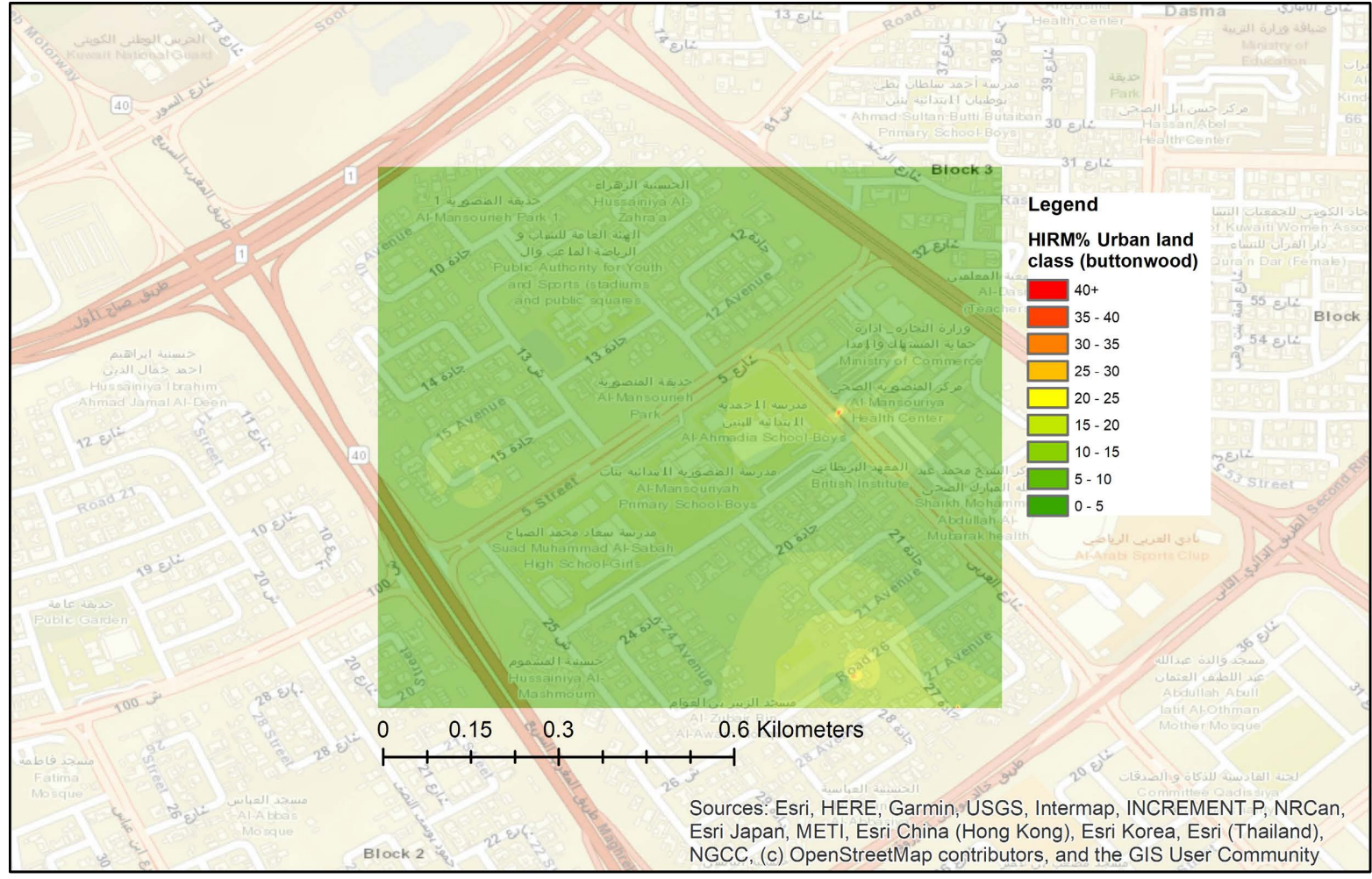

(h)

Figure 18. Urban land use class spatial distribution of SIRM ( $\mu \mathrm{A}$ ): (a) palm, (b) buttonwood. Urban land use class spatial distribution of HIRM $(\mu \mathrm{A})$ : (c) palm, (d) buttonwood. Urban land use class spatial distribution of HIRM\%: (e) palm, (f) buttonwood. Urban land use class spatial distribution of $s$-ratio: (g) palm, (h) buttonwood. 


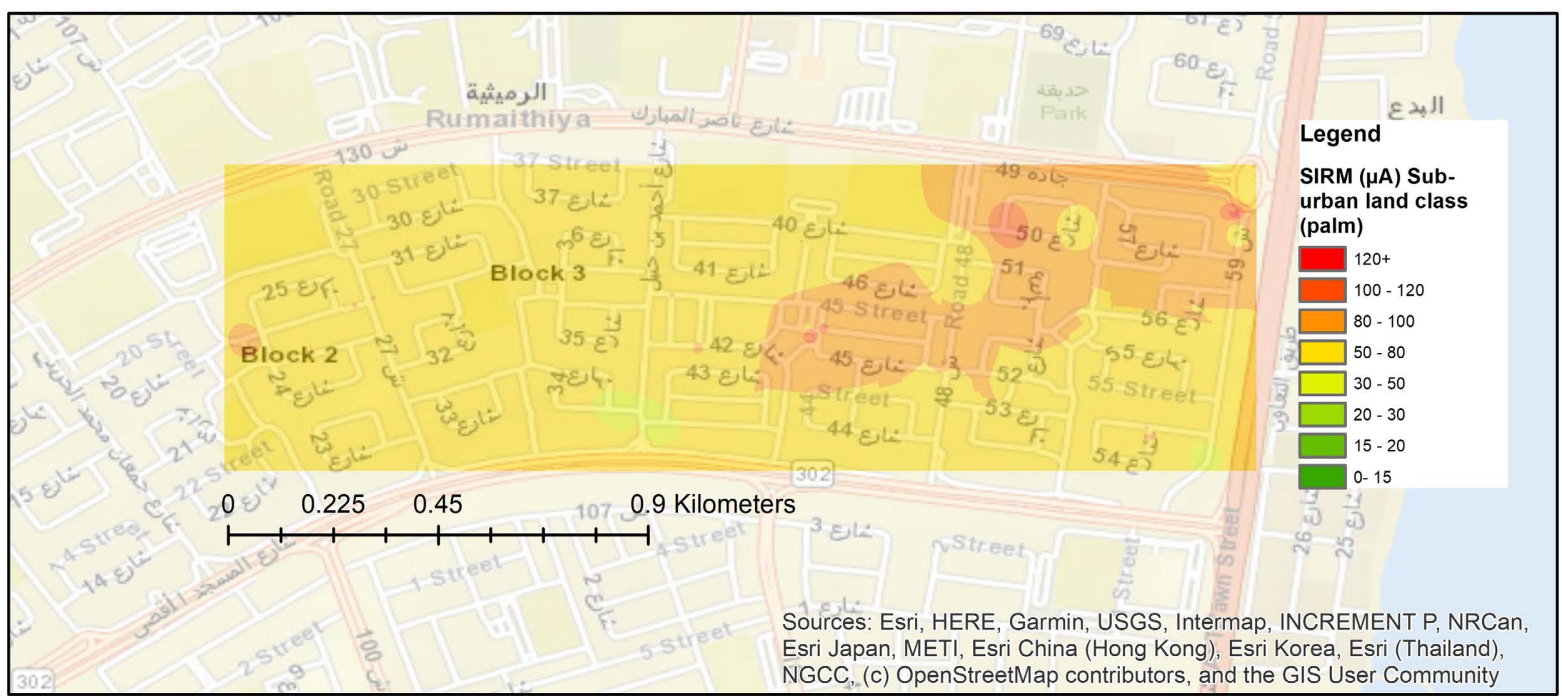

(a)

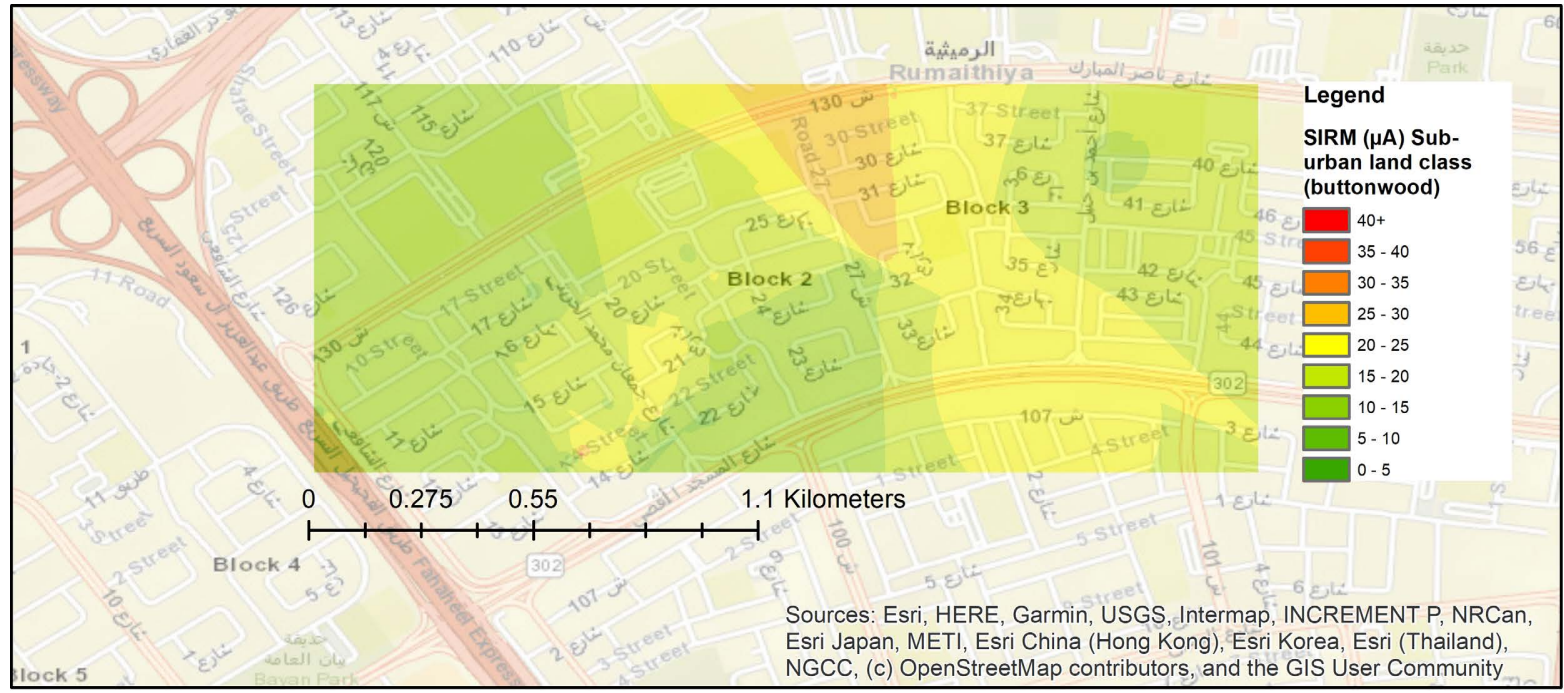

(b)

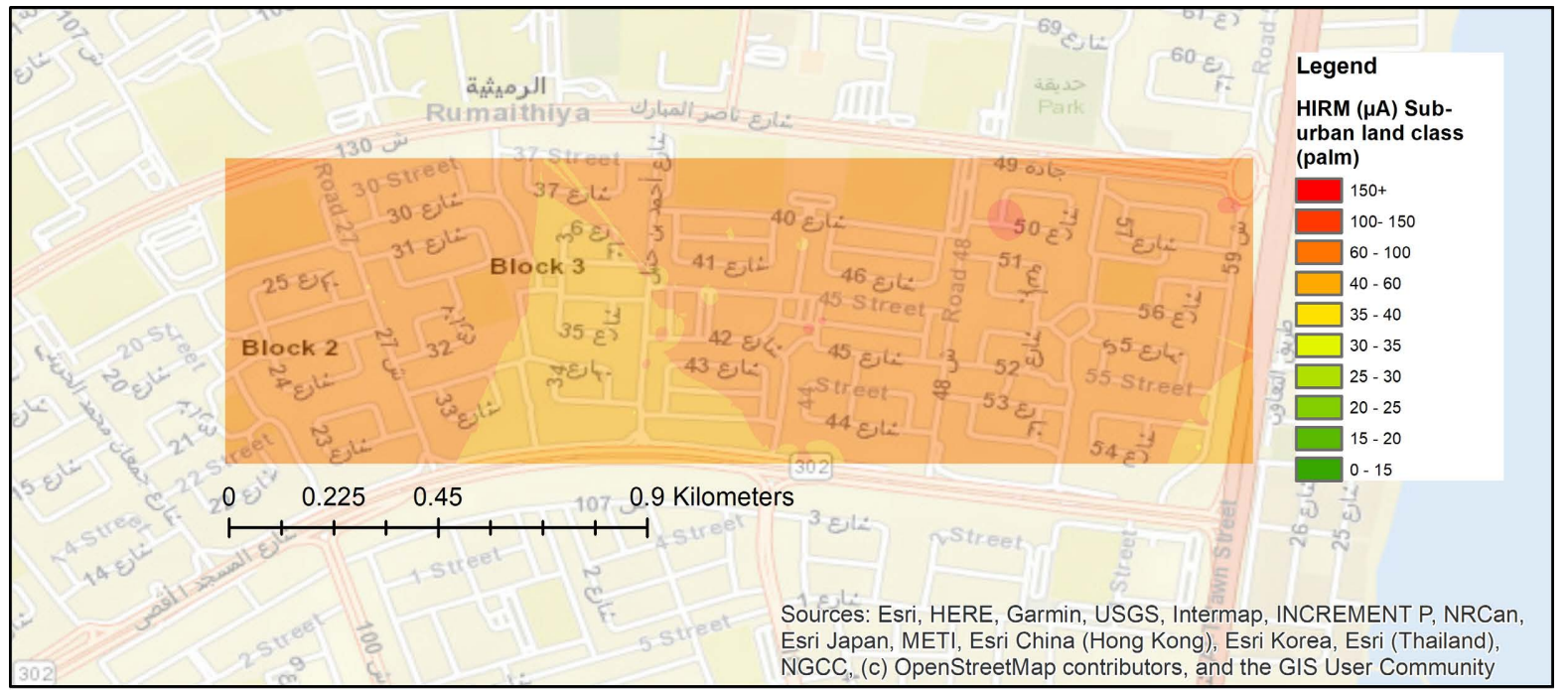

(c) 


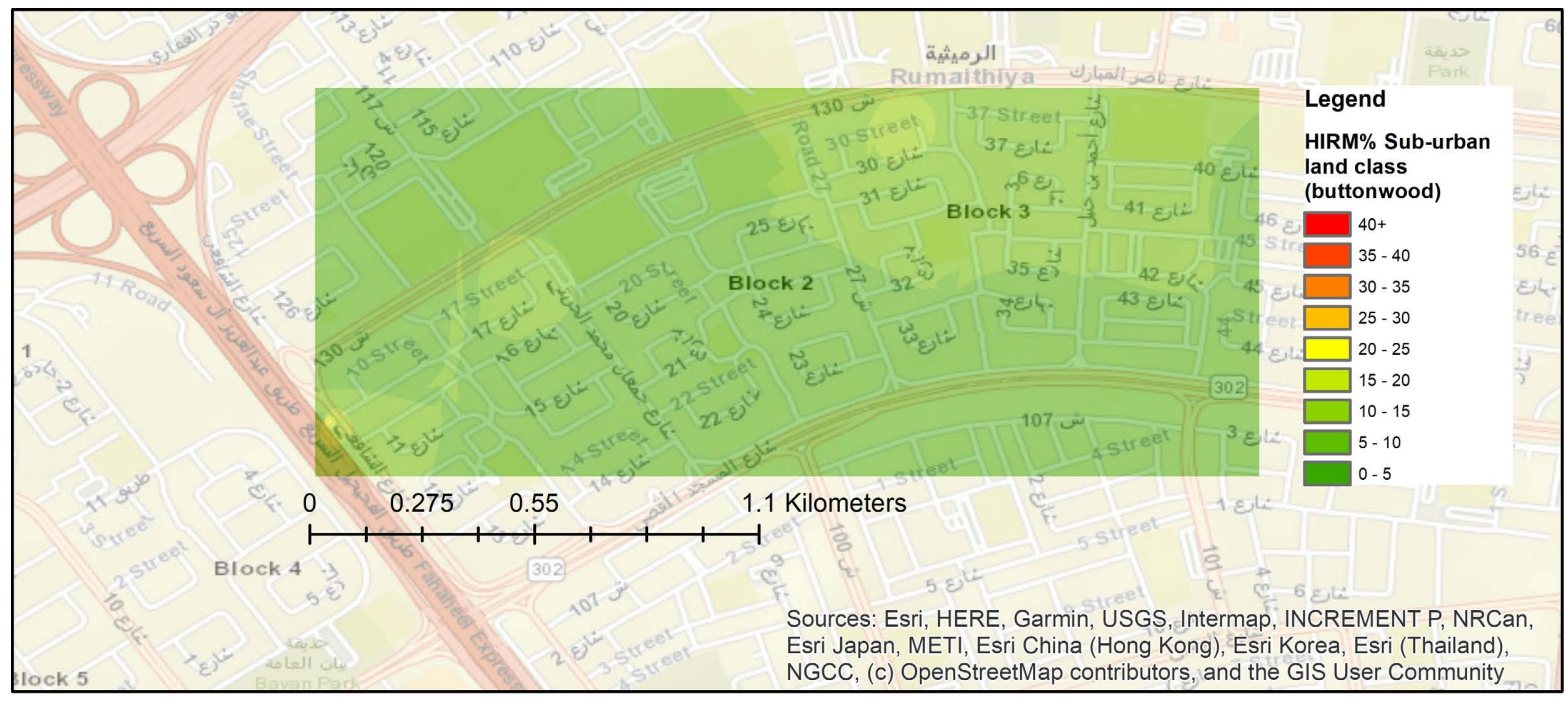

(d)

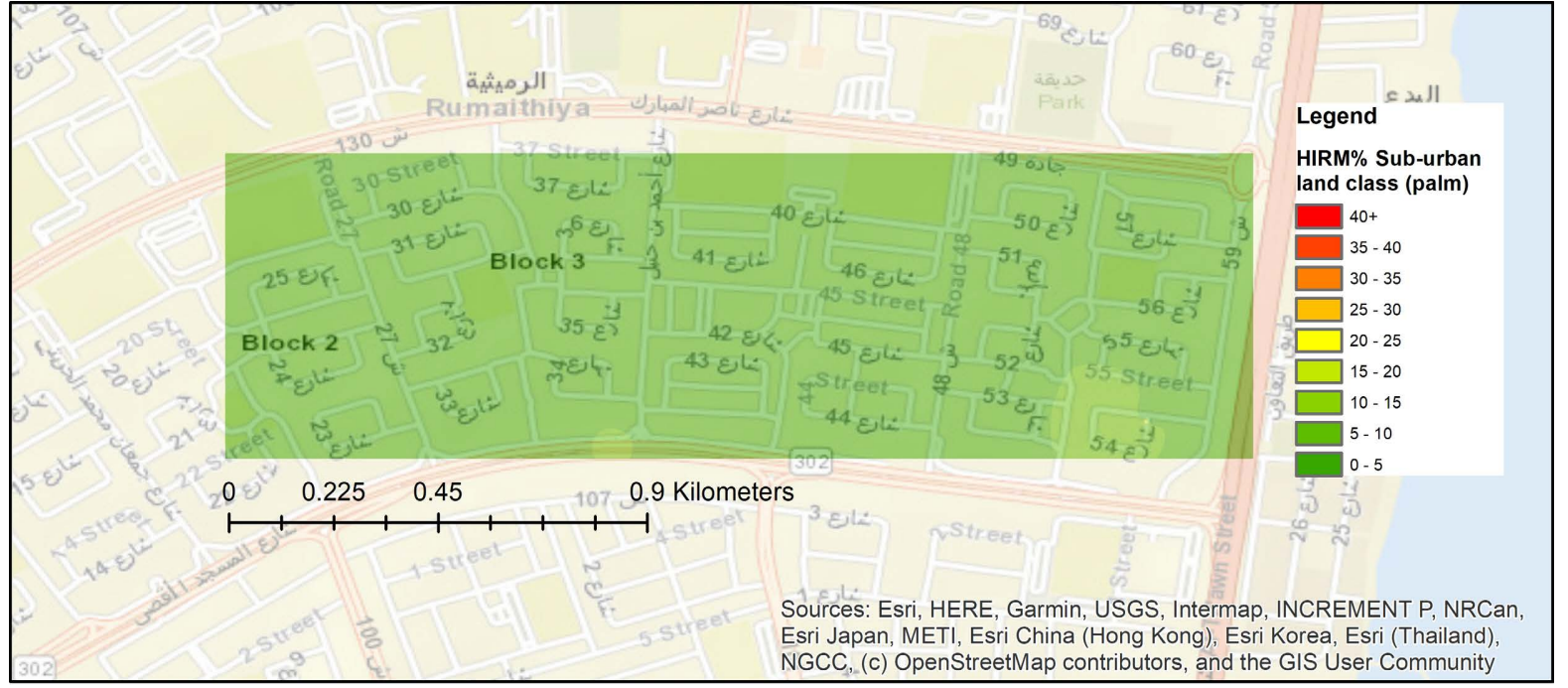

(e)

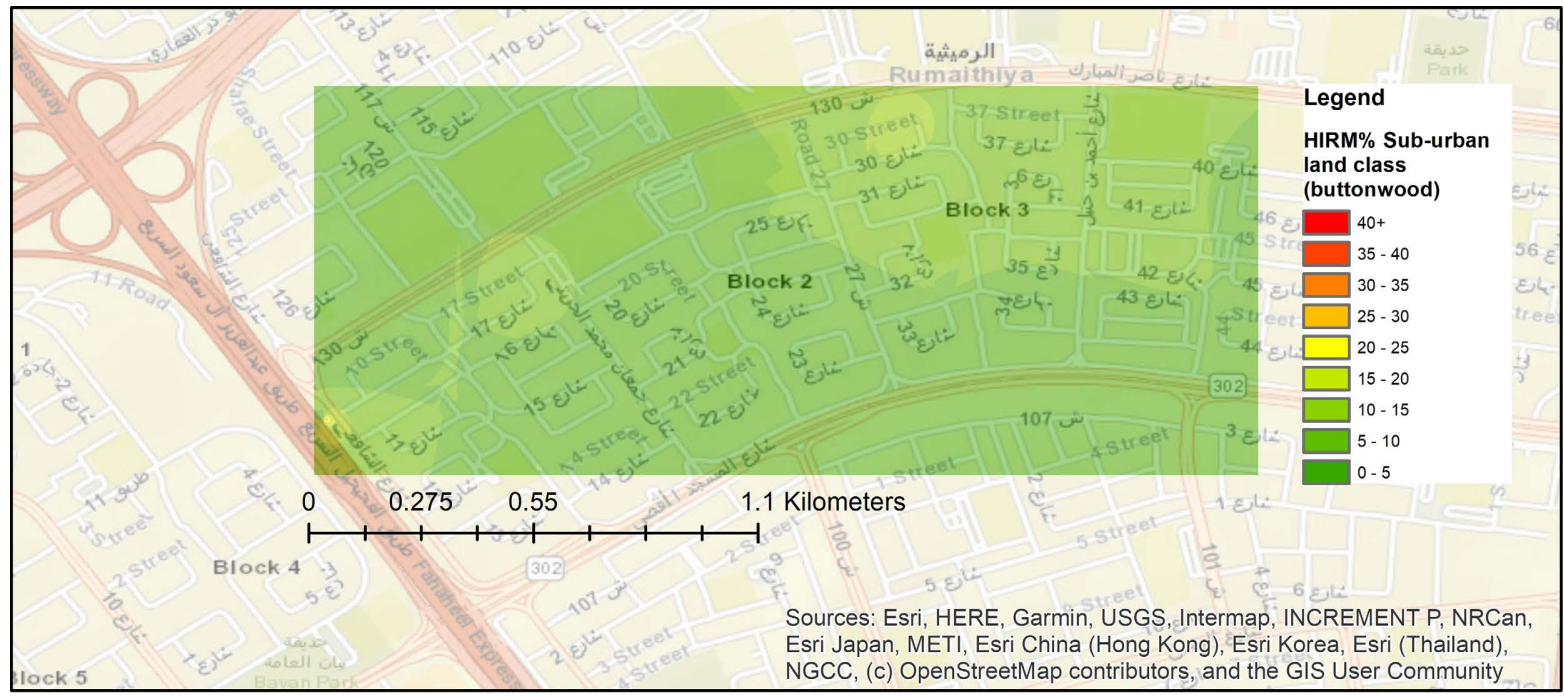




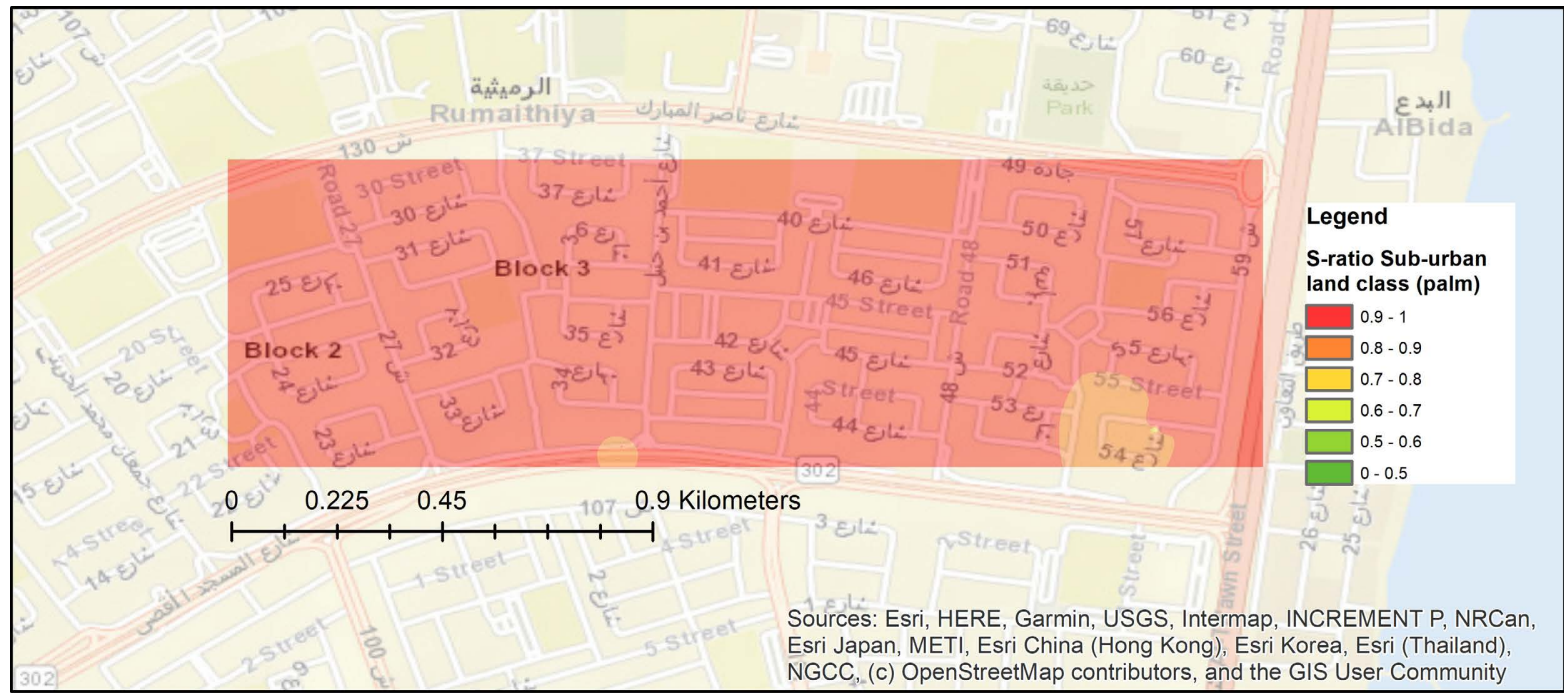

(g)

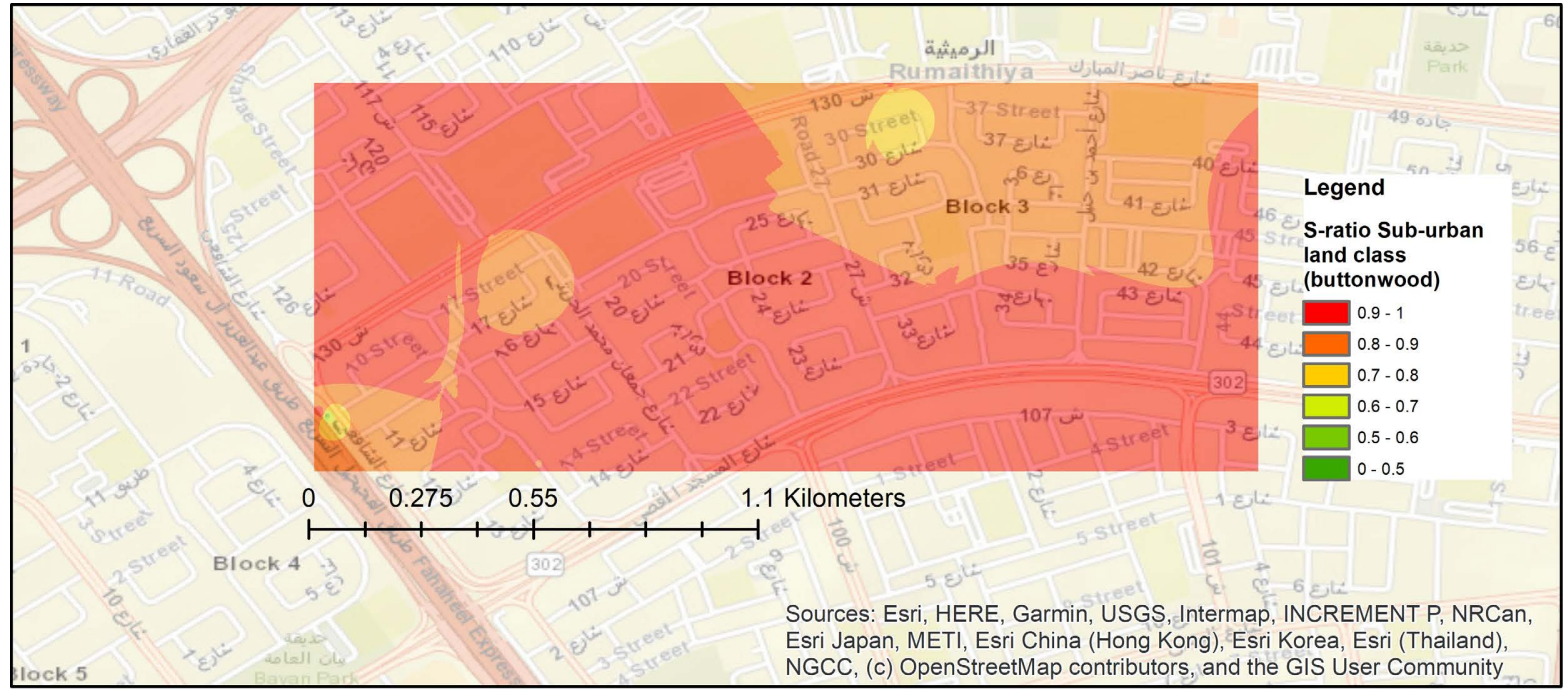

(h)

Figure 19. Suburban land use class spatial distribution of SIRM ( $\mu \mathrm{A})$ : (a) palm; (b) buttonwood. Suburban land use class spatial distribution of HIRM $(\mu \mathrm{A})$ : (c) palm; (d) buttonwood. Suburban land use class spatial distribution of HIRM\%: (e) palm; (f) buttonwood. Suburban land use class spatial distribution of $s$-ratio: (g) palm; (h) buttonwood.

the differentiation of various patterns. These two parameters displayed similar spatial distribution patterns, in relation to grain size and mineral assemblage indicating that there is not a substantial difference in mineral assemblage and grain size across land use classes and species.

A repetitive pattern is identified for each land use class, accumulation levels intensify from the north westerly direction for the industrial land use class, west direction for the urban land use class and North eastern direction for the sub-urban land class use (Figure 19). Hot spots in industrial land use class were in the vicinity of motorways that are encasing the industrial area, dead end streets and main roads leading to inner roads within the area (Figure 17(a), Figure 18(a)). While, the urban land use class had the highest SIRM values cen- 
tered in the midst of three schools (Figure 18(a)).

\section{Discussion}

\subsection{Species as Potential Biomonitors in Frequent Desert Dust Storm Environments}

Inter-species magnetic differences need to be considered when assessing atmospheric magnetic PM (MPM) pollution. As a species ability to retain atmospheric fine particles is dependent on duration of exposure, leaf area and leaf surface micromorphology [16] [21].

Palm leaf SIRM values ranged from 18.5 to $220.3 \mu \mathrm{A}$ and for buttonwood values ranged from 2.9 to $159.0 \mu \mathrm{A}$. The results seem credible in comparison to sampled plane trees (Platanus $\times$ acerfolia) in Ghent, Belgium which reported SIRM values ranging between 3.5 to $64.1 \mu \mathrm{A}$ [12]. The results in this study are probably higher due to different climatic conditions, with Belgium experiencing a significantly higher occurrence of rainfall events.

Palm averaged $120 \%$ higher SIRM values than buttonwood. Higher SIRM values for palm can be a result of longer exposure periods due to leaf longevity in comparison to buttonwood which is a broadleaved tree; therefore accumulates/ adsorbs less magnetic minerals on its epicuticular waxes or cuticles. As, leaf biomass of deciduous trees vary through seasonal changes largely from spring to summer, losing their leaves therefore creating a greater variability in leaf age as well as having shorter lifespans [45] [46] [47].

Palm leaves have a considerably prolonged longer exposure duration with a lifespan of 3 - 7 years [48]. This could explain why the NRM levels of palms in the industrial land use class were remarkably higher than buttonwood $(\mathrm{p}<$ 0.001). Magnetic dust in urban areas can be monitored short-term using deciduous species as they accumulate dust during their vegetational period, while evergreen species offer longer-term monitoring depending on the leaf lifespan [13] [16].

Leaf texture, trichome density, specific surface leaf area, epicuticular wax micromorphology and chemical composition are characteristics that can also influence PM accumulation [9] [49]. Leaves with higher trichome density and rough ridges improve particle collection in comparison to smooth leaf surfaces [17] [50] [51]. Palm leaves epicuticular wax structure is made up of crystalloids (rodlets) that vary in shape and size and appear in specific arrangements. The crystalloid structures have a polygonal morphology with a distinct longitudinal axis and often bend. Additionally, some distinct wax projections are present with irregular and sparse distribution. These projections appear as flat crystalloids connected to the crust at different angles through a narrow side likely corresponding to platelets, the most common crystalloids. Though, the structures of these crystalloids are not regular and some of these projections could also correspond to rodlets in development. Yin et al. (2013) identified that grooves are the main part the absorb 2.5, the deeper the grooves the higher the number of 
intercepted particles and decrease in number of lost particles [52]. The wax structure of the palm leaf facilitates it to intercept PM at higher quantities, in comparison to buttonwood that large and flat leaves with thick boundary layers and smooth wax leaf surfaces causing them to be more susceptible to wind resuspension, wind and rain wash-off reducing the accumulation of magnetic particles on their surface [9] [49]. A study by Neinhuis and Barthlott (1998) determined that water-repellent surfaces of Ginkgo biloba avoid lasting particulate contamination, in comparison to leaf surfaces of Fagus sylvatica and Quercus robur that accumulate fewer particles due to leaf surfaces that have high wettability [53].

There is a positive association between leaf traits and PM accumulation. The "take-up" of particles within the leaf structure can possibly contribute additionally to SIRM, during wax regeneration deposited particles could be built during the growing season, for species with waxy leaves, impacting magnetic measurements [8] [10]. A study conducted by Barima et al. (2016) determined that leaf SIRM is higher in mature leaves of Ficus benjamina as it is able to encapsulate $20 \%$ of total leaf SIRM [22]. Although, the likelihood of metal ion absorption of dust particles containing metals by underlying tissues on smooth leaves are low as they adhere weakly and can easily be removed [54].

Environmental conditions, air pollution and dust fallout can accelerate the erosion rate of epicuticular waxes and senescence of leaves impacting long term accumulation of PM [49] [55]. The cuticles of plant leaves growing in sandy environments are subjected to constant sandstorms that may alter their structure. A study by Khelil et al. (2016) established that older palm leaves in dry desert environments display effects of intense erosion where only a continuous crust remain, with several debris and sand grains present, signs of friction that reflect rubbing and sand abrasion with signs of the rodlets almost fully disappearing and being only partially present in the folds of the leaflets and around some stomata [56]. The presence of ingrained debris and dust maybe attributed to palms having higher SIRM values.

HIRM\% values were approximately double for buttonwood in comparison to palm. Indicating that buttonwood has a higher proportion of high coercivity minerals, such as canted antiferromagnetic hematite [42]. The two main sources hematite and SP magnetite in modern soils are parent materials and pedogenesis [57] [58].

\subsection{Land Use Class Effects}

Land use class has an impact on magnetic values and PM composition in relation to industries and traffic in the area regardless of species. Barima et al. (2016) identified that leaf SIRM from mature leaves of Barleria prionitis, Ficus benjamina and Jatropha interrigima ranged from $94 \mu \mathrm{A}, 106 \mu \mathrm{A}$ and $113 \mu \mathrm{A}$ at roadsides, respectively, against the same species in parks which exhibited SIRM values of $27 \mu \mathrm{A}, 20 \mu \mathrm{A}$ and $8 \mu \mathrm{A}$ [22]. In this study, the highest SIRM intensity was 
at the industrial land use class located near industries and high vehicular activity. This can be contributed to aerosols from various industrial combustion processes as they possess significant mineral magnetic components that contribute to the topsoil horizon sites downwind of industrial centers [41].

Multiple pollution sources in the industrial site hinder a source specific relationship observed between PM and SIRM. The lowest SIRM values were identified were in the urban land use class. These results coincide with Kardel et al. (2012) \& Barima et al. (2014) that higher polluted land classes were located near the vicinity of major roads and industrial areas while sub-urban, urban and green spaces were determined to be less polluted [8] [22]. In a study on the outdoor air quality in a typical residential area in Kuwait, Mansouriya (urban land use class) it was determined to have lower air pollutant levels than specified by the US EPA standards, however these levels increased during rush hours [59]. $\mathrm{NO}, \mathrm{NO}_{2}, \mathrm{O}_{3}$ and $\mathrm{CO}$ only exceed these levels by $0.75 \%, \mathrm{SO}_{2}$ by $2.5 \%$ for the duration of the study [59].

There was not much difference between land use class, the $s$-ratio values approached 1 over all classes indicating high coercivity ferrimagnetic minerals containing $\mathrm{Fe}, \mathrm{Al}$ and $\mathrm{Ni}$ such as magnetite and maghemite to magnetically dominate all three land classes [38] [41]. Sources of magnetite can be either of natural or anthropogenic origin in the studied sites, heavy metals e.g. zinc, iron, cadmium and chromium are impurities in fuels, industrial emissions or rock dust and can be the source of ferrimagnetic mineral such as magnetite $\left(\mathrm{Fe}_{3} \mathrm{O}_{4}\right)$ in samples [17] [60]. The urban land use class has the highest $s$-ratio 0.94 for both species in comparison with the industrial land use class, 0.90 for buttonwood leaves and 0.93 for palm. Lu and Bai (2006), reported similar findings in that there is only a small difference in the proportion of ferrimagnetic and antiferromagnetic components between industrial and high traffic areas and urban areas, with $s$-ratio values of 0.73 and 0.69 in roadside and industrial topsoil samples and $0.61-0.65$ in other areas [41].

HIRM\% is an effective tracer of fly ash which contains a significant fraction of magnetic minerals due to hematite components of inorganic ash spheres being released as a result of fuel combustion and industrial activities [60] [61]. Fly ash is dominated by coarse multidomain MD and fine pseudo-single domain (PSD) grains [42] [62]. Mean HIRM\% across all the land classes uses are low indicating fairly constant proportions of magnetite and hematite mineral phases in all land class uses [16]. The samples at the industrial land class use have highest level of HIRM\%, $5.38 \%$ for buttonwood and 3.68\% for palms indicating a higher amount of antiferromagnetic material for example hematite than ferrimagnetic materials in comparison to the other land class uses. Results seem consistent in relation to average values of HIRM\% determined for Baotou City (North China), were $1.90 \%$ for urban top soils of 111 urban sites respectively, indicating that samples are dominated by ferrimagnetic minerals with soft magnetic behavior [56]. 
Both species sets displayed little HIRM acquisition ( 5\%) beyond $300 \mathrm{mT}$ indicating that the samples have a low proportion of antiferromagnetic minerals, that have the magnetic behavioral characteristics of haematite with a $\sim 0.2 \mu \mathrm{m}$ grain size [63] [64]. Maher et al. (2004) tested HIRM\% values for the synthetic hematite's and determined that there is some grain size-dependence, the coarser the grain size the smaller the HIRM\% value, with HIRM\% values for the synthetic haematites ranging between $27 \%$ and $38 \%$, with some apparent grain size-dependence and between $84 \%$ and $92 \%$ for goethites [65]. Although, hematite contributions cannot be detected in samples with $10 \mathrm{wt} \%$ magnetite, as hard coercives with weak magnetic signals can be overwhelmed by that of soft coercives [63] [66]. The quantification of ultrafine SP content in haematite cannot be quantified using remanence-based methods at room temperature therefore limiting the application of $s$-ratio and HIRM\% [67].

Kuwait's dust mineralogically comprises mostly calcite and quartz with grain size ranging from 1 to $25 \mu \mathrm{m}$ [25]. The mean size of aeolian sediment sand is around $0.27 \mathrm{~mm}$ and there is a slight variation with smooth sand sheet deposits having a coarser mean size $(\sim 0.4 \mathrm{~mm})$ and active sand sheets and dunes have a finer mean size $(\sim 0.25 \mathrm{~mm})$ [25]. Areas located in the north and the coastal areas of Kuwait having particle sizes of $10-15 \mathrm{~mm}$, which are attributed to wind-blown dust events [68]. Chemically, $\mathrm{Ca}, \mathrm{Fe}, \mathrm{Mg}$, and $\mathrm{Al}$ elements are dominant in dust fallout in Kuwait with ranges of average percentage concentrations of $5.845 \%$ $12.890 \%, 0.946 \%-3.141 \%, 0.752 \%-2.513 \%$ and $0.545 \%-2.261 \%$ [25] [29]. The proximity of pollution sources; a petroleum factory and other industrial zones and being surrounded by three main motorways heavily influence magnetic mineral compositions.

\subsection{Effect of Distance on Magnetic Values over Land Use Classes}

The results show that there is a linear correlation between SIRM and HIRM values and distance from road, with distances of $0 \sim 5 \mathrm{~m}$ from the road having the highest SIRM values. Distances over $5 \mathrm{~m}$ from the road showing a decrease of $1.93 \mu \mathrm{A}$ in SIRM value with every additional meter in distance for both plant species. While, HIRM values decreased every additional meter away from the road by $0.63 \mu \mathrm{A}$ for buttonwood at the suburban land class and $0.08 \mu \mathrm{A}$ for palm at the urban class. The decrease in the accumulation in PM in relation to an increase in the distance from the road implies that motorized traffic plays a distinctive role in the spatial variation of magnetic mineral accumulation/deposition and hematite content. Barima et al. (2014) distinguished that leaf SIRM normalized by traffic density decreased respectively with an increase in roadside distance, with leaf SIRM values four times higher when located close to main roads and industrial areas in comparison compared to parks and residential areas [22]. This coincides with findings from Kardel et al. (2012) and Hoffman et al. (1999) who determined that soils and sediments on roadsides are clearly influenced by anthropogenic emissions up to a distance of $5 \mathrm{~m}$ from the road, noting that the main 
source of magnetic pollution is traffic emissions [8] [64] [69].

These results are also agreement with a study on biomonitoring traffic air pollution in Rome using magnetic properties of tree leaves by Moreno et al. (2003), that confirm that IRM decreased and the SIRM/ $\chi$ ratio increased as the distance to the roadside increased, due to a decrease in the concentration and grain size of magnetic minerals [70]. A study on Pinus sylvestris determined that wax erosion accelerated for trees that were within a $0.5 \mathrm{~km}$ distance from a factory in comparison to trees at a $10 \mathrm{~km}$ distance [41] [70]. The distance from the nearest road affects particle grain size and wind flow [16] [64] [69]. With larger particles settling closer to the emission source in comparison to smaller particles that travel further away depending on wind direction and speed [8] [71].

\subsection{Magnetic Parameters Interactions}

The results show extracted factor 1 is controlled by the concentration parameters SIRM (magnetite))/HIRM (hematite) at $40.5 \%$ and $s$-ratio and HIRM\% at $36.7 \%$. These results correlate with finding from Shu et al. (2000) on magnetic properties of daily sampled total suspended particulates in Shanghai, were SIRM/ ${ }_{X} \mathrm{ARM}, \mathrm{HIRM}, \mathrm{HIRM} \%$, and SIRM/ ${ }_{X}$, explained $93 \%$ of the total variance [42]. As well as results from Lourenço \& Gomes (2016), characterizing agricultural soils in central Portugal that determined that $22.02 \%$ of the total variance was dominated by v, SIRM, IRM-100 mT, IRM-300 mT, S-100, S-300, HIRM and $\mathrm{Mn}$, which indicative of an anthropogenic source [72].

SIRM is the best measure of low-coercivity minerals, magnetite and titanomagnetite magnetite content as it is independent of grain size, magnetite grains are associated with the industry emissions they need to be large enough $0.03 \mu \mathrm{m}$ or more to carry remanent magnetization [73] [74]. HIRM is a measure of high-coercivity mineral hematite traffic pollution is reflected by $\mathrm{Pb}$, HIRM and Zn, while natural sources are reflected by HIRM\%, HIRM and Ti [57]. Haematite and goethite are often associated with fine mineral fractions $(<10 \mu \mathrm{m})$, such as fine silt and clay-sized and occur commonly as discrete nano-scale particles, also surface coatings on larger particles, and as much larger, diagenetic overgrowths and/or replacements of original iron bearing mineral grain [75]. Neoformed iron oxide nanoparticles from aeolian haematite and goethite particles can be generated via dissolution and re-precipitation effects through cloud processing reactions that involve large alternations in $\mathrm{pH}(\sim \mathrm{pH} 2$ to $\sim 5-6)$ during transport [75]. Which allow them to achieve long atmospheric residence times (i.e. days) and long-distance transport paths (>1000 km) [75]. This evident in a study testing soil samples collected close to aerosol sampling sites that determined that elemental concentrations are largely reflective of regional geology and soils, they contained $\mathrm{SiO}_{2}$ comprising of quartz and to a lesser extent feldspars and clays, with a mean concentration of $55 \%$ and $87 \%$ on the coastal areas of Kuwait [68]. 


\subsection{Spatial Distribution Mapping of Magnetic Parameters}

Mapping the various magnetic parameters can provide various insights on the spatial distribution, concentration, degree of contaminants and sources towards PM accumulation in each land class. Both species were effective biomonitors species as magnetic measurements displaying distinct hot spots between and within land use classes even though the concentrations values of SIRM, HIRM and $s$-ratio are distinctly lower for buttonwood, however this has been tackled by creating a different range. Whilst PM accumulation differences between species is determined to be based on leaf characteristic as wells as functional plant types and families are associated with distinct epicuticular wax structure (EWS) types that maybe due to the phylogeny [21] [49].

The maps are logical and coincide with several studies that identify that there is a spatial distinction in leaf SIRM values in relation to PM sources, alongside major roads, industrial areas, school or community services that experience higher levels of traffic [8] [15] [69]. The maps for both species show that HIRM spatial distribution maps are not practical in differentiating hot spots, due to low variability of HIRM percentage over all land use classes; indicating proportionally similar balance of ferrimagnetic (magnetite) and antiferromagnetic minerals (haematite) across all land use classes. It must be noted that even data contouring is visualizing the spatial distribution of magnetic dust, care must be taken when mapping values since samples in closer vicinity of a pollution sources (main roads, traffic light, industrial areas), as may not be a true indicator of mineral assemblages of the total area but more an indication of local effects similar issues were faced by Moreno et al. (2003) [16].

The total PM removed and standard pollution removal per unit tree cover is dependent on duration of in-leaf season, pollution concentration as well as environmental conditions; precipitation, climate and wind velocity at each site [50]. The distribution patterns of PM are indicative to the locality of pollution sources as well as wind direction. The industrial land use class is situated in the northern shoreline in vicinity of Shuwaikh Port and three major power-generating stations (Doha east, Doha west and Subiya) cause it to experience higher levels of air pollution due to industrial sources as well as dust fallout translating to higher SIRM and HIRM map values and pattern from the north. This is supported by previous research conducted by Al-Ghadban \& El-Sammak (2005) that determined that the distribution pattern of PM, particularly in the northeastern part of Kuwait Bay are influenced by the proximity of Shatt Al-Arab river that discharges from the north of Kuwait, which tidally can induce the transport of PM and dust fallout and the industrial land use class in located in the main dust storm axis in the North Westerly direction [76]. The sea breeze playing a role in the recirculation of pollutants in coastal areas, with winds passing over the southeastern part of the Shatt Al-Arab flood plain [59] [76]. Whilst, Mansouriya (urban) and Rumathiyah (suburban) are located closer to the southern shorelines which are highly developed as commercial and metropolitan 
areas and experience high vehicular traffic in addition to dust fallout and wind and their spatial distribution pattern is more from the south [7]. Elevated concentrations of $\mathrm{Pb}, \mathrm{Cu}$, and As in the east, southeast and west sectors of Kuwait city center have been identified by Al-Awadhi \& Aldhafiri (2016) confirming that traffic is not the single source of heavy metals in Kuwait city but that seasonal dust fallout may also be contributing factor [28] [77]. Short term dust events exacerbate the PM produced from dirt roads, agricultural activities and disturbed desert surface soil leading to PM annual exposure guidelines and standards being exceeded, at an annual average of $303 \mu \mathrm{g} / \mathrm{m}^{3}$ for PM 10 in central Kuwait [68]. Dust events originating fromSyria, Iraq, Sudan and extend into Kuwait [78].

A case study conducted by Al-Bassam \& Khan (2004) on Mansouriya (urban land use class) monitoring pollutants concluded that the majority of the pollution in the area is due to traffic emissions as a result of being surrounded by main roads, that were in the vicinity of several schools, banks and a big super-market [79]. This coincided with a study conducted by ElKarim et al. (1991) on traffic air pollution in Kuwait, over 21 locations that established that almost all schools and community service centers adjacent to major streets accounted for relatively high mean concentrations of carbon monoxide (CO), ranging from 11 - 13 ppm and nitrogen oxide (NOx) levels, ranging from 232 - 323 ppm [80].

\section{Conclusions}

The analysis of magnetic properties of particulate matter deposited on palm and buttonwood leaves using SIRM, HIRM, HIRM\% and $s$-ratio have been conducted for the first time in Kuwait. Results have shown that samples located in the vicinity of motorways and industrial areas have higher magnetic concentrations; the lowest magnetic values being in the urban land use class while the highest being in the industrial land use class indicating that magnetic mineral deposition rates are considerably higher in relation to industrial sources and high vehicular activity. SIRM and HIRM values were affected by the spatial distribution of plants, however, it is not possible to claim an overall tendency that is valid to all species and land use classes. Both species display HIRM\% acquisition $\sim 5.38 \%$ that has the magnetic behavioral characteristics of haematite with $\sim 0.2$ $\mu \mathrm{m}$ grain size. The magnetic properties of dust in samples were dominated by high coercivity, coarse ferrimagnetic minerals mostly likely hematite over all land uses classes and species.

Magnetic biomonitoring methodology has been proven to be applicable to dry desert environments with high events of dust storms. The wide geographic spread of palm trees and buttonwood throughout the Arabian Peninsula provides an opportunity to assess the levels and the spatial distribution of atmospheric PM throughout the region, in areas that are remote as well as only a few meters apart in a non-destructive manner. Both species offer distinctive information on PM pollution; buttonwood offers short-term monitoring, while palm 
is more long-term. Palm is proven to have a higher level of particulate matter retention this is confirmed through the SIRM results. Further research can be applied to a more exhaustive scale through combining geochemical analysis, dust and soil magnetic measurements to distinguish between airborne and soil contamination to provide further qualitative and quantitative results. The characterization of PM in soil and plant material throughout Kuwait could provide useful information towards source appointment, PM spatial distribution and wind direction interaction. The data can be potentially useful towards strategic urban development planning and plant selection.

\section{Acknowledgements}

Special thanks was sent to Fatema Al-Qallaf from the Public Authority of Agriculture and Fisheries (PAAF), Kuwait for her assistance with the ArcGIS mapping, and also to Gert Nuyts from the AXES Research Group, Department of Chemistry, University of Antwerp, Belgium for conducting the SEM imaging.

\section{Conflicts of Interest}

The authors declare no conflicts of interest regarding the publication of this paper.

\section{References}

[1] Chen, R., Hu, B., Liu, Y., Xu, J., Yang, G., Xu, D. and Chen, C. (2016) Beyond PM 2.5 $^{\text {: }}$ The Role of Ultrafine Particles on Adverse Health Effects of Air Pollution. Biochimica et Biophysica Acta, 1860, 2844-2855. https://doi.org/10.1016/j.bbagen.2016.03.019

[2] Qian, P., Zheng, X., Zhou, L., Jiang, Q., Zhang, G. and Yang, J. (2011) Magnetic Properties as Indicator of Heavy Metal Contaminations in Roadside Soil and Dust along G312 Highways. Procedia Environmental Sciences, 10, 1370-1375. https://doi.org/10.1016/j.proenv.2011.09.219

[3] Bealey, W.J., McDonald, A.G., Nemitz, E., Donovan, R., Dragosits, U., Duffy, T.R. and Fowler, D. (2007) Estimating the Reduction of Urban $\mathrm{PM}_{10}$ Concentrations by Trees Within an Environmental Information System for Planners. Journal of Environmental Management, 85, 44-58. https://doi.org/10.1016/j.jenvman.2006.07.007

[4] Morris, W.A., Versteeg, J.K., Bryant, D.W., Legzdins, A.E., McCarry, B.E. and Marvin, C.H. (1995) Preliminary Comparisons between Mutagenicity and Magnetic Susceptibility of Respirable Airborne Particulate. Atmospheric Environment, 29, 3441-3450. https://doi.org/10.1016/1352-2310(95)00203-B

[5] Norouzi, S. and Khademi, H. (2015) Source Identification of Heavy Metals in Atmospheric Dust Using Platanus orientalis L. Leaves as Bioindicator. Eurasian Journal of Soil Science, 4, 144-152. https://doi.org/10.18393/ejss.2015.3.144-152

[6] Kumar Rai, P., Moni Chutia, B., Rai, P.K. and Chutia, B.M. (2014) Biomagnetic Monitoring of Atmospheric Particulate Pollution Through Roadside Tree Leaves in Aizawl City, Mizoram and Their Temporal and Spatial Variations. International Research Journal of Environment Sciences, 3, 46-53.

[7] Hansard, R., Maher, B.A. and Kinnersley, R. (2011) Biomagnetic Monitoring of Industry-Derived Particulate Pollution. Environmental Pollution, 159, 1673-1681. 
https://doi.org/10.1016/j.envpol.2011.02.039

[8] Kardel, F., Wuyts, K., Maher, B.A. and Samson, R. (2012) Intra-Urban Spatial Variation of Magnetic Particles: Monitoring via Leaf Saturation Isothermal Remanent Magnetization (SIRM). Atmospheric Environment, 55, 111-120.

https://doi.org/10.1016/j.atmosenv.2012.03.025

[9] Kardel, F., Wuyts, K., Maher, B.A., Hansard, R. and Samson, R. (2011) Leaf Saturation Isothermal Remanent Magnetization (SIRM) as a Proxy for Particulate Matter Monitoring: Inter-Species Differences and In-Season Variation. Atmospheric Environment, 45, 5164-5171. https://doi.org/10.1016/j.atmosenv.2011.06.025

[10] Mitchell, R., Maher, B.A. and Kinnersley, R. (2010) Rates of Particulate Pollution Deposition onto Leaf Surfaces: Temporal and Inter-Species Magnetic Analyses. Environmental Pollution, 158, 1472-1478. https://doi.org/10.1016/j.envpol.2009.12.029

[11] Mitchell, R. and Maher, B.A. (2009) Evaluation and Application of Biomagnetic Monitoring of Traffic-Derived Particulate Pollution. Atmospheric Environment, 43, 2095-2103. https://doi.org/10.1016/j.atmosenv.2009.01.042

[12] Hofman, J., Stokkaer, I., Snauwaert, L. and Samson, R. (2013) Spatial Distribution Assessment of Particulate Matter in an Urban Street Canyon Using Biomagnetic Leaf Monitoring of Tree Crown Deposited Particles. Environmental Pollution, 183, 123-132. https://doi.org/10.1016/j.envpol.2012.09.015

[13] Kapper, K.L., Bautista, F., Goguitchaishvili, A., Bógalo, M.F., Cejudo-Ruíz, R. and Solano, M.C. (2019) The Use and Misuse of Magnetic Methods to Monitor Enviromental Pollution in Urban Areas. Boletín de la Sociedad Geológica Mexicana, 72, Article ID: e111219. https://doi.org/10.18268/bsgm2018v72n1a111219

[14] Amorim, J.H., Rodrigues, V., Tavares, R., Valente, J. and Borrego, C. (2013) CFD Modelling of the Aerodynamic Effect of Trees on Urban Air Pollution Dispersion. Science of the Total Environment, 461-462, 541-551. https://doi.org/10.1016/j.scitotenv.2013.05.031

[15] Speak, A.F., Rothwell, J.J., Lindley, S.J. and Smith, C.L. (2012) Urban Particulate Pollution Reduction by Four Species of Green Roof Vegetation in a UK City. Atmospheric Environment, 61, 283-293. https://doi.org/10.1016/j.atmosenv.2012.07.043

[16] Moreno, E., Sagnotti, L., Dinarès-Turell, J., Winkler, A. and Cascella, A. (2003) Biomonitoring of Traffic Air Pollution in Rome Using Magnetic Properties of Tree Leaves. Atmospheric Environment, 37, 2967-2977. https://doi.org/10.1016/S1352-2310(03)00244-9

[17] Castanheiro, A., Hofman, J., Nuyts, G., Joosen, S., Spassov, S., Blust, R., et al. (2020) Leaf Accumulation of Atmospheric Dust: Biomagnetic, Morphological and Elemental Evaluation Using SEM, ED-XRF and HR-ICP-MS. Atmospheric Environment, 221, Article ID: 117082. https://doi.org/10.1016/j.atmosenv.2019.117082

[18] Limo, J., Paturi, P. and Mäkinen, J. (2018) Magnetic Biomonitoring with Moss Bags to Assess Stop-and-Go Traffic Induced Particulate Matter and Heavy Metal Concentrations. Atmospheric Environment, 195, 187-195.

https://doi.org/10.1016/j.atmosenv.2018.09.062

[19] Chakrabortty, S. and Paratkar, G.T. (2006) Biomonitoring of Trace Element Air Pollution Using Mosses. Aerosol and Air Quality Research, 6, 247-258. https://doi.org/10.4209/aaqr.2006.09.0002

[20] Bondaruk, J., Janson, E., Wysocka, M. and Chałupnik, S. (2015) Identification of Hazards for Water Environment in the Upper Silesian Coal Basin Caused by the Discharge of Salt Mine Water Containing Particularly Harmful Substances and Ra- 
dionuclides. Journal of Sustainable Mining, 14, 179-187.

https://doi.org/10.1016/j.jsm.2016.01.001

[21] Muhammad, S., Wuyts, K., Nuyts, G., De Wael, K. and Samson, R. (2020) Characterization of Epicuticular Wax Structures on Leaves of Urban Plant Species and Its Association with Leaf Wettability. Urban Forestry and Urban Greening, 47, Article ID: 126557. https://doi.org/10.1016/j.ufug.2019.126557

[22] Barima, Y.S.S., Angaman, D.M., N’Gouran, K.P., Koffi, N.A., Kardel, F., De Cannière, C. and Samson, R. (2014) Assessing Atmospheric Particulate Matter Distribution Based on Saturation Isothermal Remanent Magnetization of Herbaceous and Tree Leaves in a Tropical Urban Environment. Science of the Total Environment, 470-471, 975-982. https://doi.org/10.1016/j.scitotenv.2013.10.082

[23] Giordano, S., Adamo, P., Spagnuolo, V., Tretiach, M. and Bargagli, R. (2013) Accumulation of Airborne Trace Elements in Mosses, Lichens and Synthetic Materials Exposed at Urban Monitoring Stations: Towards a Harmonisation of the Moss-Bag Technique. Chemosphere, 90, 292-299.

https://doi.org/10.1016/j.chemosphere.2012.07.006

[24] Alhaddad, A., Ettouney, H. and Saqer, S. (2015) Analysis of Air Pollution Emission Patterns in the Vicinity of Oil Refineries in Kuwait. Journal of Engineering Research, 3, 1-24.

[25] Al-Hurban, A.E. and Al-Ostad, A.N. (2010) Textural Characteristics of Dust Fallout and Potential Effect on Public Health in Kuwait City and Suburbs. Environmental Earth Sciences, 60, 169-181. https://doi.org/10.1007/s12665-009-0177-3

[26] Al-Haider, S.A. and Al-Salem, S.M. (2008) Outdoor Air Quality Data Analysis of Al-Mansoriah Residential Area (Kuwait): Air Quality Indices Results. WIT Transactions on Ecology and the Environment, 116, 189-196. https://doi.org/10.2495/AIR080201

[27] Farahat, A. (2016) Air Pollution in the Arabian Peninsula (Saudi Arabia, the United Arab Emirates, Kuwait, Qatar, Bahrain, and Oman): Causes, Effects, and Aerosol Categorization. Arabian Journal of Geosciences, 9, Article No. 196. https://doi.org/10.1007/s12517-015-2203-y

[28] Al-Awadhi, J.M. and Aldhafiri, B.T. (2016) Heavy Metal Concentration s in Roadside-Deposited Sediments in Kuwait City. Arabian Journal of Geosciences, 9, Article No. 535. https://doi.org/10.1007/s12517-016-2543-2

[29] Khalaf, F.I. and Al-Ajmi, D. (1993) Aeolian Processes and Sand Encroachment Problems in Kuwait. Geomorphology, 6, 111-134. https://doi.org/10.1016/0169-555X(93)90042-Z

[30] Thalib, L. and Al-Taiar, A. (2012) Dust Storms and the Risk of Asthma Admissions to Hospitals in Kuwait. Science of the Total Environment, 433, 347-351.

https://doi.org/10.1016/j.scitotenv.2012.06.082

[31] Abd El-Wahab, R.H. and Al-Rashed, A.R. (2010) Vegetation and Soil Conditions of Phytogenic Mounds in Subiya Area Northeast of Kuwait. Catrina, 5, 87-95.

[32] Brebbia, C.A., Wadhwa, L.C., Al Bassam, E. and Khan, A. (2004) Air Pollution and Road Traffic in Kuwait. In: Brebbia, C.A. and Wadhwa, L.C., Eds., Urban Transport X: Urban Transport and the Environment in the 21 st Century, WIT Press, Southampton, 741-750.

http://ovidsp.ovid.com/ovidweb.cgi?T=JS\&PAGE=reference $\& D=t s p t \& N E W S=N \&$ $\underline{\mathrm{AN}=\mathrm{E} 128752}$

[33] Al-Dousari, A.M. and Al-Awadhi, J. (2012) Dust Fallout in Northern Kuwait, Major Sources and Characteristics. Kuwait Journal of Science and Engineering, 39, 171-187. 
[34] Al-Harahsheh, S. (2020) Spatial and Seasonal Variations of the Particulate Matters $\left(\mathrm{PM}_{10}\right)$ at Selected Sites in the State of Kuwait. Pollution Research, 39, 19-32.

[35] Public Authority for Civil Information (PACI-Kuwait) (2018) Statistical Reports. http://stat.paci.gov.kw/englishreports/

[36] Naseer, M., Hameed, M., Zahoor, A., Ahmad, F., Fatima, S., Ahmad, M.S.A., et al. (2017) Photosynthetic Response in Buttonwood (Conocarpus Erectus L.) to Salt Stress. Pakistan Journal of Botany, 49, 847-856.

[37] Castanheiro, A., Samson, R. and De Wael, K. (2016) Magnetic- and Particle-Based Techniques to Investigate Metal Deposition on Urban Green. Science of the Total Environment, 571, 594-602. https://doi.org/10.1016/j.scitotenv.2016.07.026

[38] Liu, Q., Roberts, A.P., Torrent, J., Horng, C.S. and Larrasoaña, J.C. (2007) What Do the HIRM and S-Ratio Really Measure in Environmental Magnetism? Geochemistry, Geophysics, Geosystems, 8, Article ID: Q09011. https://doi.org/10.1029/2007GC001717

[39] Thompson, R. and Oldfield, F. (1986) Environmental Magnetism. Allen and Unwin, London. https://doi.org/10.1007/978-94-011-8036-8

[40] Wilhelm, B., Christoph, N., David, C., Friedrich, D., Iris, M., Inge, T. and Hiltrud, W. (1998) Classification and Terminology of Plant Epicuticular Waxes. Botanical Journal of the Linnean Society, 126, 237-260. https://doi.org/10.1111/j.1095-8339.1998.tb02529.x

[41] Lu, S.G. and Bai, S.Q. (2006) Study on the Correlation of Magnetic Properties and Heavy Metals Content in Urban Soils of Hangzhou City, China. Journal of Applied Geophysics, 60, 1-12. https://doi.org/10.1016/j.jappgeo.2005.11.002

[42] Shu, J., Dearing, J.A., Morse, A.P., Yu, L. and Li, C. (2000) Magnetic Properties of Daily Sampled Total Suspended Particulates in Shanghai. Environmental Science and Technology, 34, 2393-2400. https://doi.org/10.1021/es9910964

[43] Horng, C.S., Huh, C.A., Chen, K.H., Huang, P.R., Hsiung, K.H. and Lin, H.L. (2009) Air Pollution History Elucidated from Anthropogenic Spherules and Their Magnetic Signatures in Marine Sediments Offshore of Southwestern Taiwan. Journal of Marine Systems, 76, 468-478. https://doi.org/10.1016/j.jmarsys.2007.09.014

[44] Abbasi, S., Keshavarzi, B., Moore, F., Hopke, P.K., Kelly, F.J. and Dominguez, A.O. (2020) Elemental and Magnetic Analyses, Source Identification, and Oxidative Potential of Airborne, Passive, and Street Dust Particles in Asaluyeh County, Iran. Science of the Total Environment, 707, Article ID: 136132. https://doi.org/10.1016/j.scitotenv.2019.136132

[45] Muñoz, D., Aguilar, B., Fuentealba, R. and Préndez, M. (2017) Environmental Studies in Two Communes of Santiago De Chile by the Analysis of Magnetic Properties of Particulate Matter Deposited on Leaves of Roadside Trees. Atmospheric Environment, 152, 617-627. https://doi.org/10.1016/j.atmosenv.2016.12.047

[46] Gillooly, S.E., Shmool, J.L.C., Michanowicz, D.R., Bain, D.J., Cambal, L.K., Shields, K.N. and Clougherty, J.E. (2016) Framework for Using Deciduous Tree Leaves as Biomonitors for Intraurban Particulate Air Pollution in Exposure Assessment. Environmental Monitoring and Assessment, 188, Article ID: 479. https://doi.org/10.1007/s10661-016-5482-1

[47] Huttunen, S. (1994) Effects of Air Pollutants on Epicuticular Wax Structure. In: Percy, K.E., Cape, J.N., Cape, J.N., Jagels, R., Jagels, R. and Simpson, C.J., Eds., Air Pollutants and the Leaf Cuticle, Springer, Berlin, Heidelberg, 81-96. https://doi.org/10.1007/978-3-642-79081-2_6

[48] Al-Shayeb, S.M., Al-Rajhi, M.A. and Seaward, M.R.D. (1995) the Date Palm (Phoe- 
nix dactylifera L.) as a Biomonitor of Lead and Other Elements in Arid Environments. Science of the Total Environment, 168, 1-10. https://doi.org/10.1016/0048-9697(95)04556-G

[49] Sæbø, A., Popek, R., Nawrot, B., Hanslin, H.M., Gawronska, H. and Gawronski, S.W. (2012) Plant Species Differences in Particulate Matter Accumulation on Leaf Surfaces. Science of the Total Environment, 427-428, 347-354. https://doi.org/10.1016/j.scitotenv.2012.03.084

[50] Nowak, D.J., Crane, D.E. and Stevens, J.C. (2006) Air Pollution Removal by Urban Trees and Shrubs in the United States. Urban Forestry and Urban Greening, 4, 115-123. https://doi.org/10.1016/j.ufug.2006.01.007

[51] Beckett, K.P., Freer-Smith, P.H. and Taylor, G. (2000) Particulate Pollution Capture by Urban Trees: Effect of Species and Windspeed. Global Change Biology, 6, 995-1003. https://doi.org/10.1046/j.1365-2486.2000.00376.X

[52] Yin, G., Hu, S., Cao, L., Roesler, W. and Appel, E. (2013) Magnetic Properties of Tree Leaves and Their Significance in Atmospheric Particle Pollution in Linfen City, China. Chinese Geographical Science, 23, 59-72.

https://doi.org/10.1007/s11769-013-0588-7

[53] Neinhuis, C. and Barthlott, W. (1998) Seasonal Changes of Leaf Surface Contamination in Beech, Oak, and Ginkgo in Relation to Leaf Micromorphology and Wettability. New Phytologist, 138, 91-98. https://doi.org/10.1046/j.1469-8137.1998.00882.x

[54] Sawidis, T., Krystallidis, P., Veros, D. and Chettri, M. (2012) A Study of Air Pollution with Heavy Metals in Athens City and Attica Basin Using Evergreen Trees as Biological Indicators. Biological Trace Element Research, 148, 396-408. https://doi.org/10.1007/s12011-012-9378-9

[55] Fuhrer, J. and Bungener, P. (1999) Effects of Air Pollutants on Plants. Analusis, 27, 355-360. https://doi.org/10.1051/analusis:1999270355

[56] Khelil, R., Jardé, E., Cabello-Hurtado, F., Ould-El-Hadj Khelil, A. and Esnault, M.A. (2016) Structure and Composition of the Wax of the Date Palm, Phoenix Dactylifera L., from the Septentrional Sahara. Scientia Horticulturae, 201, 238-246. https://doi.org/10.1016/j.scienta.2016.02.012

[57] Wang, B., Xia, D., Yu, Y., Chen, H. and Jia, J. (2018) Source Apportionment of Soil-Contamination in Baotou City (North China) Based on a Combined Magnetic and Geochemical Approach. Science of the Total Environment, 642, 95-104. https://doi.org/10.1016/j.scitotenv.2018.06.050

[58] Reynolds, R.L., Goldstein, H.L. and Miller, M.E. (2010) Atmospheric Mineral Dust in Dryland Ecosystems: Applications of Environmental Magnetism. Geochemistry, Geophysics, Geosystems, 11, Article No. Q07009. https://doi.org/10.1029/2010GC003103

[59] Bouhamra, W.S. and Abdul-Wahab, S.A. (1999) Description of Outdoor Air Quality in a Typical Residential Area in Kuwait. Environmental Pollution, 105, 221-229. https://doi.org/10.1016/S0269-7491(98)00221-8

[60] Power, A.L., Tennant, R.K., Jones, R.T., Tang, Y., Du, J., Worsley, A.T. and Love, J. (2018) Monitoring Impacts of Urbanisation and Industrialisation on Air Quality in the Anthropocene Using Urban Pond Sediments. Frontiers in Earth Science, 6, Article No. 131. https://doi.org/10.3389/feart.2018.00131

[61] Naimi, S. and Ayoubi, S. (2013) Vertical and Horizontal Distribution of Magnetic Susceptibility and Metal Contents in an Industrial District of Central Iran. Journal of Applied Geophysics, 96, 55-66. https://doi.org/10.1016/j.jappgeo.2013.06.012 
[62] Kapička, A., Jordanova, N., Petrovsky, E. and Ustjak, S. (2000) Magnetic Stability of Power-Plant Fly Ash in Different Soil Solutions. Physics and Chemistry of the Earth, Part A: Solid Earth and Geodesy, 25, 431-436. https://doi.org/10.1016/S1464-1895(00)00067-3

[63] Yang, D., Wang, M., Lu, H., Ding, Z., Liu, J. and Yan, C. (2019) Magnetic Properties and Correlation with Heavy Metals in Mangrove Sediments, the Case Study on the Coast of Fujian, China. Marine Pollution Bulletin, 146, 865-873. https://doi.org/10.1016/j.marpolbul.2019.07.035

[64] Matzka, J. and Maher, B.A. (1999) Magnetic Biomonitoring of Roadside Tree Leaves: Identification of Spatial and Temporal Variations in Vehicle-Derived Particulates. Atmospheric Environment, 33, 4565-4569. https://doi.org/10.1016/S1352-2310(99)00229-0

[65] Maher, B.A., Karloukovski, V.V. and Mutch, T.J. (2004) High-Field Remanence Properties of Synthetic and Natural Submicrometre Haematites and Goethites: Significance for Environmental Contexts. Earth and Planetary Science Letters, 226, 491-505. https://doi.org/10.1016/j.epsl.2004.05.042

[66] Ahmadzadeh, M., Romero, C. and McCloy, J. (2018) Magnetic Analysis of Commercial Hematite, Magnetite, and Their Mixtures. AIP Advances, 8, Article ID: 056807. https://doi.org/10.1063/1.5006474

[67] Roberts, A.P., Zhao, X., Heslop, D., Abrajevitch, A., Chen, Y.H., Hu, P., et al. (2020) Hematite $\left(\alpha-\mathrm{Fe}_{2} \mathrm{O}_{3}\right)$ Quantification in Sedimentary Magnetism: Limitations of Existing Proxies and Ways Forward. Geoscience Letters, 7, Article No. 8. https://doi.org/10.1186/s40562-020-00157-5

[68] Engelbrecht, J.P., McDonald, E.V., Gillies, J.A., Jayanty, R.K.M., Casuccio, G. and Gertler, A.W. (2009) Characterizing Mineral Dusts and Other Aerosols from the Middle East-Part 1: Ambient Sampling. Inhalation Toxicology, 21, 297-326. https://doi.org/10.1080/08958370802464273

[69] Hoffmann, V., Knab, M. and Appel, E. (1999) Magnetic Susceptibility Mapping of Roadside Pollution. Journal of Geochemical Exploration, 66, 313-326. https://doi.org/10.1016/S0375-6742(99)00014-X

[70] Kupcinskiene, E. and Huttunen, S. (2005) Long-Term Evaluation of the Needle Surface Wax Condition of Pinus sylvestris around Different Industries in Lithuania. Environmental Pollution, 137, 610-618. https://doi.org/10.1016/j.envpol.2005.01.047

[71] Zhu, Y., Hinds, W.C., Kim, S. and Sioutas, C. (2002) Concentration and Size Distribution of Ultrafine Particles near a Major Highway. Journal of the Air and Waste Management Association, 52, 1032-1042. https://doi.org/10.1080/10473289.2002.10470842

[72] Lourenço, A.M. and Gomes, C.R. (2016) Integration of Magnetic Measurements, Chemical and Statistical Analysis in Characterizing Agricultural Soils (central Portugal). Environmental Earth Sciences, 75, Article No. 968. https://doi.org/10.1007/s12665-016-5775-2

[73] Rosenbaum, J.G. and Reynolds, R.L. (2004) Basis for Paleoenvironmental Interpretation of Magnetic Properties of Sediment from Upper Klamath Lake (Oregon): Effects of Weathering and Mineralogical Sorting. Journal of Paleolimnology, 31, 253-265. https://doi.org/10.1023/B:JOPL.0000019228.46421.f4

[74] Özdemir, Ö. and Dunlop, D.J. (1997) Effect of Crystal Defects and Internal Stress on the Domain Structure and Magnetic Properties of Magnetite. Journal of Geophysical Research: Solid Earth, 102, 20211-20224. 
https://doi.org/10.1029/97JB01779

[75] Maher, B.A. (2011) The Magnetic Properties of Quaternary Aeolian Dusts and Sediments, and Their Palaeoclimatic Significance. Aeolian Research, 3, 87-144. https://doi.org/10.1016/j.aeolia.2011.01.005

[76] Al-Ghadban, A.N.N. and El-Sammak, A. (2005) Sources, Distribution and Composition of the Suspended Sediments, Kuwait Bay, Northern Arabian Gulf. Journal of Arid Environments, 60, 647-661. https://doi.org/10.1016/j.jaridenv.2004.07.017

[77] Al-Awadhi, J.M. and Al Shuaibi, A.A. (2013) Dust Fallout in Kuwait City: Deposition and Characterization. Science of the Total Environment, 461-462, 139-148. https://doi.org/10.1016/j.scitotenv.2013.03.052

[78] Cao, H., Amiraslani, F., Liu, J. and Zhou, N. (2015) Identification of Dust Storm Source Areas in West Asia Using Multiple Environmental Datasets. Science of the Total Environment, 502, 224-235. https://doi.org/10.1016/j.scitotenv.2014.09.025

[79] Al-Bassam, E. and Khan, A. (2004) Air Pollution and Road Traffic in Kuwait. WIT Transactions on the Built Environment, 75, 741-750.

[80] El Karim, M.A.A., Khogali, M. and Zeqlam, H. (1991) Traffic Air Pollution in Kuwait: Preliminary Results for Nitrogen Oxides and Carbon Monoxide. Science of the Total Environment, 106, 111-119. https://doi.org/10.1016/0048-9697(91)90024-9 